\title{
Hydrogen-Fueled Internal Combustion Engines
}

\author{
Sebastian Verhelst ${ }^{\mathrm{a}, *}$, Thomas Wallner ${ }^{\mathrm{b}}$ \\ ${ }^{a}$ Department of Flow, Heat and Combustion Mechanics, Ghent University, \\ Sint-Pietersnieuwstraat 41, B-9000 Gent, Belgium \\ ${ }^{b}$ Energy Systems Division, Argonne National Laboratory, Building 362, 9700 South Cass Avenue, \\ Argonne, IL 60439-4815, USA
}

\begin{abstract}
The threat posed by climate change and the striving for security of energy supply are issues high on the political agenda these days. Governments are putting strategic plans in motion to decrease primary energy use, take carbon out of fuels and facilitate modal shifts.

Taking a prominent place in these strategic plans is hydrogen as a future energy carrier. A number of manufacturers are now leasing demonstration vehicles to consumers using hydrogen-fueled internal combustion engines $\left(\mathrm{H}_{2} \mathrm{ICEs}\right)$ as well as fuel cell vehicles. Developing countries in particular are pushing for $\mathrm{H}_{2}$ ICEs (powering two- and three-wheelers as well as passenger cars and buses) to decrease local pollution at an affordable cost.

This article offers a comprehensive overview of $\mathrm{H}_{2}$ ICEs. Topics that are discussed include fundamentals of the combustion of hydrogen, details on the different mixture formation strategies and their emissions characteristics, measures to convert existing vehicles, dedicated hydrogen engine features, a state of the art on increasing power output and efficiency while controlling emissions and modeling.
\end{abstract}

Key words: hydrogen, internal combustion engine, $\mathrm{NO}_{\mathrm{X}}$ emissions, direct injection, port fuel injection, abnormal combustion

\section{Contents}

1 Introduction

${ }^{*}$ Corresponding author. Tel.: +32 9264 3306; fax: +32 92643590 .

Email addresses: Sebastian.Verhelst@UGent.be (Sebastian Verhelst), twallnereanl.gov (Thomas Wallner) 
1.1 Incentives and drawbacks for hydrogen as an energy carrier . . . 7

1.2 Using hydrogen in internal combustion engines: sense or nonsense? 8

1.3 Motivation and outline . . . . . . . . . . . . . . 9

2 Fundamentals 10

2.1 Physical and chemical properties of hydrogen relevant to engines . 10

2.2 Laminar burning velocity, influence of preferential diffusion . . . 13

2.2.1 Flame front instabilities . . . . . . . . . . . 13

2.2.2 The laminar burning velocity at atmospheric conditions . . 16

2.2.3 The laminar burning velocity at engine conditions . . . . . 19

2.3 Turbulent burning velocity ............... 21

2.3.1 Experimental and numerical work on the role of instabilities and the effects of stretch on $u_{t} \ldots \ldots$. . . . . . 21

2.3.2 Implications for the combustion of hydrogen-air mixtures in engines . . . . . . . . . . . . . . . . 24

2.3.3 Implications for modeling of turbulent combustion of hydrogenair mixtures . . . . . . . . . . . . . . 25

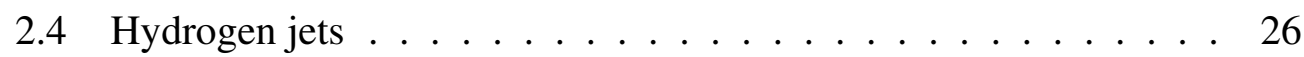

2.4 .1 Un-ignited jets . . . . . . . . . . . . . . . 26

2.4 .2 Ignited jets . . . . . . . . . . . . . . 28

3 Modeling regular combustion $\quad 29$

3.1 Thermodynamic analysis of the working cycle . . . . . . . . . 30

3.2 Thermodynamic models . . . . . . . . . . . . 31

3.3 CFD models . . . . . . . . . . . . . . . . . . . 34

3.4 Heat transfer sub-model . . . . . . . . . . . . 35

4 Abnormal combustion $\quad 37$

4.1 Pre-ignition . . . . . . . . . . . . . . . 37

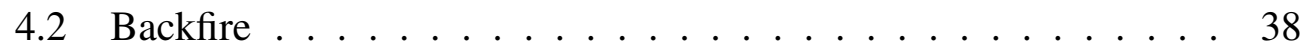

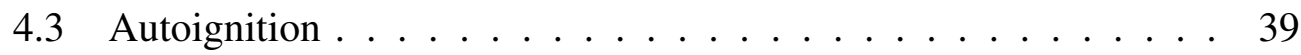

4.4 Modeling abnormal combustion phenomena . . . . . . . . . . 41

4.5 Avoiding abnormal combustion . . . . . . . . . . . 42

5 Measures for engine design or conversion $4 \mathbf{4 2}$

5.1 Spark plugs . . . . . . . . . . . . . . . 43

5.2 Ignition system . . . . . . . . . . . . . . . . 43

5.3 Injection system . . . . . . . . . . . . 43 


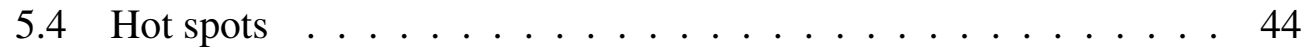

5.5 Piston rings and crevice volumes . . . . . . . . . . . . . . 44

5.6 Valve seats and injectors . . . . . . . . . . . . . 45

5.7 Lubrication . . . . . . . . . . . . . . . . 44 45

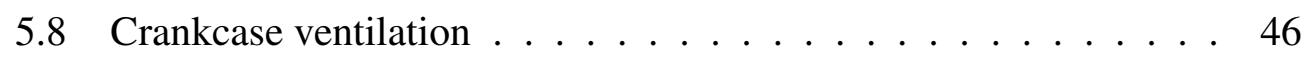

5.9 Compression ratio . . . . . . . . . . . . . . . . . . . . 46

5.10 In-cylinder turbulence . . . . . . . . . . . . . . . . . 46

5.11 Electronic throttle . . . . . . . . . . . . . . . . . . . 46

5.12 Materials .................... 47

6 Mixture formation and load control strategies 48

6.1 Introduction, classification of strategies . . . . . . . . . . . 48

6.2 Mixture formation strategies . . . . . . . . . . . . . 49

6.2.1 Supplying pressurized hydrogen . . . . . . . . . . 50

6.2.2 Spark ignition port injection ........... 51

6.2.3 Spark ignition direct injection ........... 55

6.2.4 Compression ignition direct injection . . . . . . . . . . 58

6.3 Measures for $\mathrm{NO}_{\mathrm{x}}$ control . . . . . . . . . . . . . . 59

6.4 Summary of possible control strategies . . . . . . . . . . 61

7 Hydrogen safety 63

7.1 Test cell design . . . . . . . . . . . . . . . . 63

7.1.1 Test cell ventilation ........................ 63

7.1.2 Hydrogen sensors . . . . . . . . . . . . . . . 64

7.1.3 Hydrogen flame detectors . . . . . . . . . . . 65

7.1.4 Hydrogen supply system . . . . . . . . . . . . . . 66

7.2 In-vehicle applications . . . . . . . . . . . 68

8 Hydrogen internal combustion engine vehicles 68

8.1 History ........................ 69

8.2 Hydrogen vehicle characterization . . . . . . . . . . . 70

8.3 Conversion vehicles . . . . . . . . . . . . . 70

8.4 Bi-fuel vehicles . . . . . . . . . . . . . . . . 71

8.5 Dedicated hydrogen vehicles .................... 71

8.6 Overview of hydrogen vehicles . . . . . . . . . . . 72 
9 Hydrogen in combination with other fuels $\mathbf{7 3}$

9.1 Overview - motivation . . . . . . . . . . 73

9.2 Blends with hydrogen as a constituent . . . . . . . . . 73

9.2.1 Natural gas dominated blends ........... . . . 73

9.2.2 Hydrogen dominated blends . . . . . . . . . . . . . . 74

9.2.3 Multiple gas blends . . . . . . . . . . . . . . . 74

9.3 Dual-fuel applications . . . . . . . . . . . . . . . . . 75

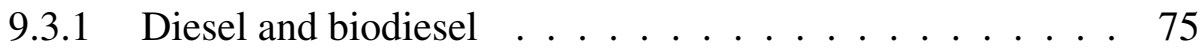

9.3.2 Gasoline and alcohol fuels . . . . . . . . . . . 75

10 Filling in the blanks $\quad 76$

$\begin{array}{ll}11 \text { Conclusion } & 77\end{array}$

12 Acknowledgments $\quad \mathbf{8 0}$

Nomenclature

Abbreviations

BDC bottom dead center

BMEP brake mean effective pressure

BTDC before top dead center

CA crank angle

CFD computational fluid dynamics

CFR cooperative fuel research

$\mathrm{CI}$ compression ignition

$\mathrm{CO}$ carbon monoxide

$\mathrm{CO}_{2} \quad$ carbon dioxide

CPU central processing unit

DI direct injection

DME dimethyl ether

DNS direct numerical simulation

DOE (United States) Department of Energy

EGR exhaust gas recirculation

EZEV equivalent zero emission vehicle

FC fuel cell

FTP federal test procedure

$\mathrm{HC}$ hydrocarbon 
HCCI homogeneous charge compression ignition

HEV hybrid electric vehicle

$\mathrm{H}_{2} \quad$ hydrogen

$\mathrm{H}_{2} \mathrm{FC} \quad$ hydrogen fuel cell

$\mathrm{H}_{2} \mathrm{ICE}$ hydrogen-fueled internal combustion engine

IMEP indicated mean effective pressure

IR infrared

IVC inlet valve closing

LES Large Eddy Simulation

LHV lower heating value

MBT minimum spark advance for best torque

MN methane number

MON motor octane number

mpg miles per (U.S.) gallon

NO nitric oxide

$\mathrm{NO}_{\mathrm{X}} \quad$ nitrogen oxides

NSR $\quad \mathrm{NO}_{\mathrm{X}}$ storage reduction

NTP normal temperature and pressure (300 K, 1 atm)

OEM original equipment manufacturer

pdf probability density function

PFI port fuel injection

RME rapeseed methyl ester

rms root mean square

RON research octane number

RPM revolutions per minute

SCR selective catalytic reduction

SI spark ignition

SOI start of injection

SULEV Super Ultra Low Emission Vehicle

TDC top dead center

THC total hydrocarbons

TLEV transitional low emission vehicle

ULEV ultra low emission vehicle

ULSD ultra low sulphur diesel

UV ultraviolet

WOT wide open throttle

WWMP World Wide Mapping Point

ZEV zero emission vehicle 
Symbols

$\begin{array}{ll}\text { A } & \text { (flame) area } \\ \mathrm{D}_{\mathrm{M}} & \text { mass diffusivity } \\ \mathrm{D}_{\mathrm{T}} & \text { thermal diffusivity } \\ \mathrm{L} & \text { Markstein length } \\ \mathrm{Le} & \text { Lewis number } \\ \mathrm{p} & \text { pressure } \\ \mathrm{r} & \text { (flame) radius } \\ \mathrm{Re} & \text { Reynolds number } \\ \mathrm{S} & \text { flame speed } \\ \mathrm{t} & \text { time } \\ \mathrm{T} & \text { temperature } \\ \mathrm{u} & \text { burning velocity } \\ \mathrm{u} & \text { rms turbulent velocity }\end{array}$

Greek symbols

$\alpha \quad$ (flame) stretch rate

$\gamma \quad$ residual gas fraction

$\lambda \quad$ air to fuel equivalence ratio

$\rho$ density

$\phi \quad$ fuel to air equivalence ratio

Subscripts

b burned

exc excess reactant

1 laminar

$\lim$ limiting reactant

n normal

S stretch-free

$\mathrm{t}$ turbulent

$\mathrm{u}$ unburned 


\section{Introduction}

\subsection{Incentives and drawbacks for hydrogen as an energy carrier}

The current way of providing the world's energy demand, based primarily on fossil fuel, is becoming increasingly untenable. Fossil fuel reserves, once hardly ever given a second thought, now are clearly exhaustible. Fossil fuel prices have never been more volatile, influenced first by economic acceleration mostly in China and India and subsequently by economic recession. The difficulty of controlling prices and the uncertain reserves are strong incentives for pursuing energy security. Global warming and local pollution hot spots associated with fossil fuel usage are further significant environmental and societal problems.

These are strong drivers for research, development and demonstrations of alternative energy sources, energy carriers, and in the case of transportation, powertrains. The use of hydrogen as an energy carrier is one of the options put forward in most governmental strategic plans for a sustainable energy system. The United States Department of Energy; the European Commission's Directorate-General for Research; the Japanese Ministry of Economy, Trade and Industry; the Indian Ministry of New and Renewable Energy and many others have formulated vision reports and published funding calls for hydrogen programs [1, 2, 3, 4].

The attractiveness of hydrogen lies in the variety of methods to produce hydrogen as well as the long term viability of some of them (from fossil fuels, from renewable energy: biomass, wind, solar [5], from nuclear power etc.), the variety of methods to produce energy from hydrogen (internal combustion engines, gas turbines, fuel cells), virtually zero harmful emissions and potentially high efficiency at the point of its use. Compared to biofuels, a recent study reported the yield of final fuel per hectare of land for different biomass derived fuels, and of hydrogen from photovoltaics or wind power [6]. The results show that the energy yield of land area is much higher when it is used to capture wind or solar energy. Compared to electricity, using hydrogen as an energy carrier is advantageous in terms of volumetric and gravimetric energy storage density. However, there are also serious challenges to overcome when hydrogen is to be used as an energy carrier. Although better than batteries in storage terms, its very low density implies low energy densities compared to the fuels in use today, even when compressed to 700 bar or liquefied, both of which incur substantial energy losses. Thus distribution, bulk storage and on board vehicle storage are heavily compromised. Also, in case of hydrogen-fueled vehicles, care must be taken to ensure that the well-to-wheel greenhouse gas emission reduction compared to hydrocarbon fuel 
turns out to be positive [7]. Nevertheless, the advantages offered by hydrogen are significant enough to warrant the exploration of its possibilities.

\subsection{Using hydrogen in internal combustion engines: sense or nonsense?}

There are numerous works and opinions as to what constitutes the 'best' fuel/ energy carrier as well as powertrain: heavily optimized hydrocarbon fueled engines, biofuels, electricity, hydrogen, etc. However, there are always a multitude of aspects to be taken into account, ranging from well-to-wheel (or cradle-tograve) primary energy use, greenhouse gas emissions, tailpipe emissions relating to local pollution, cost, practicality, to customer acceptance, etc., which clearly are not all easily scored and ranked, making it very hard to predict the winner(s). Moreover, there appears to be no silver bullet, and numerous choices merit a detailed study in exploring the possibilities and drawbacks.

Concerning hydrogen as an energy carrier, Shelef and Kukkonen [7] have compared hydrogen fuel cell $\left(\mathrm{H}_{2} \mathrm{FC}\right)$ vehicles and $\mathrm{H}_{2} \mathrm{ICE}$ vehicles to gasoline vehicles and electric vehicles, on the basis of well-to-wheel carbon dioxide $\left(\mathrm{CO}_{2}\right)$ emissions and primary energy use. Fifteen years have passed since that study, but overall the arguments and challenges for the implementation of hydrogen as a vehicle fuel largely hold. However, the data that were used clearly need updating to see how this affects the conclusions. Shelef and Kukkonen concluded that the $\mathrm{H}_{2} \mathrm{FC}$ vehicle could decrease primary energy use and greenhouse gas emissions compared to gasoline and natural gas vehicles, but that $\mathrm{H}_{2} \mathrm{ICE}$ vehicles increased both. However, a recent study at Argonne National Laboratory that compares the fuel economy potential of hydrogen powertrains to conventional gasoline vehicles concludes that by 2045 a $_{2}$ ICE hybrid electric vehicle (HEV) would only consume $9 \%$ more than a $\mathrm{H}_{2} \mathrm{FC} \mathrm{HEV}$, as a result of the recent and expected future significant improvements in hydrogen engine technology [8].

Thus, the perceived large difference in fuel economy between a $\mathrm{H}_{2} \mathrm{FC} \mathrm{HEV}$ and $\mathrm{H}_{2} \mathrm{ICE} \mathrm{HEV}$ is lower than frequently reported and will decrease over time. Currently, $\mathrm{H}_{2}$ ICEs are much cheaper than $\mathrm{H}_{2} \mathrm{FCs}$, both directly and in terms of fuel cost (with high fuel purity requirements for the $\mathrm{H}_{2} \mathrm{FCs}$ ). Furthermore, using ICEs allows bi-fuel operation (e.g., the engine can run on gasoline as well as on hydrogen), alleviating fuel station density and autonomy requirements. This could facilitate the start-up of a hydrogen infrastructure, where the experience gained with transport, fueling and storage directly translates to fuel cell vehicles.

This explains the U.S. Department of Energy's position that while FC vehicles consistently achieve the highest fuel efficiency, the $\mathrm{H}_{2} \mathrm{ICE}$ can serve as a bridging technology and might help in the development of the infrastructure needed 
for hydrogen fuel [1]. Similarly, the well-to-wheels study of the European Commission's Directorate General Joint Research Center, in cooperation with CONCAWE and EUCAR, concludes that $\mathrm{H}_{2} \mathrm{ICE}$ vehicles are available in the near term at a lower cost than fuel cell vehicles [9].

\subsection{Motivation and outline}

This paper sets out to review hydrogen engine technology. It does not discuss where, when and if hydrogen should be used as an energy carrier. The previous sections provide a brief summary of the attractiveness of using hydrogen, the interest in $\mathrm{H}_{2}$ ICEs and a warning about the challenges.

Previous articles have already discussed hydrogen engine technology, with excellent reviews by Das [10,11], Eichlseder et al. [12] and White et al. [13]. Most of these papers focus on the application without attention to the fundamentals of hydrogen combustion, and mostly cover only certain aspects of $\mathrm{H}_{2}$ ICEs. Given the multitude of recent studies as well as ongoing efforts in developing $\mathrm{H}_{2} \mathrm{ICEs}$ and $\mathrm{H}_{2} \mathrm{ICE}$ vehicles, it is considered timely to offer a comprehensive review.

The following starts out by considering the fundamental properties of hydrogen and hydrogen combustion. Some important $\mathrm{H}_{2} \mathrm{ICE}$ features can already be expected from the physical and chemical properties of hydrogen compared to hydrocarbons; these are discussed in Section 2.1. Sections 2.2 and 2.3 cover the laminar and turbulent burning velocities of hydrogen mixtures at engine conditions, to set the stage for Section 3 on modeling of $\mathrm{H}_{2}$ ICEs and subsequent chapters. In most of the initial work on $\mathrm{H}_{2}$ ICEs, abnormal combustion encountered with operation on hydrogen was the main subject, so this is covered in Section 4, after which engine features are discussed (Section 5) which allow the operation of a hydrogen-fueled engine. For these designated or converted hydrogen engines, Section 6 discusses the possibilities of controlling the power output while striving for maximum efficiency and minimum emissions. Section 7 reviews some safety aspects (those relevant to experimental $\mathrm{H}_{2} \mathrm{ICE}$ work), after which the performance of $\mathrm{H}_{2} \mathrm{ICEs}$ in vehicles is evaluated using selected examples in Section 8. Section 9 presents the use of mixtures of other fuels with hydrogen. Concluding Sections 10 and 11 summarize the gaps remaining in current knowledge and the most important points from the current work.

Experimental data presented to clarify the effects of heat flux (Section 3.4), combustion anomalies (Section 4) and mixture formation (Sections 3.1 and 6) on combustion were collected on automotive-size single-cylinder research engines operated at the Center for Transportation Research at Argonne National Laboratory, the Institute for Internal Combustion Engines at Graz University of Tech- 
nology and the Department of Flow, Heat and Combustion Mechanics at Ghent University.

\section{Fundamentals}

\subsection{Physical and chemical properties of hydrogen relevant to engines}

Starting from some physical and chemical properties of hydrogen and hydrogenair mixtures, a number of $\mathrm{H}_{2} \mathrm{ICE}$ features can already be defined or expected.

Table 1 lists some properties of hydrogen compared to methane and iso-octane $[14,15,16,17]$, which are taken here as representing natural gas and gasoline, respectively, as it is easier to define properties for single-component fuels. The small and light hydrogen molecule is very mobile (high mass diffusivity) and leads to a very low density at atmospheric conditions.

The wide range of flammability limits, with flammable mixtures from as lean as $\lambda=10$ to as rich as $\lambda=0.14(0.1<\phi<7.1)$ allows a wide range of engine power output through changes in the mixture equivalence ratio. The flammability limits widen with increasing temperature, with the lower flammability limit dropping to $2 \mathrm{vol} \%$ at $300{ }^{\circ} \mathrm{C}$ (equivalent to $\lambda=20 / \phi=0.05$ ) [18]. The lower flammability limit increases with pressure [18], with the upper flammability limit having a fairly complex behavior in terms of pressure dependence [19] but of lesser importance to engines. As will be discussed later, in practice, the lean limit of $\mathrm{H}_{2}$ ICEs is reached for lower air to fuel equivalence ratios than mentioned above, in the vicinity of $\lambda=4 / \phi=0.25$. The lower flammability limit is mostly determined by the classical method of flame propagation in a tube. As mentioned above, the mass diffusivity of hydrogen is high, and this causes a difference in the limit for upward or downward propagating flames, due to preferential diffusion in the presence of buoyancy [20,21] (see Section 2.2). For upward propagating flames, mixtures as lean as $4 \%$ hydrogen in air are still flammable but are non-coherent and burn incompletely. The value of $4 \%$ pertains to one particular experimental configuration, so in real-world situations, the limit may well be below $4 \%$ (or above, depending on conditions). The absolute limit is thus not well known even today. However, this limit is important for safety considerations but less so for engine combustion.

The minimum ignition energy of a hydrogen-air mixture at atmospheric conditions is an order of magnitude lower than for methane-air and iso-octane-air mixtures. It is only $0.017 \mathrm{~mJ}$, which is obtained for hydrogen concentrations of $22-26 \%(\lambda=1.2-1.5 / \phi=0.67-0.83)$ [22]. The minimum ignition energy is normally measured using a capacitive spark discharge, and thus is dependent on 
the spark gap. The figure quoted above is for a gap of $0.5 \mathrm{~mm}$. Using a $2 \mathrm{~mm}$ gap, the minimum ignition energy is about $0.05 \mathrm{~mJ}$ and more or less constant for hydrogen concentrations between $10 \%$ and $50 \%(\lambda=0.42-3.77, \phi=0.27-2.38)$, with a sudden increase when the concentration of $\mathrm{H}_{2}$ is below $10 \%$ [22].

The quenching distance can be experimentally derived from the relation between the minimum ignition energy and the spark gap size [23] or directly measured [24]. It is minimal for mixtures around stoichiometry, and decreases with increasing pressure and temperature. As can be seen in Table 1, it is about onethird that for methane and iso-octane. This affects crevice combustion and wall heat transfer, as will be discussed later.

Finally, note the large difference between the lower and higher heating values of hydrogen compared to methane and iso-octane, which is easily explained as $\mathrm{H}_{2} \mathrm{O}$ is the sole combustion product of hydrogen. Also note the large difference in stoichiometric air-to-fuel ratio of hydrogen compared to methane and iso-octane, as well as the large difference in stoichiometric air-to-fuel ratio in mass terms versus in mole terms.

The properties of the different fuels also determine their ability to efficiently store enough energy on board a vehicle. The U.S. Department of Energy (DOE) has set goals for volumetric as well as gravimetric storage densities of hydrogen storage systems. Figure 1 shows a comparison of DOE targets, current energy density levels of gaseous as well as liquid hydrogen storage systems as well as the energy density of gasoline and a lithium ion battery system for comparison. Neither compressed nor liquid hydrogen storage can currently meet the 2010 DOE goals of $1.5 \mathrm{kWh} / \mathrm{L}$ and $2 \mathrm{kWh} / \mathrm{kg}$, respectively [25].

Table 2 lists the properties of hydrogen-air mixtures, at stoichiometric and at the lean limit mentioned above, compared to stoichiometric methane-air and isooctane-air mixtures $[14,15,16,17]$. The volume fraction of fuel in the fuel-air mixture can be directly calculated from the molar stoichiometric air-to-fuel ratio listed in Table 1. The large volume fraction occupied by hydrogen has consequences for the attainable engine power density (see further below). Combined with the wide flammability limits, it also has an important effect on mixture properties such as the kinematic viscosity, thermal conductivity, etc. These properties vary much more than in conventionally fueled engines. This affects, for example, non-dimensional numbers used in modeling (see Section 3), such as Reynolds numbers, which can substantially differ from the numbers for hydrocarbon combustion. The comparatively large variation in mixture density and thus, the speed of sound, affects the gas dynamics in engines with external mixture formation.

An increased ratio of specific heats results in an increased amount of compres- 
sion work. However, the actual compression work, particularly for direct injection operation, strongly depends on the injection strategy (see Section 6). Calculations have shown that injection timing and duration are the dominating factors compared to the fuel properties, and efficiency benefits of up to $4 \%$ can be gained when employing an optimized injection strategy [26].

There is some ambiguity concerning the autoignition temperature of fuels in general and hydrogen in particular. For instance, for methane values have been found ranging from $810 \mathrm{~K}$ [27] to $868 \mathrm{~K}$ [28]. For hydrogen, values were found from $773 \mathrm{~K}$ [29] to $858 \mathrm{~K}$ [30]. Some sources list the autoignition temperature for hydrogen as lower than that for methane; other sources list the opposite. This ambiguity can be at least partly explained by the sensitivity of autoignition temperatures to the experimental apparatus, the experimental procedure and the criterion used for defining the value [31].

For spark ignition engines, with a propagating flame front, autoignition of the unburned mixture ahead of the flame front is unwanted, as it can result in knocking ${ }^{1}$ combustion. The efficiency of a spark ignition engine is influenced by the compression ratio and the ignition timing (among others), the choices of which are dependent on the autoignition temperature of the fuel-air mixture, so this is an important parameter. For liquid hydrocarbons, the octane rating is more commonly used as a measure of the propensity of a fuel-air mixture to undergo pre-flame reactions. For hydrogen, a research octane number (RON) in excess of 130 and a motor octane number (MON) of 60 have been reported [33, 34]. It is also noteworthy that for the determination of the "methane number" of a gaseous fuel, hydrogen is taken as a reference fuel, having a methane number of zero [35], giving the impression that it is very prone to knock (for details, see Section 4).

The laminar burning velocity of stoichiometric hydrogen-air mixtures is much higher than that of methane and iso-octane. However, if lean-burn strategies are used, the burning velocity can be much lower (see value for $\lambda=4 / \phi=0.25$ ). For mixtures around stoichiometry, the high burning velocity and high adiabatic flame temperature point to high nitrogen oxides $\left(\mathrm{NO}_{\mathrm{X}}\right)$ emissions (see later). The laminar burning velocity of hydrogen mixtures is extensively discussed in Section 2.2 .

Combining the lower heating value (LHV) of hydrogen, its density and the

\footnotetext{
${ }^{1}$ The term "knock" is commonly used to denote end-gas autoignition but in itself is a poor term, as it denotes the physical manifestation of abnormal oscillations in the cylinder pressure [32] and can also result from, e.g., surface ignition.
} 
stoichiometric air requirement, one can calculate the maximum theoretical power density of different engine concepts. Table 3 compares the theoretical power density of hydrogen- and methane-fueled engines with an iso-octane-fueled engine as the reference. Values for both port fuel injection (PFI) engines and direct injection (DI) engines are quoted. Note the large difference for the gaseous fuels, with a (theoretical) power density increase of $38 \%$ for hydrogen when switching from PFI to DI.

Finally, it is noteworthy that the possibility of qualitative load control (changing the mixture richness at wide open throttle (WOT)), the tolerance for substantial mixture dilution (either through excess air or exhaust gas recirculation (EGR)), the high autoignition temperature (allowing high compression ratios) and the generally fast burn rate, all are factors contributing to potentially high engine efficiencies. As will be discussed in Section 6, this has been experimentally confirmed. As will be briefly discussed in Section 3.4, however, heat losses from cylinder gases to the combustion chamber walls can be higher with hydrogen compared to conventional fuels, negatively affecting efficiencies.

\subsection{Laminar burning velocity, influence of preferential diffusion}

The laminar burning velocity, $u_{l}$, of a fuel-air mixture is an important physicochemical property due to its dependence on pressure, temperature, mixture equivalence ratio and diluent concentration. It affects the combustion rate in an engine, the equivalence ratio limits for stable combustion, the tolerance for EGR etc. Most engine combustion models assume the flame structure to be that of a (stretched) laminar flame, with the effect of the in-cylinder turbulence to be one of stretching and wrinkling the flame, thereby increasing the flame area. Consequently, data on the laminar burning velocity and its dependence on pressure, temperature, mixture composition and stretch rate are a prerequisite. In the following, the available data are discussed, along with the effects of preferential diffusion. These effects have long been known [36] but are not always familiar to engine researchers. As the effects are very pronounced for the case of hydrogen, the issue is discussed here at some length.

\subsubsection{Flame front instabilities}

Several mechanisms exist that can trigger instability of a laminar flame. As these instabilities have important implications on hydrogen combustion, this section gives a brief overview of the effects a disturbance (perturbation) can have on a flame front, mainly from a phenomenological point of view [37, 38, 39]. 
When the laminar flame is regarded as a passive surface (an infinitely thin interface separating low density burned gases from higher density unburned gases), a wrinkling of the flame front will not affect the flame intensity but will increase the volumetric burning rate through increased flame area. The discontinuity of density $\left(\rho_{u} \rightarrow \rho_{b}\right)$ causes a hydrodynamic instability known as the DarrieusLandau instability $[37,38]$. Simply speaking, a wrinkle of the flame front will cause a widening of the streamtube to the protrusion of the flame front into the unburned gases, resulting in a locally decreased gas velocity. This will cause a further protrusion of this flame segment as the flame speed remains unchanged (because the flame structure is not affected). Thus, a flame is unconditionally unstable when only considering hydrodynamic stretch and neglecting the effect of flame stretch (see later) on the structure of the flame.

The lower density of the burned gases compared to the unburned gases is also the cause for a second instability arising from gravitational effects. This bodyforce or buoyant instability, also known as the Rayleigh-Taylor instability, arises when a less-dense fluid is present beneath a more-dense fluid; such is the case in, e.g., an upwardly propagating flame.

Finally, flame instability can be caused through unequal diffusivities [37, 38]. As the flame propagation rate is largely influenced by the flame temperature, and this is in turn influenced by the conduction of heat from the flame front to the unburned gases and the diffusion of reactants from the unburned gases to the flame front, a perturbation of the balance between diffusivities can have important effects. Three diffusivities are of importance: the thermal diffusivity of the unburned mixture $\left(D_{T}\right)$ the mass diffusivity of the so-called deficient ${ }^{2}$ reactant $\left(D_{M, l i m}\right)$ and the mass diffusivity of the so-called excess ${ }^{3}$ reactant $\left(D_{M, e x c}\right)$. The ratio of two diffusivities can be used to judge the stability of a flame when subjected to a perturbation or flame stretch.

The Lewis number $L e$ of the deficient reactant is defined as the ratio of the thermal diffusivity of the unburned mixture to the mass diffusivity of the deficient reactant:

$$
L e=\frac{D_{T}}{D_{M, l i m}}
$$

If this Lewis number is greater than unity, the thermal diffusivity exceeds the

\footnotetext{
${ }^{2}$ This refers to the reactant limiting the rate of reaction. Thus, in a lean flame, the deficient reactant is the fuel; in a rich flame, it is oxygen.

${ }^{3}$ For a lean flame, this is oxygen; for a rich flame, this is the fuel component.
} 
mass diffusivity of the limiting reactant. When this is the case, a wrinkled flame front will have parts that are "bulging" towards the unburned gases lose heat more rapidly than diffusing reactants can compensate for. The parts that recede in the burned gases, on the contrary, will increase in temperature more rapidly than being depleted of reactants. As a result, the flame speed of the "crests" will decrease and the flame speed of the "troughs" will increase, which counteracts the wrinkling and promotes a smooth flame front. The mixture is then called thermo-diffusively stable. When the Lewis number is smaller than unity, similar reasoning shows that a perturbation is amplified, which indicates unstable behavior.

Another mechanism involving unequal diffusivities is the following: when the limiting reactant diffuses more rapidly than the excess reactant $\left(D_{M, l i m}>\right.$ $D_{M, e x c}$, it will reach a bulge of the flame front into the unburned gases more quickly and cause a local shift in mixture ratio. As in this case, the more diffusive reactant is the limiting reactant, the local mixture ratio will shift so that it is nearer to stoichiometry, and the local flame speed will increase. Thus, a perturbation is amplified and the resulting instability is termed a preferential diffusion instability. This mechanism is easily illustrated by the propensity of rich heavier-than-air fuels (e.g., propane/air [40], iso-octane/air [41]) and lean lighter-than-air fuels (e.g., methane/air [42, 43], hydrogen/air [40]) to develop cellular flame fronts (see also the review paper by Hertzberg [21]). The selective diffusion of reactants can be viewed as a stratification of the mixture [44].

Both mechanisms involving unequal diffusivities are sometimes called differential diffusion instabilities, or instabilities due to non-equidiffusion.

In reality, all mechanisms described above are simultaneously present. Disturbances of a flame front causing it to deviate from a steady planar flame can be summarized in one scalar parameter, the rate of flame stretch, $\alpha$, which is defined as the normalized rate of change of an infinitesimal area element of the flame:

$$
\alpha=\frac{1}{A} \frac{d A}{d t}
$$

The combined effect of the instability mechanisms is dependent on the magnitude of the stretch rate. For instance, thermo-diffusively stable spherically expanding flames start out smooth, as the stretch rate is initially high enough for thermodiffusion to stabilize the flame against hydrodynamic instability. For small to moderate rates of stretch, the effect of stretch on the burning velocity can be expressed to first order [37] by:

$$
u_{l}-u_{n}=L \alpha
$$


where the subscript " $n$ " denotes the stretched value of the normal burning velocity, and $L$ is a Markstein length. Depending on the sign of $L$ and whether the flame is positively or negatively stretched, the actual burning velocity can be increased or decreased compared to the stretch-free burning velocity, $u_{l}$. A positive Markstein length indicates a diffusionally stable flame, as flame stretch decreases the burning velocity. Any disturbances (wrinkles) of the flame front will thus tend to be smoothed out. A negative Markstein length indicates an unstable flame. A perturbation of the flame front will then be enhanced, and such flames quickly develop into cellular structures. The Markstein length is also a physicochemical parameter that embodies the effect of a change in flame structure when the flame is stretched. Thus, when measuring burning velocities, it is important that this is done at a well-defined stretch rate and the Markstein length is simultaneously measured so that the stretch-free burning velocity can be calculated. It has taken a while for the effects of stretch to be understood and for measuring methodologies to be developed that could take the effects into account. As illustrated in the following section, this is the main reason for the large spread in the reported data on hydrogen mixture burning velocities throughout the years.

\subsubsection{The laminar burning velocity at atmospheric conditions}

Contemporary reviews of data and correlations for the laminar burning velocity of hydrogen-air mixtures show a wide spread of experimental and numerical results $[45,46]$. Figure 2 plots laminar burning velocities against the equivalence ratio for hydrogen-air mixtures at normal pressure and temperature (NTP). Note the large difference in burning velocities, with stoichiometric burning velocities varying from $2.1 \mathrm{~m} / \mathrm{s}$ up to $2.5 \mathrm{~m} / \mathrm{s}$, with even larger differences for the lean mixtures (e.g., for $\lambda=2$ from $56 \mathrm{~cm} / \mathrm{s}$ to $115 \mathrm{~cm} / \mathrm{s}$ ). The cause of this large spread can be found in the influence of the flame stretch rate on experimentally observed burning velocities.

The solid symbols in Fig. 2 denote stretch-free burning velocities (or rather, burning velocities that were corrected to account for the effects of the flame stretch rate), as measured by Taylor [47], Vagelopoulos et al. [48], Kwon and Faeth [49] and Verhelst et al. [50]. The open symbols denote other measurements that did not take stretch rate effects into account, as reported by Liu and MacFarlane [51], Milton and Keck [52], Iijima and Takeno [53] and Koroll et al. [54]. These experiments result in consistently higher burning velocities, with the difference increasing for leaner mixtures.

Because of the very high mass diffusivity of hydrogen (the highest of all fuels), a lean to stoichiometric hydrogen/air flame (i.e. for equivalence ratios such as 
used in homogeneous charge hydrogen engines) will be diffusionally unstable, both from the Lewis number $\left(D_{T} \ll D_{M, H 2}\right)$ as from the preferential diffusion $\left(D_{M, H 2} \gg D_{M, O 2}\right)$ point of view. Thus, these flames are very sensitive to the flame stretch rate. Figure 3 shows schlieren photographs of a centrally ignited $\lambda=1.43 / \phi=0.7,365 \mathrm{~K}, 1$ bar $\mathrm{H}_{2}$-air flame propagating in a constant volume "bomb" [46].

The flame starts out smooth but quickly evolves into a fully cellular flame. From image processing of the schlieren photographs, the flame radius, $r$, can be obtained as a function of time, $t$. Figure 4 plots the flame speed, $S_{n}=d r / d t$, versus the flame stretch rate, $\alpha$, which can be calculated as $2 S_{n} / r$ for spherically expanding flames. In spherically expanding flames, the flame starts out highly stretched and as the flame grows, the stretch rate decreases; thus Fig. 4 should be read from right to left. Such a plot demonstrates a number of things. First, the methodology of obtaining stretch-free flame speeds. This can be seen from the data points between the "spark affected" and "cellular" regions. After the effects of the spark "boost" have decayed, a regime is found where the flame speed varies linearly with the flame stretch rate. This can be used to extrapolate towards zero stretch and obtain a stretch-free flame speed, $S_{s}$ (as illustrated in Fig. 4, in this case $S_{s}=8.9 \mathrm{~m} / \mathrm{s}$ ). After dividing $S_{s}$ by the density ratio of unburned to burned gases, $\rho_{u} / \rho_{b}$, one obtains the laminar burning velocity, $u_{l}$ (for this particular case, $\left.u_{l}=1.77 \mathrm{~m} / \mathrm{s}\right)$.

In principle, this procedure does not produce the laminar burning velocity that would be found by a steady, planar ideal computation with perfect thermodynamics, transport and chemical kinetics. Equation 3 applies only in the linear range which actually occurs at low stretch (the cellular range in the figure). However, the procedure illustrated in Fig. 4 is a convenient one leading to a very good approximation of $u_{l}$.

A second property that can be derived from Fig. 4 is the slope of the linear relation between $S_{n}$ and $\alpha$, which is called the burned gas Markstein length, $L_{b}$, and is a measure of the sensitivity of the flame to flame stretch. The sign of $L_{b}$ is indicative of the thermodiffusive stability of the flame: if $L_{b}$ is positive, $S_{n}$ decreases for increasing $\alpha$, so that flame perturbations (causing an increase in local stretch rate) are smoothed out, leading to a stable flame. In the case of Fig. $4, L_{b}$ is positive, so the flame is diffusively stable. In this case, thermo-diffusion initially stabilizes the flame against the inherent hydrodynamic stability. When the stretch rate falls below a critical stabilizing value, the flame becomes cellular [55, 56]. This can be seen clearly in Fig. 4 from the sudden acceleration of the flame once the flame stretch rate drops below roughly $500 \mathrm{~s}^{-1}$. 
This behavior is probably the reason for the large spread in burning velocities shown in Fig. 2: the correlations by Liu and MacFarlane [51], Milton and Keck [52], Iijima and Takeno [53] and Koroll et al. [54] were derived from data that did not take the effects of the stretch rate into account. As just explained, the flame stretch rate can cause an increase in burning velocity or flame acceleration due to cellularity.

When comparing the burning velocities predicted by, for example, the experimental correlation of Iijima and Takeno [53] with the measurements performed by Verhelst et al. [50], it can clearly be seen that the burning velocities of Iijima and Takeno are all in the cellular region. As Iijima and Takeno calculated burning velocities from pressure records obtained from bomb explosions, flame instabilities could not be seen. If the larger radii were used in the derivation of burning velocities, the flames would have developed cellularity. Figure 5 illustrates this: burning velocity predictions obtained with the correlation of Iijima and Takeno were multiplied by the density ratio to give flame speeds and were added to the $S_{n}$ vs. $\alpha$ plot for some NTP hydrogen-air flames [46]. The predictions all fall in the cellular region, which explains the consistently higher values. The burner measurements of Liu and MacFarlane [51] and the double kernel measurements of Koroll et al. [54] also report higher burning velocities. The deviations with the stretch-corrected measurements increase when going leaner, which could be explained by the decreasing Markstein length (with $L_{b}$ negative and thus becoming larger in absolute value), resulting in a larger increase in the burning velocity when the flame is positively stretched. The measurements of Liu and MacFarlane are highly stretched due to the very small nozzle used in their measurements [57].

The burning velocity for a stoichiometric hydrogen-air mixture predicted by the correlation by Milton and Keck [52] is lower than the values obtained with stretch rate correction (see Fig. 2), which could also be due to stretch (a stoichiometric hydrogen-air flame is stable and will thus propagate slower when subjected to positive stretch), if the burning velocity was taken at a small flame radius (i.e., before the onset of cellularity).

The stretch-free measurements show reasonably good correspondence, although the values reported by Vagelopoulos et al. [48] are lower than the others. All bomb-derived data (Taylor [47], Kwon and Faeth [49] and Verhelst et al. [50]) correspond closely.

Note that the very rich equivalence ratio at which the laminar burning velocity peaks (see Fig. 2: $u_{l}$ peaks at $\lambda \sim 0.6 / \phi \sim 1.7$ ) can also be explained by the high mass diffusivity of hydrogen [21]. It is noteworthy that the equivalence ratio at which $u_{l}$ peaks is much richer than the equivalence ratio at which the flame 
temperature peaks (around stiochiometry).

To conclude this section, Fig. 6 compares stretch-free burning velocities at atmospheric pressure and $\sim 360 \mathrm{~K}[41,43,46,58]$ for hydrogen, methane and isooctane as a function of equivalence ratio. The figure demonstrates the much higher laminar burning velocity of hydrogen-air mixtures and its strong dependence on the equivalence ratio.

\subsubsection{The laminar burning velocity at engine conditions}

The previous section demonstrated that care must be taken in using published data for the laminar burning velocity of hydrogen mixtures. The section highlighted this for atmospheric conditions. The current section discusses the laminar burning velocity at engine conditions.

There are very few data available at engine conditions. The range of conditions covered by the correlations of Liu and MacFarlane [51], Milton and Keck [52], Iijima and Takeno [53] and Koroll et al. [54], mentioned above, include lean to rich mixtures and elevated temperatures (up to $550 \mathrm{~K}$ ) and pressures (up to 25 atm). However, as discussed previously, they did not account for the effects of stretch and instabilities, which grow stronger with pressure as the flame thickness decreases [50].

Experimental data [59] show hydrogen/air flames at atmospheric conditions to have positive Markstein lengths close to stoichiometric, but all mixture ratios with $\lambda \geq 1 / \phi \leq 1$ have negative Markstein lengths as soon as the pressure exceeds about 4 bar. The consequence of this increasing instability with pressure is illustrated in Fig. 7, which shows schlieren photographs of a $\lambda=1.25 / \phi=0.8$, $300 \mathrm{~K}, 5$ bar $\mathrm{H}_{2}$-air flame.

In this case, the flame is cellular from inception onwards, accelerating throughout its growth. The flame speed increases faster than linearly with decreasing flame stretch rate, consequently the methodology of obtaining stretch-free burning velocities $u_{l}$ (and its dependence on stretch rate), described in the previous section, is no longer applicable [50,60]. To study the influence of temperature, pressure and residual gas content, Verhelst et al. [46, 50] determined the burning velocity of a spherically expanding flame at a flame radius of $10 \mathrm{~mm}$, for $1 \leq \lambda \leq 3.3 / 0.3 \leq \phi \leq 1,300 \mathrm{~K} \leq T \leq 430 \mathrm{~K}, 1$ bar $\leq p \leq 10$ bar and $0 \%$ $\leq f \leq 30 \%$ (with $f$, the residual gas content, in vol\%). This burning velocity is not a fundamental parameter but, as the authors claim, is indicative of the burning rate at a fixed, repeatable condition, representing a compromise that involves a sufficiently large radius to minimize the effects of the spark ignition, while being small enough to limit the acceleration due to the instabilities. It is noteworthy that 
these are the only data that include the effects of residual gas content, an important parameter, given the operating strategies that are proposed for $\mathrm{H}_{2} \mathrm{ICEs}$ (see Section 6). A correlation for the burning velocity was derived from this experimental data and partly validated using an engine code [61].

An alternative methodology has been proposed to obtain $u_{l}$ and Markstein lengths at higher pressures, also from freely expanding spherical flames. The laminar burning velocity $u_{l}$ as well as Markstein numbers have been reported for equivalence ratios from $\lambda=3.3 / \phi=0.3$ up to stoichiometric, for pressures of 1, 5 and 10 bar [60]. However, this involved numerous experiments and very high camera frame rates, but experimental uncertainty is rather high, especially on the Markstein lengths.

An alternative to experimental determination is the use of a one-dimensional chemical kinetics code to calculate $u_{l}$. The $\mathrm{H}_{2} / \mathrm{O}_{2}$ system is one of the simplest reaction mechanisms, it is fairly well known (with more than 100 mechanisms reported in the literature, e.g., [62]) and computations of $u_{l}$ are reasonably fast. However, it is perhaps surprising to learn that even for this simple system, there still exists a number of uncertainties, as recently reviewed by Konnov [63]. As the previous discussion has shown, stretch-free data are scarce, especially at enginelike conditions. Thus, validation of reaction mechanisms is very limited at best.

Results were reported using a chemical kinetics code to calculate $u_{l}$, using several published reaction mechanisms [46, 64]. First, from initial results the reaction mechanism of Ó Conaire et al. [65] was chosen as it gave the best correspondence with the selected experimental data at atmospheric conditions. Secondly, calculation results were compared with the experimental results from Verhelst et al. $[46,50]$ for a range of pressures, temperatures, equivalence ratios and residual gas fractions. Note that these experimental results are not stretch-free burning velocities (see above). The authors report that the calculations break down for (very) lean mixtures and higher pressures. The inability of steady, planar calculations to predict burning velocities at very lean mixtures in correspondence with experimentally observed values has recently been elucidated by Williams and Grcar [66]. For moderately lean to stoichiometric mixtures, the effect of temperature and dilution with residuals is reported to be predicted reasonably well. The authors conclude that simulations of the effect of residuals could thus be considered to replace experiments with residuals, which are rather cumbersome.

Bradley et al. [60] compare their stretch-free data at 5 and 10 bar to calculations using the reaction mechanisms of Ó Conaire et al. [65] and Konnov [67]. The results using Konnov's scheme are reported to correspond to the experimental results within the rather large uncertainty bands. Knop et al. [58] propose a 
correlation for $u_{l}$ for use in an engine code, based on published experimental results and chemical kinetic calculations. The comparison between simulated and measured engine cycles reported in the paper represents a limited validation of the correlation. Other studies reporting correlations based on chemical kinetic calculations are cited in Section 3 on modeling.

To conclude this section: the current state is that experimental data of laminar burning velocities of hydrogen-air mixtures at engine conditions are mostly nonexistent, and (consequently) numerical data are nonvalidated. Clearly, this is an area requiring further study. Konnov [63] wrote, "new accurate measurements of hydrogen burning velocities are therefore extremely important for [reaction mechanism] validation".

However, as discussed above, accurate burning velocity measurements at lean conditions are next to impossible because of instability. An alternative approach is to test reaction mechanisms on the basis of measured autoignition times [68].

\subsection{Turbulent burning velocity}

The turbulent burning velocity, $u_{t}$, of hydrogen mixtures is a convenient parameter to calculate the fuel mass burning rate in a hydrogen engine. Contrary to the laminar burning velocity, it depends not only on the mixture properties but also on the flow, the geometry and the history of the flame [69]. In light of the previous section, an important question is, to what extent flame stretch and instabilities influence the turbulent burning velocity of hydrogen flames.

\subsubsection{Experimental and numerical work on the role of instabilities and the effects of stretch on $u_{t}$}

First, an overview is given on work evaluating the effect of stretch and laminar flame instabilities on turbulent combustion. A lot of work is devoted to this subject (see the excellent review paper by Lipatnikov and Chomiak [70]). The following overview is limited to work including hydrogen mixtures.

- Bradley and co-workers: Abdel-Gayed et al. [71] investigated the effect of the Lewis number Le (and thus, the laminar flame stability) by measuring the turbulent burning velocity in a fan-stirred bomb using a double kernel method. The measurements comprised hydrogen, propane and iso-octane, mixed with air at various equivalence ratios, and indicated an increase in $u_{t}$ for unstable mixtures. Later, Abdel-Gayed et al. [72] compiled all contemporary data on the turbulent burning velocity and found a confirmation of this trend; additional measurements by the authors using the fan-stirred 
bomb also revealed the existence of cellular structures in the turbulent flame for thermo-diffusively unstable flames. Recent measurements by Bradley et al. [73] of the turbulent burning velocity in a (different) fan-stirred bomb of statistically spherical explosion flames showed an increase in the ratio $u_{t} / u_{l}$ for decreasing Markstein number for mixtures with the same ratio of root mean square (rms) turbulent velocity, $u^{\prime}$, to $u_{l}$.

- Faeth and co-workers: Wu et al. [74, 75] used a turbulent jet burner to measure turbulent burning velocities for hydrogen-air mixtures with various equivalence ratios. The measurements not only showed an increase in $u_{t}$ for unstable mixtures, but also a "dampening" of turbulent fluctuations, and thus a decrease of $u_{t}$ for stable mixtures. Later, Aung et al. [76] reported measurements of statistically spherical explosion flames in a fan-stirred bomb. Mixtures of hydrogen, nitrogen and oxygen were prepared with almost identical laminar burning velocities but different thermo-diffusive stability (stable/neutral/unstable). Again, $u_{t}$ clearly increased for unstable mixtures. Both measurements on the burner and the bomb showed a strong dependence of $u_{t}$ on mixture stability even for strong turbulence.

- Koroll et al. [54] recorded schlieren photographs of double kernel explosions in a fan-stirred bomb using hydrogen-air mixtures of varying equivalence ratios. They found a dependence of $u_{t} / u_{l}$ on the equivalence ratio, with the ratio being much higher for lean mixtures.

- Goix and Shepherd [77] used a stagnation point flame burner to compare $u_{t}$ for lean hydrogen-air and propane-air flames with similar laminar burning velocities. At similar rms turbulent velocities, the turbulent burning velocity for the hydrogen mixture was higher than that for the propane mixture. The fractal dimension of the flame surface was compared and was found to be larger for the hydrogen mixture. The ratio $u_{t} / u_{l}$ was much higher than the surface area ratio wrinkled/smooth, indicating a substantial difference in local flame speeds.

- Renou et al. [78] measured local flame speeds of spark-ignited flames in a vertical wind tunnel, for stoichiometric methane-air and propane-air mixtures and lean hydrogen-air mixtures. The probability density function (pdf) of local flame speeds was strongly dependent on the Lewis number. For the lean hydrogen/air mixtures, the pdf was much broader indicating the strong effect of stretch on the local flame speed. 
- Kido and co-workers: Kido et al. [79] measured local flame speeds of methane, propane and hydrogen turbulent flames in the weak turbulence region (low $u^{\prime}$ ) with identical laminar burning velocities using a fan-stirred bomb. For a fixed $u^{\prime}$, the surface area ratio turbulent/laminar was almost constant but the turbulent burning velocity was very different, caused by a strong difference in local flame speeds. The variation in local flame speeds could be qualitatively explained from the preferential diffusion concept. Later, Kido et al. [80] measured turbulent lean hydrogen flames of different equivalence ratio but similar laminar burning velocity, again for low $u^{\prime}$, in the fan-stirred bomb. The turbulent burning velocity increased strongly for leaner mixtures, although the relative increase was found to be much smaller beyond an equivalence ratio of $\lambda=2.0$. Again, this was found to be qualitatively consistent with changes in local flame speeds due to changes in the local equivalence ratio caused by the preferential diffusion effect.

- Lipatnikov et al. [81] reviewed measurements using a fan-stirred bomb on turbulent burning velocities for lean hydrogen-air mixtures with similar $u_{l}$ but different Lewis numbers and found a difference in $d u_{t} / d u^{\prime}$ amounting to an order of magnitude. The turbulent burning velocity was found to be strongly dependent on the Lewis number even for strong turbulence $\left(u^{\prime} / u_{l} \gg 1\right)$. The authors also reported a decrease in the smallest wrinkling scale for decreasing $L e$.

- Chen and Im: Chen and Im [82] looked at the correlation of flame speed with stretch in turbulent methane/air flames using two-dimensional direct numerical simulation (2-D DNS) with detailed chemistry. Lean and stoichiometric flames were simulated and it was shown that for moderate stretch rates the local correlation between flame speed and stretch was approximately linear. However, large negative stretch rates (compression) were also found, obtained solely through curvature effects, causing an overall nonlinear correlation of flame speed with stretch. Changes in flame speed were consistent with preferential diffusion theory. Chen and Im [83] also looked at hydrogen-air flames, for equivalence ratios ranging from lean to rich, again using 2-D DNS with detailed chemistry. Strong interactions between stretch and preferential diffusion were found to exist in the turbulent flames; the local correlations between burning velocities and strain and curvature were according to expected diffusive-thermal effects. Im and Chen [84] expanded the work on hydrogen-air flames studying the interaction of 
twin premixed hydrogen-air flames with 2-D DNS and detailed chemistry; the interaction of both rich-rich and lean-lean flames were studied. The local flame front response to turbulence was according to the preferential diffusion mechanism. This resulted in a significant burning rate enhancement for the lean-lean case. This was caused by the global positive stretch on the flame surface increasing the local flame speed, as well as by a "selfturbulization" and increased flame wrinkling.

\subsubsection{Implications for the combustion of hydrogen-air mixtures in engines}

The measurements and simulations reviewed in the previous section clearly indicate the existence of an effect of flame instabilities on the turbulent burning velocity that can be very strong in some cases. The influence of pressure was not discussed in the above. One could assume that the effect of local stretch on $u_{t}$ will decrease with pressure $[85,86]$, as Markstein numbers have been shown to decrease with pressure (see, e.g., [41, 43, 87]) and the flame thus gets less sensitive to stretch. However, flames at higher pressure have also been shown to get increasingly unstable, as demonstrated in Section 2.2, with the dependence of the onset of cellularity on pressure. Turbulent flames have been shown to be more finely wrinkled at higher pressures [86, 88, 89], which suggests an increasing instability and a larger effect on $u_{t}$ as pressures increase [90]. Flame instability effects can thus be expected to be relevant to turbulent combustion in spark-ignition engines.

Due to the very high mass diffusivity of hydrogen, hydrogen mixtures show a very pronounced preferential diffusion effect. A majority of the work reported in the previous section used hydrogen mixtures exactly for that reason, and several authors advanced turbulent lean hydrogen combustion as the most challenging test for turbulent combustion models [74, 81]. Practical mixtures in hydrogen engines will most probably show increased turbulent burning velocities because of instability effects. Heywood and Vilchis [91] compared spark-ignition engine operation on hydrogen and propane, with stoichiometric mixtures, by recording schlieren photographs of the flame development in an optically accessible square piston engine. The turbulent flame speed for the propane mixture was an order of magnitude larger than the laminar flame speed, whereas for hydrogen it was of the same order ${ }^{4}$ (though larger). The characteristic wrinkling scale was found to be smaller for the hydrogen flames.

\footnotetext{
${ }^{4}$ Note that the laminar flame speeds used in their work were taken from [52] and included stretch effects.
} 


\subsubsection{Implications for modeling of turbulent combustion of hydrogen-air mix- tures}

This section presents some of the current knowledge on modeling of turbulent combustion. Most of the issues discussed below are not hydrogen specific. However, these were included to highlight the remaining uncertainties in modeling turbulent combustion so that the reader has a feeling for the extent to which the assumptions of the various engine modeling work presented in Section 3 are justified. As discussed in the previous section, the combustion of hydrogen is quite particular, and consequently stresses many of the usual assumptions made for turbulent combustion modeling.

A number of turbulent combustion models, dating back to the seminal work by Damköhler (1940), assume the sole effect of turbulence to be an increase in flame surface area through turbulent wrinkling, based on the observations showing an increase in $u_{t}$ with $u^{\prime}$. These models only implement a dependence of $u_{t}$ on $u^{\prime}$ and $u_{l}$; these models are numerous and are still popular today.

As more measurements were published, more phenomena became apparent that could not be explained when only considering flame surface wrinkling (e.g., the bending of the $u_{t}$ versus $u^{\prime}$ curve $[72,86,92]$, qualitatively illustrated in Fig. 8, with quantitative figures shown in, e.g., [70]). Models were proposed that included quenching effects at excessive flame stretch [92, 93]. Later, various $u_{t}$ correlations based on experimental data or obtained through theoretical work were proposed with additional dependencies: mostly a length scale of turbulence and a transport property of the unburned mixture, for a better correspondence with measurements or resulting from explicit inclusion of stretch effects (e.g., [92, 94, 95] and others). Also, the effects of turbulence on surface wrinkling as well as on local flame speeds, assuming a linear relation between flame speed and flame stretch (see Section 2.2), were modeled [96].

However, for increasing stretch, a linear relation between flame speed and flame stretch no longer applies, as demonstrated through simulations of highly perturbed laminar flames [97], DNS of turbulent flames [82] as well as through experimental data [81], despite the larger range of applicability of the linear relation than could be assumed from theoretical considerations [82]. Models accounting for this observation are few and still in their infancy. Lipatnikov et al. [81, 97] propose a model based on the leading point concept, which (in simplified terms) assumes the global reaction rate to be primarily dominated by the faster burning parts of the flame. Measurements by Kido et al. [79, 80] seem to confirm this mechanism with observations of "active" (in the case of lean hydrogen: the 
convex parts) and "inactive" parts of a flame front. The model proposed by Lipatnikov et al. starts from an experimental $u_{t}$ correlation and substitutes the chemical (laminar) time scale with a time scale calculated from the "laminar consumption velocity" of "critically perturbed flamelets", obtained through simulations of stretched laminar flames [97]. Other approaches are suggested by Kobayashi et al. [88] and Bradley et al. [98].

Ultimately, models that include flame front wrinkling as well as stretch-dependent local flame speeds through a stretched laminar flamelets library are envisaged, but such a library asks for much more data than is currently available (namely, laminar burning velocities, strain and curvature Markstein lengths for a large range of pressures, temperatures and mixture compositions). Areas requiring more research in order to work towards such models are suggested by Bradley [90] (Peters' book [99] also is a valuable reference on modeling turbulent combustion). There is also uncertainty on this approach, however [100], as these models use a library of steady stretched flamelets, whereas flamelets have been shown to behave differently under transient stretch [44] (e.g., being more resistant to quenching under transient than under steady stretch).

Also noteworthy is that for typical hydrocarbon combustion, $u^{\prime} / u_{l}$ is quite high, and therefore many of turbulent combustion models start from this assumption. For hydrogen, however, this ratio is much lower at near-stoichiometric conditions due to the high laminar burning velocities, and this assumption is thus invalid.

\subsection{Hydrogen jets}

As described later, most modern mixture formation systems for hydrogen engines rely on injection of gaseous hydrogen into air using pulsed fuel injection devices. This section discusses some relevant features of hydrogen jets.

\subsubsection{Un-ignited jets}

Regardless of the mixture formation system, the injection process of gaseous hydrogen into air consists of several steps. The actual injection process can be divided into the flow of hydrogen in the injector and nozzle, the transitional flow of the fuel from the injector tip into the downstream volume (intake manifold or combustion chamber), the interaction of the gas jet with the surrounding media and the consequent generation of turbulence and heat exchange, mixing and eventual combustion of the fuel. Although the injection event of a gaseous fuel into another gaseous medium may appear simple compared to liquid fuel injection, the disparate length scales in the gas flow present a considerable challenge 
to the computational modeling of the injection event. Under the assumption of a choked flow and hydrogen being a nearly perfect gas that flows isentropically through the nozzle, the pressure ratio between upstream fuel-supply pressure, $p_{k}$, and back-pressure, $p_{0}$, is defined as:

$$
\frac{p_{k}}{p_{0}}=\left(\frac{2}{\gamma+1}\right)^{\frac{\gamma}{\gamma-1}}
$$

For hydrogen with a polytropic coefficient, $\gamma$, of approximately 1.4 , the critical pressure ratio results to be around 0.53 , requiring the fuel-supply pressure to be roughly twice the back-pressure to obtain critical conditions. Injection is usually designed to be sonic to allow for high mass flow rates and short injection durations even at high engines speeds [13]. Critical injection conditions are also beneficial to the engine control strategy because the amount of injected fuel is independent of back-pressure at critical conditions.

The generalized configuration of the near-field of an underexpanded jet is well documented, a simplified model of which is presented in Fig. 9 [101]. The flow at the exit plane of the nozzle is assumed to be choked, i.e., $M a=1$. Immediately upon exit from the nozzle, the high ratio of exit pressure to surrounding pressure causes expansion of the gas. Flow subsequently accelerates, thereby generating expansion waves. When these expansion waves meet at the outer boundary, they are reflected as compression waves. Finally, these compression waves coalesce to form an oblique shock structure of barrel shape. This structure encloses a supersonic flow region termed the "zone of silence", wherein it is assumed that no entrainment takes place, i.e., the mass flux at the nozzle exit is conserved throughout this region. For an exit pressure to ambient pressure ratio above approximately 2 , the barrel shock culminates in a disk-shaped normal shock called a "Mach disk" and a reflected shock. At sufficiently high pressure ratios this process may repeat several times, resulting in a succession of barrel and normal shock structures. Downstream of the final Mach disk, the flow is subsonic, with the adjacent flow from the reflected shock remaining supersonic. Following the abrupt change of density after the Mach disk, pressure in the subsonic flow is assumed to be consistent with that of the surroundings.

The ratio of the largest length scale, the penetration of the gas jet, to the smallest length scale, the flow variations within the orifice, is estimated to be around 4000 [102], precluding the straightforward approach of treating the entire process in a single computational mesh that resolves all length scales, because it would result in impractical computational times. 
Various approaches to solve above mentioned problem have been developed and tested, including dividing the flow problem into tractable portions [102], scaling theories based on conservation of energy equations [103] and combinations of scaling theories with free jet theories [101]. The overarching goal of above mentioned approaches is to accurately predict the injection characteristics like penetration depth, mixing and spreading of the jet. Past and ongoing research focuses on the general prediction of these jet characteristics and was widely based on a comparison to results from injection test rigs or pressure chambers [104].

Additional factors that influence the injection and mixture formation event in an actual engine include, but are not limited to, in-cylinder charge motion, changes in supply as well as back-pressure during the injection event, surface interaction of the injection jet, effects between adjacent injection jets, etc. The effect of charge motion and in particular swirl on the development of transient hydrogen jets has been studied experimentally [105]. Experimental investigations on an optical engine also documented effects between adjacent injection jets as well as injection jets and in-cylinder surfaces [106]. It was found that neighboring injection jets from multi-hole nozzles tend to collapse to one jet. Also, jets close to an in-cylinder surface tend to get drawn towards that surface. Both phenomena are attributed to the so-called Coanda effect [106]. Development and application of simulation tools as well as application and improvements of optical techniques for hydrogen engines have allowed considerable progress and yielded further understanding of the dominant processes for mixing of un-ignited hydrogen jets, e.g., [107].

\subsubsection{Ignited jets}

Development of advanced mixture formation concepts like late injection just before spark timing, multiple injection strategies with injection pulses during compression as well as combustion or compression ignition require consideration of flame propagation processes in ignited hydrogen jets. Similar considerations related to hydrogen safety have also been employed to analyze the effects of jet flames resulting from unintended hydrogen releases. Houf et al.[108] emphasized that the knowledge of the flame length and thermal radiation heat flux distribution is important for the safety aspect of hydrogen. Brennan et al. [109] compared modeling results of high-pressure hydrogen jet fires with experimental results. This work was driven by the need to develop contemporary tools for safety assessment of real-scale under-expanded hydrogen jet fires and to study large eddy simulation (LES) model performance to reproduce such large-scale jet fires in an industrial safety context. Mohammadi et al. [110] experimentally investigated the 
ignition, combustion and flame behavior of high-pressure and intermittent hydrogen jets in a constant-volume combustion chamber. With parametric studies of the effects of injection pressure, nozzle size, ambient pressure and spark location for various spark timings and equivalence ratios, they revealed that stable ignition can be achieved even during injection. They also concluded that ignition of hydrogen jets at the end of injection offers the shortest combustion duration, while combustion control is much easier when the jet is ignited just at the time when the jet tip reaches the spark gap. In addition, igniting hydrogen jets at the boundary of the jet is very effective for stabilizing the ignition, and that in combination with advanced spark timing, the intense combustion of hydrogen can be controlled.

Kawanabe et al. [111] confirmed that the flame propagation process qualitatively agreed with experimental data for a wide variety of injection conditions and ignition timings using incompressible-flow type computational fluid dynamics (CFD) with a k- $\epsilon$ turbulence model and the flamelet concept. Differences in flame propagation were reported for jet-tip ignition cases in which the flame mainly propagates along the jet-tip edge and then the burned area grows compared to inner jet ignition cases in which the start of flame propagation is slightly delayed after ignition and the burned area spreads from the inner region of the jet. They also concluded that for the flame propagation process in a hydrogen jet, a local value of the laminar burning velocity significantly affects the turbulent burning velocity. Development of improved jet combustion models also benefits the accuracy of combustion and ultimately emissions prediction of in-cylinder combustion events.

\section{Modeling regular combustion}

The following sections discuss the efforts undertaken to analyze and model the regular combustion of hydrogen in engines, i.e., where combustion is initiated by the spark after which a turbulent flame develops and propagates throughout the combustion chamber, consuming all of the fuel-air mixture [15]. The discussion is limited to the combustion of pure hydrogen. The interested reader is referred elsewhere for works modeling the effects of hydrogen in addition to other fuels [112] (see also the references cited in Section 9). Also, the focus is on work devoted to the development of hydrogen engines and not on work where hydrogen was mainly chosen as a convenient fuel in terms of CPU time, e.g. to come to a better understanding of HCCI (homogeneous charge compression ignition) combustion $[113,114]$ by including the detailed chemical kinetics without this leading to prohibitive computing times. 
From Sections 2.2 and 2.3, it is clear that many uncertainties remain concerning both fundamental data on hydrogen-air combustion properties and modeling approaches. This has to be borne in mind in the following discussion (Sections 3.2 and 3.3, in particular) of the works reporting modeling of the engine cycle of hydrogen engines.

\subsection{Thermodynamic analysis of the working cycle}

The engine efficiencies and losses of the working cycle can be calculated using test data from different operating modes. Starting from a theoretical efficiency of an engine without losses, the individual losses due to incomplete combustion, actual rate of heat release, wall heat losses and gas exchange can be calculated [15]. Figure 10 shows the efficiencies and losses for gasoline and hydrogen operation with both port injection and direct injection. The data for all fuels were collected on a single-cylinder research engine at an engine speed of 2000 RPM and indicated mean effective pressures of 2 bar and 6 bar. In hydrogen direct injection, the fuel was injected early during the compression stroke (with the start of injection at $120^{\circ} \mathrm{CA}$ BTDC and an injection pressure of 150 bar), resulting in a fairly homogeneous mixture at spark timing.

At the low load point of 2 bar indicated mean effective pressure (IMEP) the efficiency of the ideal engine calculated using actual gas properties in gasoline operation is significantly lower than in hydrogen operation. Since this value is mainly influenced by the compression ratio and the air/fuel ratio, hydrogen operation results in higher values, due to the lean operation (see Section 6). Losses due to incomplete combustion can be determined by measuring unburned fuel components in the exhaust. These consist of hydrocarbons and carbon monoxide in gasoline operation and unburned hydrogen when fueled with hydrogen. Due to the extremely lean conditions in hydrogen operation $(\lambda=5.3 / \phi=0.19)$, the losses due to incomplete combustion are significantly higher than in stoichiometric gasoline operation. The loss due to actual combustion rather than an ideal constant-volume combustion at top dead center in gasoline operation is around $3 \%$. Due to the lean combustion in hydrogen operation, the losses due to actual combustion are slightly higher than in gasoline operation. Due to the higher pressure levels in hydrogen operation resulting from unthrottled operation, the wall heat losses are considerably higher than in gasoline operation. The higher in-cylinder charge motion in hydrogen direct-injection operation results in higher wall heat losses compared to port injection. Finally, the gas exchange losses in hydrogen operation are only a fraction compared to gasoline, since the engine is 
operated unthrottled. Overall this results in an advantage in indicated thermal efficiency for hydrogen port injection over hydrogen DI and gasoline operation. The indicator diagrams for the 2 bar IMEP case are shown in Fig. 11.

At the medium load point of 6 bar IMEP, the efficiency of the ideal engine in gasoline operation is lower than in hydrogen operation. This is again due to the lean operation. The air-fuel ratio, and hence the theoretical efficiency in hydrogen port injection, is lower than in hydrogen direct injection due to the air displacement effect with port-injection operation (DI: $\lambda=2.3 / \phi=0.43$; PFI: $\lambda=1.8$ $/ \phi=0.56$ ). For this operating point, the loss due to incomplete combustion in gasoline operation is slightly more than $1 \%$. In hydrogen operation both with port and direct injection, the loss accounts for less than $0.5 \%$. The very complete combustion in hydrogen operation is mainly due to the fast flame speed and small quenching distance at this air-fuel ratio. The loss due to actual combustion in gasoline operation is around $2 \%$. Although the engine is operated unthrottled and therefore lean in hydrogen operation, the combustion is still faster than in gasoline operation. This results in lower losses due to actual combustion in hydrogen operation. However, the higher flame speeds and the smaller quenching distance, which positively affected previous losses, are the main reason for the increased wall heat losses in hydrogen operation compared to gasoline operation. DI shows even higher wall heat losses compared to port injection, which is likely due to the higher level of in-cylinder charge motion and turbulence caused by the DI event. Finally, the gas exchange losses in hydrogen operation are significantly lower than in gasoline operation since the engine is operated unthrottled. At this operating point, this results in an overall advantage in indicated thermal efficiency of approximately $2.5 \%$ in hydrogen operation, both with port and direct injection, compared to gasoline operation. The indicator diagrams for the 6 bar IMEP case are shown in Fig. 12.

In both cases, further improvements with hydrogen DI could be gained with stratification resulting from an efficiency optimized injection strategy (see Section $6)$.

\subsection{Thermodynamic models}

The earliest attempts at modeling the combustion in hydrogen-fueled engines date from the 1970s. Fagelson et al. [115] used a two-zone quasi-dimensional ${ }^{5}$

\footnotetext{
${ }^{5} \mathrm{~A}$ term used to denote multi-zone thermodynamic engine models, in which certain geometrical parameters are included in the basic thermodynamic approach, mostly the radius of a thin
} 
model to calculate power output and $\mathrm{NO}_{\mathrm{X}}$ emissions from a hydrogen spark ignition (SI) engine. They used a semiempirical turbulent combustion model of the form $u_{t}=A R e^{B} u_{l}$, where $A$ and $B$ are constants; Re is the Reynolds number based on piston diameter, mean piston speed and burned gas properties; and $u_{t}$ and $u_{l}$ are the turbulent and laminar burning velocities, respectively. Spherical flame propagation was assumed, heat transfer was neglected and $\mathrm{NO}_{\mathrm{X}}$ formation was calculated using 10 constant mass zones in the burned gases and the extended Zeldovich mechanism. The laminar burning velocity was calculated from an overall second-order reaction with an estimated activation energy. The model was validated against measurements with varying equivalence ratio and ignition timing only. Prabhu-Kumar et al. [117] used this model to predict the performance of a supercharged hydrogen engine, with no changes made to the original model. They reported an overestimation of the rate of pressure rise (and thus of the burning velocity). Sadiq Al-Baghdadi et al. [118, 119] also used the model by Fagelson et al. [115]. They compared simulations to measured power output, $\mathrm{NO}_{\mathrm{X}}$ emissions and brake thermal efficiency for varying compression ratio and supercharging pressure [118], no pressure diagrams were shown in the paper. In another paper [119], the same model was used and experimental values for varying compression ratio, equivalence ratio and engine speed were compared to simulations. Again, only brake quantities were compared without detailing the correspondence in terms of burning rate and cylinder pressure development.

Keck [120] reported measurements in an optically accessible engine operated on propane as well as hydrogen, and used a turbulent entrainment model to compare predicted trends with experimentally observed trends. Excellent agreement was found between predictions and measurement, indicating a much smaller flame brush thickness for hydrogen operation compared to propane and a much higher initial flame expansion speed (with the difference in flame speeds decreasing throughout the combustion duration but with the flame speed always remaining higher for hydrogen).

Zero- and multi-dimensional models have been used for hydrogen engine simulation at the Czech Technical University [121, 122]. A zero-dimensional model (i.e., models where the thermodynamic state of a single zone, encompassing the complete cylinder contents, is calculated) based on the GT-Power code was used with Wiebe's law fitted to measured rates of heat release. The extended Zeldovich

interface (the flame) separating burned from unburned gases, resulting in a "two-zone" formulation [116]. 
mechanism [123] was used to calculate $\mathrm{NO}_{\mathrm{X}}$ emissions. The so-called Advanced Multizone Eulerian Model was developed for multi-dimensional simulation. This model was a combination of zero-dimensional and multi-dimensional elements: the combustion chamber seemed to be limited to simple geometries because of limitations to grid generation, and the heat transfer was modeled for the cylinder contents as a bulk volume. The combustion model was a "semiempirical pdflike" model that relied on a measured rate of heat release and the assumption of a hemispherical flame front to track flame propagation.

Ma et al. [124] used a zero-dimensional model using Wiebe's law. It is not clear to what data this law was fitted. The model was used to calculate the effects of varying compression ratio and ignition timing and to determine an "optimum cylinder diameter" for a fixed equivalence ratio. No validation against experimental data or any justification for extrapolating outside the conditions for which the fit is valid was given, so the quality of the reported results is doubtful.

D'Errico et al. [125, 126] reported full-cycle simulations using 1D gas dynamic calculations combined with a quasi-dimensional combustion model, for a hydrogen engine with cryogenic port injection. The gas dynamic algorithm was adapted so that the injection and transport of cryogenic hydrogen along the intake ducts were incorporated. The methodology proposed by Verhelst and Sierens [45] was used to construct a correlation for the laminar burning velocity from chemical kinetic calculations using an in-house reaction scheme. The burning rate was modeled using a fractal approach in Ref. [125] and Zimont's model in Ref. [126]. Nitric oxide (NO) emissions were calculated using the "super extended Zeldovich" mechanism. Simulations were run for varying engine speed and equivalence ratio and compared to experiments. The simulated and measured pressure traces in the intake and exhaust duct systems showed very good agreement. The combustion pressure was well predicted for stoichiometric and moderately lean mixtures, but was less satisfactory for (very) lean conditions at medium to high engine speeds. The authors pointed to the effects of differential diffusion and instabilities for these (very lean) conditions and the high ratios of turbulent to laminar burning velocities reported for these mixtures [70], which were unaccounted for in the combustion model.

Verhelst and Sierens [61] reported calculations of the power cycle of a hydrogenfueled engine using a quasi-dimensional two-zone combustion model framework. They reported the difficulties in obtaining stretch-free laminar burning velocities and proposed a correlation based on measurements of cellular flames [46, 50]. This correlation was then used with a number of turbulent burning velocity models, comparing simulations to measurements on a hydrogen-fueled Cooperative 
Fuel Research (CFR) engine for varying compression ratio, ignition timing and equivalence ratio. All models predicted the effects of compression ratio and ignition timing well, but some did not predict the effects on equivalence ratio well.

Safari et al. [127] used a similar approach, taking the laminar burning velocity correlation from Verhelst and Sierens [61], with the fractals turbulent combustion model that was one of the models performing reasonably well in Ref. [61]. They included the reaction kinetics of the $\mathrm{H}_{2}-\mathrm{O}_{2}-\mathrm{N}_{2}$ system to allow calculations of NO emissions. The wall heat transfer model by Woschni [128] was empirically adapted for hydrogen. After validation lean burn, "cooled dry" EGR and "hot wet" EGR strategies were examined numerically.

\subsection{CFD models}

Johnson [129] used the Kiva-3V engine simulation code developed at Los Alamos National Laboratory with the standard eddy-turnover model to simulate a hydrogen engine at a fixed equivalence ratio and volumetric efficiency. The standard model contains one free parameter that was adapted for hydrogen and held constant for varying ignition timing and engine speed. The model was validated for bulk quantities (NO emissions and brake thermal efficiency) against the experiments reported in Ref. [130]. Fontana et al. [131] modified the Kiva-3V code to simulate an SI engine fueled with a hydrogen/gasoline mixture. They used a hybrid model in which the global reaction rate is either given by the standard eddy-turnover model or a weighed reaction rate based on two global reaction rate expressions, one for hydrogen combustion and one for gasoline. They validated the model for gasoline operation and then calculated the effects of adding various hydrogen concentrations to gasoline.

Shioji et al. [132] calculated flame propagation and $\mathrm{NO}_{\mathbf{X}}$ formation for two hydrogen-fueled engines using an in-house CFD code, with a flame area evolution model and the laminar burning velocity correlation by Liu and MacFarlane [51]. They also evaluated the use of laminar burning velocities obtained from chemical kinetic calculations. Agreement with experimental results was fair, apart from high engine speed, lean mixture conditions. The authors quote these findings to "suggest the requirement for the consideration of an increase in local laminar burning velocity due to the selective diffusion of hydrogen".

Adgulkar et al. [133] used the AVL Fire software for a CFD simulation of the power cycle in a simplified engine geometry. Several combustion models were evaluated by comparing calculations to the results from Ma et al. [124]. As stated in the previous section, the results reported by Ma et al. [124] are doubtful, so this is a poor validation of these calculations. 
CFD simulations have been used by a team from TU Graz and BMW to investigate the mixture formation and combustion in DI engines $[134,135,136]$. The Fluent code was used with the turbulent burning velocity model by Zimont [95]. The laminar burning velocity was obtained from chemical kinetic calculations using the reaction scheme of Ó Conaire et al. [65], neglecting the influence of residual gas. The prediction of the flame propagation and rate of heat release corresponds well with measurements obtained on an optical engine.

At the Institut Français du Pétrole (IFP), the Extended Coherent Flame Model has been adapted for a better representation of hydrogen combustion in engines by adding a source term to the flame surface density transport equation [137]. The terms representing laminar flame propagation in the flame surface density transport equation are usually neglected. However, in the case of hydrogen, due to the high laminar burning velocity of mixtures around stoichiometry, this cannot be justified, so the laminar term was added to the model. Knop et al. [58] discussed the problems in finding a suitable correlation for the laminar burning velocity, and proposed a correlation based largely on the correlation of Verhelst $[46,50,61]$ but extended to rich mixtures (presumably through chemical kinetic calculations but not detailed in the paper) to allow computations of stratified combustion in DI engines. Another important contribution in the paper by Knop et al. [58] is an extended Zeldovich model of which the reaction rate constants were adapted for hydrogen, based on the work of Miller and Bowman [123]. The resulting CFD model was validated both for an engine with cryogenic port injection and a DI engine. The detailed mixture distribution obtained from the CFD simulations was used to explain the sensitivity of flame propagation and $\mathrm{NO}_{\mathrm{X}}$ formation to mixture heterogeneity.

\subsection{Heat transfer sub-model}

Most of the works cited in the engine combustion modeling sections above use a heat transfer sub-model to calculate the heat transfer between the cylinder gases and the combustion chamber walls. For SI engines, heat transfer due to radiation is small $(<10 \%)$ compared to convection and can be neglected given the current uncertainties in modeling convection [138]. The instantaneous heat transfer can be modeled as [134, 138]:

$$
\frac{d Q}{d t}=h A\left(T-T_{\text {wall }}\right)
$$

where $h$ is the convection coefficient averaged over the heat transfer surface, $A$ is the total wall surface area, $T$ is the bulk gas temperature and $T_{\text {wall }}$ is the wall 
temperature averaged over the heat transfer surface. Several models exist for evaluating the heat transfer coefficient $h$, of which the correlations of Woschni [128] and Annand [139] are the most widely used.

Wei et al. [140] and Shudo et al. [141, 142] have measured instantaneous heat transfer coefficients in hydrogen fueled engines. Wei et al. found transient heat transfer coefficients during hydrogen combustion to be twice as high as during gasoline combustion. They evaluated heat transfer correlations and found Woschni's equation to underpredict the heat transfer coefficient by a factor of two, whereas Annand's equation gave reasonable results. Shudo et al. compared the heat transfer coefficients during stoichiometric hydrogen and methane combustion, finding them to be larger in the case of hydrogen. The correlation by Woschni was tested and found to be inadequate.

The shorter quenching distance of a hydrogen flame (see Section 2) is put forward as the cause of this increased heat transfer, leading to a thinner thermal boundary layer. Furthermore, for near-stoichiometric combustion, flame speeds are high and cause intensified convection. Hydrogen also has a higher thermal conductivity compared to hydrocarbons, greatly affecting mixture thermal conductivity (see Table 2). Shudo et al. [142] construct an alternative heat transfer correlation with an improved correspondence with their measurements. However, the correlation contains two calibration parameters dependent on ignition timing and equivalence ratio.

Recent work reported by Nefischer et al. [143] proposes an adaptation to Schubert's formula [144], using a more detailed description of the turbulent kinetic energy from which the characteristic velocity used in the formula is calculated. For hydrogen engines, the turbulent kinetic energy is reported to be affected through the change (decrease) during the combustion of the number of moles (see Table 2). Also, for DI engines, the direct gaseous injection affects the turbulent kinetic energy.

Figure 13 shows recent results of heat flux measurements on a CFR engine operated on hydrogen and on methane [145]. The figure plots local heat flux (measured at the cylinder liner) for three conditions that produce the same indicated power: methane-air at a lean equivalence ratio of $\lambda=1.25 / \phi=0.8$ and wide open throttle (WOT), stoichiometric methane-air using throttling and stoichiometric hydrogen-air WOT. All measurements were performed at MBT spark timing. The much higher peak heat flux on hydrogen confirms the works cited above $[140,141]$. 


\section{Abnormal combustion}

The same properties that make hydrogen such a desirable fuel for internal combustion engines also bear responsibility for abnormal combustion events associated with hydrogen. In particular, the wide flammability limits, low required ignition energy and high flame speeds can result in undesired combustion phenomena generally summarized as combustion anomalies. These anomalies include surface ignition and backfiring as well as autoignition [146].

Surface ignition is used here to denote uncontrolled ignition induced by a hot spot in the combustion chamber. Pre-ignition generally describes combustion events occurring inside the combustion chamber during the engine compression stroke with the actual start of combustion prior to spark timing. Backfiring, also called back-flash, refers to events in which the hydrogen-air charge combusts during the intake stroke, usually in an intake runner or intake manifold. Engine "knock" is the term used for typical SI engines to describe autoignition of the remaining end-gas during the late part of the combustion event with high pressure oscillations and the typical pinging noise. As already briefly discussed in Section 2 , care must be taken in using the term knock with hydrogen engines, as further explained below.

\subsection{Pre-ignition}

The typical premature combustion during the engine compression stroke with closed intake valves resulting from pre-ignition, a surface ignition anomaly, can have numerous causes. Because pre-ignition is a stochastic event, detailed investigations of pre-ignition are complicated, and the actual cause of pre-ignition is often nothing more than speculation. Sources for the fresh charge to combust during the compression stroke include hot spark plugs or spark plug electrodes, hot exhaust valves or other hot spots in the combustion chamber, residual gas or remaining hot oil particles from previous combustion events [147] as well as residual charge of the ignition system. In general, both high temperatures as well as residual charge can cause pre-ignition. Due to the dependence of minimum ignition energy on the equivalence ratio, pre-ignition is more pronounced when the hydrogen-air mixtures approach stoichiometric levels. Also, operating conditions at increased engine speed and engine load are more prone to the occurrence of pre-ignition due to higher gas and component temperatures.

Figure 14 shows the in-cylinder pressure trace as well as the crank-angle resolved intake manifold pressure for a combustion cycle in which pre-ignition occurred. A regular combustion event is shown for comparison. The data were 
taken on an automotive-size single-cylinder hydrogen research engine at an engine speed of 3200 RPM and an IMEP of 7 bar for the regular combustion case (dotted line). The almost symmetrical phasing of the cylinder pressure caused by the pre-ignition results in the IMEP to drop almost to 0 . It is interesting to note that the peak pressure for the pre-ignition case is higher than the regular combustion cycle. However, due to the early pressure rise that starts around $80{ }^{\circ} \mathrm{CA}$ $\mathrm{BTDC}$, the indicated mean effective pressure for the pre-ignition case is around 0 bar. The intake pressure trace for the pre-ignition case does not show any significant difference from the regular trace, because the pre-ignition occurred after the intake valves closed.

Measures to avoid pre-ignition include proper spark plug design, design of the ignition system with low residual charge, specifically designed crank case ventilation, sodium-filled exhaust valves as well as optimized design of the engine cooling passages to avoid hot spots (see Section 5). Hydrogen direct injection into the combustion chamber is another measure to effectively reduce or eliminate the occurrence of pre-ignition depending on the injection strategy (see Section 6).

\subsection{Backfire}

Backfiring, or flash-back, describes combustion of fresh hydrogen-air charge during the intake stroke in the engine combustion chamber and/or the intake manifold. With the opening of the intake valves, the fresh hydrogen-air mixture is aspirated into the combustion chamber. When the fresh charge is ignited at combustion chamber hot spots, hot residual gas or particles or remaining charge in the ignition system, backfiring occurs, similar to pre-ignition. The main difference between backfiring and pre-ignition is the timing at which the anomaly occurs. Pre-ignition takes place during the compression stroke with the intake valves already closed whereas backfiring occurs with the intake valves open. This results in combustion and pressure rise in the intake manifold, which is not only clearly audible but can also damage or destroy the intake system. Due to the lower ignition energy, the occurrence of backfiring is more likely when mixtures approach stoichiometry. Because most operation strategies with hydrogen DI (see Section 6) start injection after the intake valves close, the occurrence of backfiring is generally limited to external mixture formation concepts.

Figure 15 shows the cylinder and intake pressure traces for a backfiring cycle measured on an automotive-size hydrogen single-cylinder engine at an engine speed of 3200 RPM and an IMEP of 7 bar. A regular intake and combustion pressure trace is shown as a reference. As soon as the intake valves open, the fresh charge is ignited and combusts in the intake manifold, resulting in an increase of 
intake pressure of up to 3 bar. The pressure rise is also reflected in the cylinder pressure trace. Once the entire fresh charge is burned, the pressure in the intake manifold decreases; the cylinder pressure at intake valve closing is increased compared to the regular trace. The peak cylinder pressure for this backfiring cycle is only about 30 bar and the indicated mean effective pressure is actually negative. For comparison, the peak pressure in motored operation is approximately 21 bar.

Limited information available on combustion anomalies also indicates that pre-ignition and backfiring are closely related with pre-ignition as the predecessor for the occurrence of backfiring. Pre-ignition thereby heats up the combustion chamber, which ultimately leads to backfiring in a consecutive cycle [148, 149, 150]. Consequently, any measures that help avoid pre-ignition also reduce the risk of backfiring. In addition work, has been done on optimizing the intake design and injection strategy to avoid backfiring [151]. Injection strategies that allow pure air to flow into the combustion chamber to cool potential hot spots before aspirating the fuel-air mixture were proposed as one potential approach. As a result of experimental and simulation work on a hydrogen PFI engine, a predictive model and guidelines for backfire-free operation were derived. These guidelines were based on the finding that the possibility of backfire mainly depends on the concentration of $\mathrm{H}_{2}$ residual in the intake ports in PFI hydrogen engines; thus, the leaner the concentration of the residual, the lower the possibility of backfire. Based on this conclusion it is suggested to limit the end of injection in a fixed range based on engine operation conditions with an earlier end of injection at lower engine speeds and richer hydrogen mixtures [152]. Although trends identified on hydrogen research engines indicated that combustion anomalies significantly limit the operation regime [153], optimization of the fuel-injection strategy in combination with variable valve timing for both intake and exhaust valves allowed operating of a port injected hydrogen engine at stoichiometric mixtures over the entire speed range [154].

\subsection{Autoignition}

When the end gas conditions (pressure, temperature, time) are such that the end gas spontaneously autoignites, there follows a rapid release of the remaining energy generating high-amplitude pressure waves, mostly referred to as engine knock. The amplitude of the pressure waves of heavy engine knock can cause engine damage due to increased mechanical and thermal stress. The tendency of an engine to knock depends on the engine design as well as the fuel-air mixture properties. 
A standard measure to define the knock characteristics of liquid fuels is the octane rating. A CFR engine is used to determine the knock behavior of a specific fuel by comparing its knock resistance to that of a mixture of normal heptane and iso-octane. The most common standardized tests to determine knock resistance on a CFR engine are the research method resulting in a Research Octane Number (RON) [155] and the motor method resulting in a Motor Octane Number (MON) [156]. Although these methods were developed and are applicable only to liquid SI engine fuels, octane ratings for hydrogen fuel have been reported in the literature. Reported values range from $\mathrm{RON}<88$ [157] to $\mathrm{RON}=130$ [158] and RON of 130+ for lean mixtures [159]. It is unclear how these values were determined; they must either be estimated values or measured with methods resembling but not according to the ASTM methods. Work has also been performed on emulating the knock measurement on the CFR engine by using low-pass filtered rate-of-change of the pressure signal; so far, this work is limited to primary reference fuels [160].

The determination of octane ratings is performed at constant spark advance (13 ${ }^{\circ} \mathrm{CA}$ BTDC for RON and $19-26{ }^{\circ} \mathrm{CA}$ BTDC, depending on the compression ratio for $\mathrm{MON}$ ). The discrepancies in nominal knock resistance of hydrogen are mainly due to the extremely high flame speeds around stoichiometry, with the strong dependence on the air-fuel ratio which makes application of standard methods for the determination of knock resistance questionable.

Because of the high knock resistance of methane $(115<\mathrm{MON}<130)$, the methane number (MN) was defined to determine the knock characteristics of gaseous fuels. The methane number uses a reference fuel blend of methane, with a MN of 100, and hydrogen, with a MN of 0 [161]. Per definition, the MN of hydrogen is 0 , which would suggest that hydrogen has a very low knock resistance. This clearly contradicts some of the octane numbers reported in the works cited above $[158,159]$.

Work has been reported on attempts to predict the knock behavior of hydrogenfueled engines. A comparison to experimental results showed good agreement for variation of compression ratio, air-fuel equivalence ratio and intake air temperature [162]. These results suggest that the operating regime of a hydrogen engine is strongly limited by the occurrence of knocking combustion. However, based on work performed on a multi-cylinder hydrogen engine at compression ratios of up to 15.3:1, it was stated that knock, as has been observed on gasoline engines, was not observed in any of this hydrogen testing regardless of compression ratio [163].

Figure 16 shows the cylinder pressure trace as well as a filtered signal for hydrogen DI operation at 2000 RPM and an engine load of 10 bar IMEP recorded 
on a single-cylinder research engine with a compression ratio of 12:1. The cylinder pressure signal shows pressure oscillations that are typical for knocking combustion; the high-pass filtered signal shows a maximum pressure amplitude of approximately 3.6 bar. For the same engine speed and load, an operating point with heavy knock was recorded, resulting from further advancing the spark timing (Fig. 17). Although the regular peak pressure for this operating point is about 90 bar, the maximum pressure with knocking operation reaches 150 bar with oscillations in the high-pass filtered signal of almost 65 bar.

Similar tests performed on a CFR engine at a compression ratio of 12:1 were targeted at determining the knock characteristics of hydrogen and the applicability of standard automotive knock-detection systems. Comparative analysis of knock intensities of gasoline and hydrogen revealed that knocking pressure traces exhibit similar peak amplitudes as well as similar durations and decays of pressure oscillations [164].

\subsection{Modeling abnormal combustion phenomena}

The literature on the simulation of abnormal combustion phenomena in a hydrogen engine is quite limited. The model of Fagelson et al. [115], described above, was extended by Sadiq Al-Baghdadi [165] with a simple model predicting the occurrence of abnormal combustion, using a "knock integral" type of approach [166]. A graph is shown comparing the simulated and measured cylinder pressure traces for normal combustion. Significant differences can be seen, which casts doubts on the subsequent validation of the "pre-ignition" sub-model.

$\mathrm{Li}$ and Karim use a two-zone quasi-dimensional model with a triangular combustion rate law fitted to experimental data coupled to a chemical kinetic scheme [162]. They propose a knock criterion, comparing the energy released by end-gas reactions to the energy released by the normal flame propagation. When this exceeds a critical value, end gas autoignition occurs. The model is used to predict the knock-limited equivalence ratio as a function of the compression ratio. Similar to the experimental results reported by these authors [167], the knocking regions are very extensive. According to the figures in the paper, which report results for compression ratios between $6: 1$ and $14: 1$, stoichiometric operation is impossible without the occurrence of knock. This clearly is contradicted by numerous works cited in the present paper.

Liu et al. [152] use a CFD calculation of the gas dynamics in a port-fueled engine to explain the dependence of backfire occurrence on the injection timing. Although the model is only partly validated, it demonstrates the existence of an optimal timing. Injecting too early leads to a backflow of hydrogen from the 
cylinder into the intake port, at the end of the intake stroke. Injecting too late results in hydrogen remaining in the intake port because of insufficient time to reach the cylinder. Thus, in both cases, hydrogen is present in the intake port at the time the intake valve opens for the next cycle. This can result in backfire through contact with hot spots (residual gases, exhaust valves, etc.). The optimal injection timing is the one that allows an initial cooling period by freshly aspirated air but also enables all of the injected hydrogen to travel to the cylinder before the intake valve closes (which has been experimentally confirmed [33]).

\subsection{Avoiding abnormal combustion}

Limiting the maximum fuel-to-air equivalence ratio is an effective measure for avoiding abnormal combustion in hydrogen operation. Due to the wide flammability limits and fast flame speeds, hydrogen internal combustion engines are usually operated employing a lean-burn strategy and thereby avoid throttle losses (see Section 6). The excess air in lean operation acts as an inert gas and effectively reduces combustion temperatures and consequently component temperatures. This significantly reduces the occurrence of abnormal combustion in lean combustion regimes. Although lean operation is also very efficient, it does limit the power output of hydrogen engines. Results from a supercharged and intercooled 1.8 inline four cylinder engine operated on gasoline as well as hydrogen showed that abnormal combustion can be effectively avoided by limiting the fuel-to-air equivalence ratio. In this particular case, the maximum fuel-to-air equivalence ratio was limited to $0.63(\lambda=1.6)$ at $1500 \mathrm{RPM}$ and further reduced as a function of engine speed with a minimum of $0.48(\lambda=2.1)$ at 6000 RPM. While effectively avoiding abnormal combustion, this measure also significantly reduces the power output from approximately $120 \mathrm{~kW}$ in gasoline operation to approximately $70 \mathrm{~kW}$ in hydrogen operation [168].

Further measures to avoid abnormal combustion are given in the next section on hydrogen engine hardware.

\section{Measures for engine design or conversion}

This section discusses some features of engines designed for, or converted to, hydrogen operation. The occurrence of combustion anomalies discussed in the previous section, or more particularly, the desire to prevent it, has led to most of the countermeasures put forward in the early work on $\mathrm{H}_{2}$ ICEs. 


\subsection{Spark plugs}

Cold-rated spark plugs are recommended to avoid spark plug electrode temperatures exceeding the autoignition limit and causing backfire [169, 170]. Coldrated spark plugs can be used, since there are hardly any spark plug deposits to burn off [169]. Spark plugs with platinum electrodes are to be avoided, as this can be a catalyst to hydrogen oxidation $[11,171]$ (platinum has been used in the exhaust to oxidize unburned hydrogen [172]).

\subsection{Ignition system}

To avoid uncontrolled ignition due to residual ignition energy, the ignition system should be properly grounded or the ignition cable's electrical resistance should be changed $[170,173]$. Also, induction ignition in an adjacent ignition cable should be avoided [174], for instance, by using a coil-on-plug system. Somewhat counterintuitively, a high voltage output ignition system should be provided, as the ignition of hydrogen mixtures asks for an increased secondary ignition voltage (probably because of the lower ion concentration of a hydrogen flame compared to a hydrocarbon flame) [170, 173, 175, 176]; coil-on-plug systems also satisfy this condition. Alternatively, the spark plug gap can be decreased to lower the ignition voltage; this is no problem for hydrogen engines, as there will be almost no deposit formation. Spark plug gaps as small as $0.25 \mathrm{~mm}$ have been used [177] (although the gap was subsequently increased to $0.5 \mathrm{~mm}$ because of cold-start difficulties due to water condensation at the spark plug tip).

\subsection{Injection system}

It is clear from Section 4 that timed injection is a prerequisite. One option is to use port injection and to program the injection timing such that an air cooling period is created in the initial phase of the intake stroke, and the end of injection is such that all hydrogen is inducted, leaving no hydrogen in the manifold when the intake valve closes. The timing described here might not be necessary, as work has been reported in which no relation between injection timing and backfire or surface ignition limited equivalence ratio was found [163]. The second option is to use DI during the compression stroke. High flow rate injectors with instantaneous flows around $4-6 \mathrm{~g} / \mathrm{sec}$ at 100 bar supply pressure are needed for DI [178]. With PFI engines, the high flow requirements can be alleviated by using multiple injectors. Timed injection also decreases the amount of unburned fuel in the intake manifold at any given time, limiting the severity of a backfire, should it occur. 


\subsection{Hot spots}

Clearly, hot spots in the combustion chamber that could initiate surface ignition or backfire are to be avoided or minimized. Measures include the use of cooled exhaust valves; multi-valve engine heads to further lower the exhaust valve temperature [171, 173, 179]; a proper oil control [147]; additional engine coolant passages around valves and other areas with high thermal loads [180] (if possible); the delay of fuel introduction to create a period of air cooling (using timed manifold or DI); and adequate scavenging (e.g., using variable valve timing $[163,181]$ ) to decrease residual gas temperatures.

\subsection{Piston rings and crevice volumes}

Experiments have been conducted in which all hot spots were eliminated (careful cleaning of the engine, enhanced oil control or even nonlubricated operation, scavenging of the residual gases, cold spark plugs, cooled exhaust valves, etc.), as well as any uncontrolled spark-induced ignition, and backfire still occurred $[177,182]$. This suggests that the small quenching distance of hydrogen (together with the wide flammability limits), allowing combustion in the piston top land (the crevice volume above the top piston ring), is a parameter that has been overlooked by many workers. Hydrogen engines have been demonstrated, running on stoichiometric mixtures without any occurrence of backfire, by careful selection of piston rings and crevice volumes, without any need for timed injection or cooled exhaust valves [180]. Workers that have paid attention to increased cooling, enhanced "oil control" by mounting different piston rings, increased scavenging etc., attribute the resulting wider backfire-free operation region to a reduction of hot spots but have simultaneously (sometimes possibly without realizing it) taken measures to suppress crevice combustion.

Thus, the piston top land clearance can be decreased to prevent hydrogen flames from propagating into the top land; Swain et al. [180] use a clearance of $0.152 \mathrm{~mm}$ to quench the hydrogen flame. Some researchers have changed the crevice volumes and/or piston rings with the aim of reducing the reflow of unburned mixture from the second land (the crevice volume between the top two piston rings) to the top land [180, 182, 183] (preventing "fueling" of a top land flame during exhaust and intake). The smaller quenching distance of a hydrogen flame also implies an increased thermal load for the piston top land; Berger et al. [184] report changes (a special coating) to the top piston ring groove area to account for this. 


\subsection{Valve seats and injectors}

The very low lubricity of hydrogen has to be accounted for; suitable valve seat materials have to be chosen $[171,173]$ and the design of the injectors should take this into account. This is the case with any dry gaseous fuel (such as natural gas) but can be more critical for hydrogen (compressed natural gas contains small amounts of oil originating from the oil mist in the compressor, whereas hydrogen compressors normally have tighter clearances to limit the leak rate).

\subsection{Lubrication}

An engine lubrication oil compatible with increased water concentration in the crankcase has to be chosen [185]. The report on the hydrogen drive test in Germany by TÜV [173] cites two options: a demulsifying oil and a synthetic oil which forms a solution with water. DeLuchi [186] claims a longer oil lifetime, as the oil is not diluted by hydrogen and there is less formation of acids (perhaps doubtful, given the large quantities of water and $\mathrm{NO}_{\mathrm{X}}$ that can be formed during stoichiometric combustion). An ashless oil is recommended to avoid deposit formation (hot spots) [154, 169]. Measurements of the composition of the gases in the crankcase at Ghent University [176] showed a very high percentage of hydrogen ( $+5 \mathrm{vol} \%$, out of range of the testing equipment) arising from the blowby. Blowby can be expected to be quite high because of the rapid pressure rise (caused by the high flame speed and resulting fast burn rate) and the low density of hydrogen gas (significantly affecting the mixture density, see Table 2). The composition of the lubricating oil was investigated and compared to that of the unused oil. The properties of the oil had severely changed with a strong decrease of the lubricating qualities.

An engine oil specifically developed for hydrogen engines is probably the best solution but currently unavailable. For safety reasons, a forced crankcase ventilation system (see also below) was mounted on the engine to keep the hydrogen concentration well below the lower flammability limit. Air is fed to the crankcase from the lab compressed air net and set to a small overpressure using a pressure regulating valve. A vacuum pump is used to evacuate the crankcase gases, which pass an oil separator first. The crankcase pressure is controlled to a slight underpressure by a balance between the compressed air pressure and a bypass valve on the vacuum pump inlet. The resulting hydrogen concentration in the crankcase with the ventilation system was measured to be below 1 vol\%. 


\subsection{Crankcase ventilation}

Positive crankcase ventilation is generally recommended due to unthrottled operation (high manifold air pressures) and to decrease hydrogen concentrations (from blowby) in the crankcase [171, 187]. As will be discussed in Section 6 wide open throttle operation is used wherever possible to increase engine efficiency, resulting in high manifold air pressures. Thus, the pressure difference between the crankcase and the intake manifold, such as in throttled gasoline engines, is absent for some operating strategies of hydrogen engines, and thus cannot be used as a driving force for crankcase ventilation. This can be solved by, e.g., a venturi placed in the intake [171] or other methods used in high manifold pressure engines (such as diesel engines).

\subsection{Compression ratio}

The choice of the optimal compression ratio is similar to that for any fuel; it should be chosen as high as possible to increase engine efficiency, with the limit given by increased heat losses or the occurrence of abnormal combustion (in the case of hydrogen, primarily surface ignition). The choice may depend on the application, as the optimum compression ratio for highest engine efficiency might be different from the optimum for highest power output [188]. Compression ratios used in $\mathrm{H}_{2}$ ICEs range from 7.5:1 [185] to 14.5:1 [163].

\subsection{In-cylinder turbulence}

Because of the high flame speeds of hydrogen, low turbulence combustion chambers (pancake or disk chamber and axially aligned symmetric intake port) can be used, which can be beneficial for the engine efficiency [130, 179, 180] (increasing the volumetric efficiency and decreasing heat losses). They might even be necessary to avoid excessive rates of pressure rise (possibly even leading to knocking combustion) at stoichiometric operation [180] (where high in-cylinder turbulence could cause very fast flame speeds).

\subsection{Electronic throttle}

For reasons discussed in Section 6, hydrogen engines should be operated at wide open throttle wherever possible, but throttling might be needed at very low loads to maintain combustion stability and limit unburned hydrogen emissions. At medium to high loads, throttling might be necessary to limit $\mathrm{NO}_{\mathrm{X}}$ emissions. This can only be realized with a drive-by-wire system, i.e., a system in which the throttle position is electronically controlled instead of mechanically linked to the accelerator pedal. 


\subsection{Materials}

The effects of hydrogen on the mechanical properties of iron and steels have been widely investigated. Regarding the embrittling effect of hydrogen, it is well known that the dominant effects are a decrease in ductility and true stress at fracture. Hydrogen embrittlement of steels can be classified into three main types [189]:

1. Hydrogen reaction embrittlement arises because of the generation of hydrogen on the surface as a result of a chemical reaction.

2. Environmental embrittlement takes place in the hydrogen containing atmospheres through adsorption of molecular hydrogen on the surface and its absorption within the lattice after dissociation into atomic form.

3. Internal hydrogen embrittlement, in contrast, takes place in the absence of a hydrogenated atmosphere and is brought about by hydrogen that has entered the lattice during processing or fabrication of steel.

The environmental embrittlement in hydrogen-containing atmospheres results in limitations for material selection of hydrogen storage and fuel systems. Studies have been performed to assess the sensitivity of commonly used stainless steels for hydrogen embrittlement [190] as well as special alloys [191]. In both studies, it was concluded that the tested materials show significant degradation due to the presence of hydrogen. All metallic materials present a certain sensitivity to hydrogen embrittlement, with the sensitivity strongly dependent on the stress level. Materials that can be used for hydrogen applications are brass and copper alloys, aluminum and aluminum alloys and copper-berillium. Nickel and high-nickel alloys as well as titanium and titanium alloys are known to be very sensitive to hydrogen embrittlement. For steels, the hydrogen embrittlement sensitivity depends on the exact chemical composition, heat or mechanical treatment, microstructure, impurities and strength [192]. Negative effects of hydrogen embrittlement have also been documented for certain types of piezo-materials used for hydrogen fuel injectors [178]. Apart from embrittlement effects of onboard hydrogen system components, hydrogen embrittlement testing performed on several grades of highstrength pipeline steels showed a loss in ductility that was, however, recoverable when a charged steel was left for seven days at ambient temperature after charging. It was concluded that control of cathodic protection systems may be more critical on high strength steel pipelines [193]. An overview of the hydrogen compatibility of materials can be found in [194].

Concerning specific engine components, intake manifolds of hydrogen internal combustion engines, in particular with port fuel injection, are mostly made of 
metal to withstand backfire. This measure is mainly taken for development and dynamometer calibration work, since the limits for abnormal combustion have to be established. For vehicle application and demonstration vehicles, calibrations that effectively avoid abnormal combustion have to be employed.

\section{Mixture formation and load control strategies}

\subsection{Introduction, classification of strategies}

The wide ignition limits of hydrogen allow an engine to be operated at extremely lean air-fuel ratios compared to conventional fuels. Concepts for partload operation of hydrogen engines have been proposed using quantitative control, qualitative control as well as combined strategies. Quantitative control refers to any approach that limits the amount of fresh charge introduced into the engine in order to limit the power output while keeping the ratio of air to fuel constant. On the other hand, qualitative control is used to describe systems that adjust the air-to-fuel ratio usually by adjusting the amount of fuel introduced to the engine while allowing maximum flow of air. The classification based on part-load operation is closely linked to the air-fuel ratio at which the engine is operated. Reports of hydrogen engines being operated at stoichiometric as well as lean air-fuel ratios have been published. The major advantages of operation at a stoichiometric airfuel ratio are the increased power output compared to lean-burn strategies as well as the fact that a conventional aftertreatment system can be employed to reduce $\mathrm{NO}_{\mathrm{X}}$ emissions. Lean-burn concepts, on the other hand, generally result in a significant increase in achievable engine efficiencies. More recently, strategies that employ both lean-burn as well as stoichiometric operation have been proposed [195, 196].

Besides the above-mentioned classification that results from the specific properties of hydrogen as a fuel for internal combustion engines, the charging strategy is another important factor to influence the performance and efficiency of hydrogen internal combustion engines. Supercharged operation has been evaluated as a promising option to mitigate the significant reduction in power output related to hydrogen operation with external mixture formation. From an efficiency standpoint, turbocharging is considered the preferred option; however, reduced throttle response and reduced exhaust energy compared to conventional fuel operation make the implementation of a turbocharged hydrogen engine more challenging.

Although the self-ignition temperature of hydrogen is considerably higher than that of conventional fuels $\left(\mathrm{H}_{2}=585{ }^{\circ} \mathrm{C}\right.$, diesel is approx. $\left.250{ }^{\circ} \mathrm{C}\right)$, which 
suggests using a spark plug as the ignition source, attempts have been made to operate hydrogen engines with compression ignition. Successful operation of compression ignition hydrogen engines has been reported for both large displacement stationary engines [197, 198] as well as automotive-size engines [199]. More recently, effort has been reported on hydrogen engines being operated in HCCI mode [200] (see Section 6.2.4).

\subsection{Mixture formation strategies}

The proper design of the mixture formation process is crucial for achieving high engine efficiencies while meeting more and more stringent emissions targets. Similar to conventionally fueled engines, hydrogen engines have gone through continuing improvement and refinement in terms of mixture formation strategies.

A primary classification of mixture formation strategies can be done based on the location of mixture formation or the location of the hydrogen dosing devices. External mixture formation refers to concepts in which hydrogen and air are mixed outside the combustion chamber, whereas internal mixture formation refers to concepts with hydrogen being introduced directly into the combustion chamber. Some researchers have also proposed combined concepts with a combination of external and internal mixture formation [201, 202, 203]. As indicated in Table 3, the mixture formation strategy, especially in hydrogen operation, has significant impact on the theoretical power output of the engine. The dramatic difference in theoretical power output is mainly caused by the low density of hydrogen, resulting in a significant decrease in mixture density when external mixture formation is being employed.

Using a classification based on the control of timing/quantity of the induced fuel, one can differentiate systems that use carburetors, mechanically controlled injection devices and electronically controlled fuel injectors. Modern hydrogen combustion engines almost exclusively use electronically controlled fuel injection systems; however, the requirements and specifications for these systems change widely based on the injection location and the temperature of the injected fuel. Generally, hydrogen injection systems for external mixture formation are operated at lower injection pressures $(2-8$ bar) compared to systems for hydrogen direct injection ( $5-250$ bar). Also, the exposure of injectors to in-cylinder temperatures and pressure in combination with increased injection pressures for internal mixture formation systems still requires further injector development to reach production standards in terms of durability [178]. Research and development has also been performed on external mixture formation concepts with cryogenic hydrogen $[126,204,205,206,207,208]$ posing challenges to the injection system due to 
extremely low temperatures (boiling temperature of hydrogen is approximately $-253{ }^{\circ} \mathrm{C}$ ) and related issues, for example, injector icing.

Finally, a classification based on the resulting or intended mixture homogeneity allows grouping hydrogen combustion engines into homogeneous and stratified concepts. Due to the relatively long time available for mixing of fuel and air, all external mixture formation concepts can be considered homogeneous. However, internal mixture formation concepts with injection of fuel directly into the combustion chamber allow influencing the mixture distribution and homogeneity. This can be of particular interest to reduce the combustion duration and improve the combustion stability at extremely lean conditions or to avoid $\mathrm{NO}_{\mathrm{X}}$ emissions critical air-fuel ratios by purposely creating lean and rich zones.

The two single most prominent mixture formation strategies for hydrogen engines are hydrogen port injection, which is being used in engine research as well as vehicle demonstrations, and hydrogen direct injection, which is still in a research stage. The following sections are intended to summarize the most typical characteristics and variations of these mixture formation concepts. First, it is important to reflect on the energy cost of supplying low pressure (in case of port injection) or high pressure (DI) hydrogen.

\subsubsection{Supplying pressurized hydrogen}

Introduction of hydrogen into the engine, either in the intake manifold or directly into the combustion chambers, requires hydrogen to be supplied at a certain delivery pressure. The most efficient way of providing the required pressure depends on the type of onboard storage as well as the pressure levels required for injection. With compressed hydrogen storage at pressure levels up to 700 bar, sufficient pressure even for high-pressure injection systems operating at pressures above 100 bar is available. However, if no additional compressor is available, the full amount of hydrogen stored in a compressed hydrogen tank cannot be utilized. Assuming a storage pressure of 700 bar and an injection pressure of 100 bar, only $6 / 7$ of the mass of hydrogen stored onboard can be used before the pressure in the tank drops below the required injection pressure. Whether hydrogen is compressed on- or off-board the vehicle, the energy required to compress hydrogen is significant. The minimal work required for compression of hydrogen results from isothermal compression, which is approximated using cooled piston compressors. Nonetheless, even under ideal conditions, the energy required to compress hydrogen from 1 bar to 1000 bar requires more than $7 \%$ of the heating value of hydrogen [209]. If hydrogen is stored onboard the vehicle in liquid cryogenic form, compression can be accomplished more efficiently in the liquid 
state. This allows cutting the compression work by a factor of 5 to 6 compared to gaseous compression. However, there are several remaining questions in construction and material selection of cryogenic pumps [209]. In addition, liquefaction of hydrogen as employed in current large-scale processes requires about $30 \%$ of the energy content of hydrogen [209]. In order to avoid the compression step of liquid hydrogen, ongoing research is performed on cryo-compressed hydrogen storage systems [210, 211].

\subsubsection{Spark ignition port injection}

Hydrogen port injection is probably the most common hydrogen mixture formation strategy and is employed in a variety of variants that differ in multiple aspects including part-load control, air-fuel ratio and charging strategy. Before evaluating the pros and cons of different mixture formation strategies, it is important to understand the principal correlation between the air-fuel ratio and oxide of nitrogen emissions that is applicable for all homogeneous mixture formation concepts. Figure 18 shows a typical trace of oxide of nitrogen emissions as a function of the equivalence ratio for homogeneous port injection operation. Combustion of lean hydrogen air mixtures with fuel-to-air equivalence ratios of less than $0.5(\lambda>2)$ results in extremely low $\mathrm{NO}_{\mathrm{X}}$ emissions. Due to the excess air available in the combustion chamber, the combustion temperatures do not exceed the $\mathrm{NO}_{\mathrm{X}}$ critical value of approximately $1800 \mathrm{~K}$ [12]. Exceeding the $\mathrm{NO}_{\mathrm{X}}$ critical equivalence ratio results in an exponential increase in oxides of nitrogen emissions, which peaks around a fuel-to-air equivalence ratio of $0.75(\lambda \sim 1.3)$. At stoichiometric conditions, the $\mathrm{NO}_{\mathrm{X}}$ emissions are at around $1 / 3$ of the peak value. The highest burned gas temperatures in hydrogen operation occur around a fuel-to-air equivalence ratio near 1.1, but at this equivalence ratio, oxygen concentration is low, so the $\mathrm{NO}_{\mathrm{X}}$ concentration does not peak there [212]. As the mixture gets leaner, increasing oxygen concentrations initially offset the falling gas temperatures, and $\mathrm{NO}_{\mathrm{X}}$ emissions peak around a fuel-to-air equivalence ratio of $0.75(\lambda=1.3)$.

In light of these dependencies of oxide of nitrogen emissions as a function of air-fuel ratio, several operating strategies have been developed that mainly aim at achieving acceptable power densities while simultaneously avoiding excessive $\mathrm{NO}_{\mathrm{X}}$ emissions. Conversion engines based on conventional gasoline engines have been operated on hydrogen employing a lean constant air-fuel ratio strategy. Using a conventional throttle and replacing the gasoline fuel system with hydrogen injectors, one can easily implement this strategy [172, 213, 214]. Selecting an equivalence ratio below the $\mathrm{NO}_{\mathrm{X}}$ emissions critical limit of $\phi \sim 0.5 / \lambda \sim 2$ results 
in extremely low emissions signatures even without the use of any aftertreatment system. Due to the relatively low combustion temperatures, the reduced thermal load of the engine and the increase in required ignition energy for lean hydrogen air mixtures, this lean operating strategy also effectively avoids combustion anomalies. Implementation of an engine with constant air-fuel ratio of $\phi \sim 0.55$ / $\lambda=1.8$ at a compression ratio of 14.5 resulted in an $18 \%$ fuel economy improvement compared to the gasoline counterpart while meeting Transitional Low Emission Vehicles (TLEV) emissions standards without any aftertreatment [215]. However, employing a constant lean air-fuel ratio strategy results in an even more significant loss in power density than shown in Table 3 for stoichiometric operation. Assuming a constant fuel-to-air equivalence ratio of $0.5(\lambda=2)$ results in a theoretical maximum power output of the hydrogen engine that is only about $50 \%$ of a regular gasoline engine in stoichiometric operation (see Fig. 19). Thus researchers have investigated the potential of using supercharging in combination with constant lean air-fuel ratio operation to mitigate the significant power loss [216, 217]. This concept has also been implemented in several versions of hydrogen-powered pickup trucks running at constant equivalence ratios around $\phi \sim 0.4 / \lambda \sim 2.5$ with compression ratios of up to $12: 1$ and boost pressures of approximately 0.8 bar [218]. The theoretical maximum power output based on a comparison of calculated mixture calorific values as a function of air-fuel ratio assuming constant efficiencies is in the range of about $80 \%$ compared to the naturally aspirated gasoline counterpart (see Fig. 19).

As has been discussed earlier, a significant increase in engine efficiency (compared to gasoline operation) can be accomplished employing a constant lean airfuel ratio operating strategy. The air-fuel ratio is generally set as high as possible to achieve acceptable power output while still meeting the emissions targets. However, reducing the equivalence ratio was shown to even further improve engine efficiencies with a peak at around $\lambda=3.3 / \phi=0.30$. This peak results from a local minimum of the losses due to increased burn duration and heat transfer as well as the more favorable properties of the working fluid. Also a sharp decrease in indicated efficiency was observed at $\lambda=4.5 / \phi=0.22$ due mostly to greater amounts of unburned hydrogen and a slower burn rate [163].

As a result, an operating strategy using a variable equivalence ratio as a function of engine load was evaluated both for naturally aspirated engines as well as supercharged engines and vehicles. Implementation of this variable equivalence ratio strategy in a range from $2<\lambda<5 / 0.2<\phi<0.5$ on a GM 454 spark ignited PFI engine (commonly known as the Chevrolet Big Block) showed a more than $20 \%$ increase in engine power compared to a carbureted version without in- 
creasing the danger of backfiring [219]. The conclusions of this study also include that as a consequence of the wide range of applied mixture composition, the range of ignition timings is also wide. The injection timing shows significant influence in the low load and speed region, and it is not critical in the high load and speed region.

Another significant increase in power density can be achieved with supercharging in combination with a variable equivalence ratio strategy. Drive-cycle simulations based on steady-state engine efficiency and emissions maps of a supercharged 2.3 L hydrogen engine suggested a $3 \%$ increase in fuel economy when employing a variable equivalence ratio strategy compared to a constant $\lambda=2$ / $\phi=0.50$ strategy while simultaneously reducing $\mathrm{NO}_{\mathrm{X}}$ emissions by more than $80 \%$. Additional simulations simulating the hydrogen engine being operated in a full hybrid-electric vehicle mode with a pre-transmission parallel hybrid architecture suggest another almost $50 \%$ increase in fuel economy while reducing $\mathrm{NO}_{\mathrm{X}}$ emissions by more than $99 \%$ compared to a conventional powertrain [220]. A similar engine control strategy was used for propelling a hydrogen shuttle bus using a $6.8 \mathrm{~L} \mathrm{V-10} \mathrm{engine.} \mathrm{Due} \mathrm{to} \mathrm{the} \mathrm{lean-burn} \mathrm{concept,} \mathrm{the} \mathrm{engine} \mathrm{achieved} \mathrm{a} \mathrm{more}$ than $12 \%$ better brake thermal efficiency compared to the gasoline counterpart at 1500 RPM and 2.62 bar brake mean effective pressure (BMEP) (Ford World Wide Mapping Point [WWMP]). In-vehicle tests confirmed an increase in power output enabling a more than $30 \%$ reduction in 0 - $35 \mathrm{MPH}$ acceleration time compared to the natural gas counterpart while achieving near zero emissions [221].

An effective way to limit the power loss compared to gasoline or diesel engines is by running hydrogen port-injection engines at stoichiometric air-fuel ratios. However, stoichiometric port fuel injection operation is prone to combustion anomalies and also requires an aftertreatment system to reduce the level of oxide of nitrogen emissions. As indicated in Table 3 and Fig. 19, stoichiometric $\mathrm{H}_{2}$ PFI operation results in a theoretical power density of approximately $86 \%$ compared to gasoline. A 6-cylinder $12 \mathrm{~L}$ displacement bus engine (MAN H $2866 \mathrm{UH} 01$ ) converted to bi-fuel operation was shown to achieve $170 \mathrm{~kW}$ in gasoline operation and $140 \mathrm{~kW}$ in stoichiometric port-fuel injected hydrogen operation, which is approximately $82 \%$ of the gasoline power output, confirming the theoretical considerations. However, in order to avoid combustion anomalies, the compression ratio of the engine had to be reduced to as low as 7.5:1 [185]. With later engine conversions by the same manufacturer, significant improvements could be achieved by using solenoid-driven hydrogen injection valves instead of rotary hydrogen valves. The MAN H2876 UH01, a 12.8 L in-line 6-cylinder engine using these improved injectors with sequential injection, achieved a peak brake thermal 
efficiency of $31 \%$ in naturally aspirated stoichiometric hydrogen operation. As can be seen from Fig. 18, stoichiometric hydrogen operation results in significant amounts of $\mathrm{NO}_{\mathrm{X}}$ emissions. The MAN H2876 UH01 engine uses a reducing catalyst with lambda control for emissions aftertreatment. Operated with slight hydrogen surplus, the engine can be operated well below Euro 5 emissions levels, which are mandatory since 2008 [185].

The previous mixture formation concepts employing hydrogen port injection result in compromises either in terms of power density with lean air-fuel ratio approaches or engine efficiency with stoichiometric concepts. A potential solution to this trade-off is combining lean-burn and stoichiometric operating strategies. This concept has been proposed based on engine research results [12, 202, 222] and has also been implemented in hydrogen demonstration vehicles [154, 195]. At low engine loads, the engine is operated at variable lean air-fuel ratios, resulting in good engine efficiencies and extremely low engine-out emissions. Once a certain engine power demand is exceeded, the operating strategy is switched to throttled stoichiometric operation. The $\mathrm{NO}_{\mathrm{X}}$ emissions critical operating regime at equivalence ratios $1<\lambda<2 / 0.5<\phi<1$ is avoided, and a conventional aftertreatment system can be used to reduce oxide of nitrogen emissions in stoichiometric operation. Tests performed on a prototype demonstration vehicle with a $6.0 \mathrm{~L} \mathrm{~V} 12$ engine employing this operating strategy showed that the emissions add up to only a fraction of the most stringent standards. The test results on a FTP-75 cycle revealed $\mathrm{NO}_{\mathrm{X}}$ emissions as low as $0.0008 \mathrm{~g} / \mathrm{mi}$ (3.9\% of the Super Ultra Low Emission Vehicle [SULEV] standard) and hydrocarbon emissions that were lower than the ambient concentration, indicating that this vehicle actively reduces the concentration of certain emissions components [196].

The low density of hydrogen was shown to significantly reduce the power density with port fuel injection compared to conventional fuels. Calculations based on a verified model have shown that the trapped air mass per cycle could be increased by up to $16 \%$ with cryogenic hydrogen port injection (injection temperature around $90 \mathrm{~K}$ ) compared to ambient hydrogen injection [126]. This leads to a significant increase in power output, making cryogenic injection an effective measure to increase the specific power of hydrogen engines [206]. However, this injection strategy is only feasible in combination with cryogenic hydrogen onboard storage, a technique with promising storage densities but significant challenges due to the complexity of the tank and infrastructure. 


\subsubsection{Spark ignition direct injection}

Efforts to avoid combustion anomalies and increase the power density of hydrogen internal combustion engines while achieving near-zero emissions have led to the development of injection systems for hydrogen DI operation. Similar to common classifications for gasoline engines, hydrogen DI mixture formation strategies have also been grouped in jet-guided, wall-guided, and air-guided concepts [107]. Based on the start of injection (SOI), one can differentiate early DI and late DI operation; however, no clear threshold between these two categories has been defined. Figure 20 shows a schematic of different hydrogen DI strategies and their respective injection timings. Early injection generally refers to any hydrogen DI during the early compression stroke shortly after intake valve closing, whereas late DI refers to strategies with the injection late in the compression stroke generally ending just before spark timing. In order to avoid displacement of fresh charge by hydrogen of low density, the start of injection even for early injection is usually set after intake valve closing. Aside from engine operation with one injection pulse per cycle, results of multiple injection strategies with two or more injection pulses per cycle have been reported [134, 175, 223].

Based on the required injection pressure, the terms low-pressure and highpressure DI have also been used in the literature. In order to flow hydrogen directly into the combustion chamber, the pressure inside the injection system has to exceed the pressure inside the cylinder. However, only if critical injection conditions are being reached, the amount of hydrogen injected into the engine becomes independent from the cylinder pressure. This is critical for engine calibrations and accurate fuel metering, with the amount of fuel determined only as a function of injection pressure and injection duration. Critical conditions are obtained at a pressure ratio of about 0.53 (see Section 2.4 for details) indicating that the injection pressure has to be approximately twice the cylinder pressure to guarantee critical conditions (choked flow). Therefore, operating strategies with early DI require injection pressures in the range of approximately 5 to 20 bar, late injection strategies up to 100 bar and multiple injection strategies with injection pulses during the actual combustion event of 100 to 300 bar [224]. The exposure of the injector tip to in-cylinder pressures and temperatures with DI operation poses significant challenges for developing durable injectors with accurate metering capabilities and high flow rates [178].

Injection timing during hydrogen DI operation has crucial influence on the mixture distribution and, therefore, on the combustion characteristics. With early injection, the injected fuel has sufficient time to mix with the air inside the com- 
bustion chamber and form an almost homogeneous mixture. With late injection, only limited time for mixing is available, resulting in a stratified charge at spark timing. Those basic trends were also confirmed by using three-dimensional CFD simulation tools (e.g. [225]) and optically accessible engines (e.g. [226]).

The impact of the above-mentioned characteristics on $\mathrm{NO}_{\mathrm{X}}$ emissions behavior is highly dependent on the engine load or the overall equivalence ratio, respectively. Figure 21 shows the $\mathrm{NO}_{\mathrm{X}}$ emissions results as a function of start of injection for various engine equivalence ratios at an engine speed of 2000 RPM collected on a single-cylinder hydrogen research engine [227, 228]. Because the engine is operated without throttling, the equivalence ratio corresponds to engine load. The injector configuration for these investigations is a side-mounted DI injector with a symmetrical 13-hole nozzle configuration $\left(60^{\circ}\right.$ included injection angle). At low engine loads, early injection results in extremely low $\mathrm{NO}_{\mathrm{X}}$ emissions because the mixture at ignition timing is very likely to be homogeneous [229]. Thus, the lean homogeneous mixture burns without forming $\mathrm{NO}_{\mathrm{X}}$ emissions. Late injection at low loads, on the other hand, results in a stratified mixture with hydrogen-rich zones, as well as zones with very lean mixtures or even pure air. Although the overall mixture is still lean, the combustion of rich zones causes a significant increase in $\mathrm{NO}_{\mathrm{X}}$ emissions. At high engine loads, this trend appears to be inverted. Early injection results in homogeneous mixtures that approach stoichiometry and produce high $\mathrm{NO}_{\mathrm{X}}$ emissions. Late injection is expected to result in stratification, with zones that are even richer than stoichiometric, along with lean zones. This kind of stratification avoids the $\mathrm{NO}_{\mathrm{X}}$ critical equivalence ratio regime of $\lambda \sim 1.3 / \phi \sim 0.75$ (see Fig. 18) and thereby reduces overall $\mathrm{NO}_{\mathrm{X}}$ emissions.

Theoretical considerations on mixture calorific values and power densities (Section 2) already led to the assumption that hydrogen DI operation results in superior power densities compared to port injection operation with both hydrogen and gasoline. Figure 22 shows a comparison of load sweeps as a function of the equivalence ratio measured on a single-cylinder $0.5 \mathrm{~L}$ research engine [12]. In the $\mathrm{H}_{2}$ DI case, an IMEP in excess of 13 bar was achieved, which is approximately $15 \%$ higher than the peak IMEP in gasoline operation and more than 75 $\%$ higher than the peak IMEP in hydrogen port-injection operation. Because of the displacement of air during the injection of hydrogen into the intake pipe and the combustion anomalies that occur at high engine loads, the maximum achievable mean effective pressure with external mixture formation is distinctly below the values for gasoline. The pattern of the IMEP as a function of equivalence ratio also shows differences between the two $\mathrm{H}_{2}$ mixture formation methods. Since 
during the direct injection of $\mathrm{H}_{2}$, the air amount remains almost constant with a changing equivalence ratio (displacement effect is precluded because $\mathrm{H}_{2}$ is not injected before the intake valves close), a leaner equivalence ratio under the same load (or the same IMEP) is established compared with the external mixture formation with $\mathrm{H}_{2}$. Since both oxides of nitrogen emissions and engine efficiency are strongly dependent on the equivalence ratio, DI operation is capable of achieving higher engine efficiencies and lower $\mathrm{NO}_{\mathrm{X}}$ emissions at the same engine load compared to port injection.

The efficiency potential of hydrogen DI operation was demonstrated on a single-cylinder Ford research engine, achieving an estimated peak brake thermal efficiency of more than $45 \%$ at an engine speed of 3000 RPM [178]. In order to reflect realistic brake thermal efficiencies, the friction values of the single-cylinder engine were not taken into account, but a friction mean effective pressure of 0.7 bar at 3000 RPM was estimated as typical for a low-friction multi-cylinder engine. Even at part-load operation, hydrogen DI can be used for optimizing engine efficiency. Although hydrogen's wide flammability limits theoretically allow unthrottled lean operation even at idling conditions, the relatively lean mixtures at those operating conditions result in longer, less efficient combustion durations. A study of basic injection strategies using a single-hole injector on a single-cylinder research engine demonstrated that the combustion duration at low engine loads (IMEP 2.5 bar) at an engine speed of 2000 RPM could be reduced from more than $50{ }^{\circ} \mathrm{CA}$ with early injection (SOI $=100{ }^{\circ} \mathrm{CA} \mathrm{BTDC}$ ) to around $15^{\circ} \mathrm{CA}$ with late injection around $60{ }^{\circ} \mathrm{CA}$ BTDC resulting in an increase in indicated thermal efficiency from $29 \%$ to more than $34 \%$ [230].

Although the efficiency improvement with hydrogen DI at low and part load as well as high engine loads is significant, a trade-off between optimizing engine efficiency and oxides of nitrogen emissions has been encountered. The abovementioned example with an increase in indicated efficiency from 29 to $34 \%$ also led to an increase in $\mathrm{NO}_{\mathrm{X}}$ emissions from around $5 \mathrm{ppm}$ with early injection to more than 100 ppm for the efficiency-optimized case [230].

In this respect, multiple injection has been demonstrated as an effective tool to simultaneously achieve high engine efficiencies and low $\mathrm{NO}_{\mathrm{X}}$ emissions. Results from a single-cylinder research engine suggest a $\mathrm{NO}_{\mathrm{X}}$ emissions reduction potential compared to single-injection strategies in excess of $95 \%$ while still achieving acceptable engine efficiencies [134, 175, 223]. However, due to the short time available for the injection pulse during the combustion phase, multi injection strategies pose demanding challenges for the hydrogen injection systems both in terms of pressure levels as well as required injector flow rates. Therefore, the 
demonstration of the potential of multiple injection strategies has so far been limited to fairly low engine speeds [223].

Hydrogen injectors for DI operation have to reliably operate at hydrogen supply pressures of up to 300 bar while the injector tip heats up to temperatures of 300 to $400{ }^{\circ} \mathrm{C}$. It is estimated that a metering accuracy of approximately $2 \%$ of the actual flow rate with minimum injection durations as short as $0.1 \mathrm{~ms}$ and leakage rates of less than $0.1 \%$ of full flow are required for hydrogen DI injectors [224]. Although various injector designs and actuation systems including solenoid, magnetostrictive and piezo-electric have been considered, currently available injector prototypes still do not meet the durability requirements needed for automotive applications. A major development goal should be to substantially increase injector life from about 200 hours to 1000 hours. This would allow the development and demonstration of an early stage multi-cylinder engine with advanced features and material technology integrated in the DI fuel system. A longer term goal is to develop and prove 20,000 hour level durability, with a production-oriented design, through further fundamental materials research, accelerated testing on injector rigs and full-scale engine validation [178].

\subsubsection{Compression ignition direct injection}

For further improvement in engine efficiencies, research has been performed on hydrogen DI operation on compression ignition (CI) engines for both stationary applications [197, 231, 232] as well as automotive engines [199]. Recently work on hydrogen HCCI engine research on an optical engine [200] as well as dimethyl ether (DME) assisted hydrogen HCCI operation [233] has been published. In all cases, the high autoignition temperature of hydrogen compared to conventional fuels has resulted in a limited operating range as well as high rates of EGR or intake air pre-heating as prerequisites to achieve autoignition temperatures. Investigations on an optical engine operated on hydrogen and heptane revealed that for pure hydrogen HCCI the effect of intake air temperature was relatively small. A $200{ }^{\circ} \mathrm{C}$ raise in intake temperature for $\lambda=1.6-2.0 / \phi=0.5-0.63 \mathrm{re}$ sulted in slightly advanced autoignition phasing and also led to a 2.5 bar increase in peak in-cylinder pressure, without causing much difference in the phasing of peak pressure. For comparison, a $20^{\circ} \mathrm{C}$ increase in intake air temperature for sole heptane HCCI with $\lambda=1.4 / \phi=0.7$ advanced the autoignition angle by 10 ${ }^{\circ} \mathrm{CA}$ and increased the peak pressure by about 3 bar [200]. Using DME to raise the cetane number and stabilize HCCI combustion in hydrogen engines showed a $13 \%$ improvement in indicated thermal efficiency compared to pure hydrogen operation. A peak indicated thermal efficiency of $42 \%$ while achieving excep- 
tionally low $\mathrm{NO}_{\mathrm{X}}$ emissions close to zero could be demonstrated [234]. Experimental investigations on a single-cylinder research engine specifically designed for CI showed that stable compression ignition of hydrogen could be achieved employing induction air heating and supercharging without intercooling. However, load ranges were limited to low and mid part load to avoid knocking phenomena. These findings led to the development of a dual injection strategy in which a first injection pulse delivered a small amount of fuel into the cylinder. Forming, compressing and finally igniting an initial mixture around top dead center (TDC) was used to generate temperature in the combustion chamber. A second pulse was subsequently injected and almost immediately converted in a diffusion type of combustion, completely inhibiting knocking phenomena. Making the combustion system more stable and flexible by igniting the first pulse using a spark plug led to an indicated efficiency of the high-pressure cycle of $44 \%$ [199].

Whether hydrogen CI operation and hydrogen HCCI operation will be relevant operating modes for hydrogen engines depends on their effective operation ranges as well as efficiency and emissions characteristics. HCCI operation has generally been limited to low engine speeds and loads. In light of the additional complications with stable engine control in HCCI operation, it remains to be seen whether significant improvements compared to conventional hydrogen operation are achievable, since these conventional operating modes already offer excellent engine efficiencies at low engine-out emissions levels at these operating conditions.

\subsection{Measures for $\mathrm{NO}_{x}$ control}

Due to the absence of carbon in the fuel, the regulated emissions of hydrogenpowered internal combustion engines are theoretically limited to oxides of nitrogen. Carbon monoxide $(\mathrm{CO})$, hydrocarbon $(\mathrm{HC})$ as well as $\mathrm{CO}_{2}$ emissions are expected to be virtually zero [12]. Measurements on a medium speed, externally supercharged, single-cylinder research diesel engine type MAN 1L 24/30 operated on hydrogen showed $\mathrm{CO}_{2}$ emissions of less than $2 \%$ compared to operation on conventional fuel [197]. It is generally assumed that traces of hydrocarbon emissions in the exhaust of hydrogen engines result from the combustion of the lubricating oil.

As shown in Fig. 18 and Fig. 21, the oxides of nitrogen emissions of hydrogen engines strongly depend on the engine load and air-to-fuel ratio. Methods for reducing $\mathrm{NO}_{\mathrm{X}}$ emissions include engine internal measures, like multiple injections, water injection or EGR as well as exhaust aftertreatment. Depending on 
the engine operating strategy, either a conventional 3-way catalyst or lean $\mathrm{NO}_{\mathrm{X}}$ aftertreatment have to be employed. Regular production-type catalysts were shown to achieve a $\mathrm{NO}_{\mathrm{X}}$ conversion efficiency in excess of $99.5 \%$ [202]. A BMW Hydrogen 7 vehicle equipped with a catalyst setup consisting of two monoliths - the first one for the stoichiometric operating regime and the second one for reducing $\mathrm{NO}_{\mathrm{X}}$ peaks that occur when switching from lean to stoichiometric operation achieved drive-cycle $\mathrm{NO}_{\mathrm{X}}$ emissions that were approximately $0.0008 \mathrm{~g} / \mathrm{mi}$, which is equal to $3.9 \%$ of the SULEV limit [196].

Although promising results in terms of $\mathrm{NO}_{\mathrm{X}}$ emission levels have been achieved with 3-way catalysts, research has been performed on more elaborate lean $\mathrm{NO}_{\mathrm{X}}$ aftertreatment systems, since the required stoichiometric operation for 3-way catalysts to work properly results in a significant loss in engine efficiency compared to lean operation. Measurements on a single-cylinder DI research engine revealed an efficiency loss of $4 \%$ with throttled stoichiometric operation compared to unthrottled lean-burn operation at 2000 RPM and an IMEP of 8 bar [26]. Methods to accomplish the reduction in oxides of nitrogen emissions generally consist of a lean $\mathrm{NO}_{\mathrm{X}}$ trap as well as other optional components including 3-way catalysts and selective catalytic reduction (SCR) converters. Initial results on a straight 6-cylinder diesel engine converted to hydrogen external mixture formation operation and equipped with a $\mathrm{NO}_{\mathrm{X}}$ absorption 3-way catalyst showed $\mathrm{NO}_{\mathrm{X}}$ emissions reductions of more than $90 \%$ with $3 \%$ of the hydrogen fuel injected into the exhaust [235]. An improved system employing hydrogen DI in combination with a $\mathrm{NO}_{\mathrm{X}}$ storage-reduction (NSR) catalyst and an oxidation catalyst showed a $\mathrm{NO}_{\mathrm{X}}$ conversion rate of $98 \%$ with fuel penalties between 0.2 and $0.5 \%$ [236]. Concepts have also been patented in which the additional reducing agent injection in the exhaust is avoided by switching operating modes from lean burn operation to fuel-rich operation using EGR in order to purge the lean $\mathrm{NO}_{\mathrm{X}}$ trap $[237,238]$.

In the mixture formation sections, a number of strategies for $\mathrm{NO}_{\mathrm{X}}$ control have already been discussed. Further provisions for engine internal $\mathrm{NO}_{\mathrm{X}}$ emission reduction include measures to reduce the in-cylinder temperatures by employing EGR and water injection [239]. Water injection was found to significantly reduce $\mathrm{NO}_{\mathrm{X}}$ emissions with only slightly negative impact on engine efficiency [240]. However, although water injection is a very effective measure for $\mathrm{NO}_{\mathrm{X}}$ emissions reduction, its practical application will depend on an efficient way of supplying the liquid, e.g., by recovering and condensing it from the engine exhaust [241].

EGR is another solution for in-cylinder $\mathrm{NO}_{\mathrm{X}}$ emissions reduction. Research on a single-cylinder engine showed that EGR application is an effective technique for reduction of engine knock and $\mathrm{NO}_{\mathrm{X}}$ emissions at the expense of engine effi- 
ciency above $20 \%$ EGR. The combustion knock values decreased substantially by about $85 \%$ and the $\mathrm{NO}_{\mathrm{X}}$ emissions reduced by about an order of magnitude when EGR levels were increased from 0 to $35 \%$ [242]. Although EGR results in an engine efficiency loss compared to unthrottled lean operation, it can still be a viable solution when stringent $\mathrm{NO}_{\mathrm{X}}$ emissions limits have to be reached since efficiency improvements compared to throttled stoichiometric operation can be accomplished [216]. An experimental study on a Ford 2.0L Zetec engine demonstrated that emissions levels of oxides of nitrogen below $1 \mathrm{ppm}$ can be achieved by combining exhaust gas recirculation and a 3-way catalyst [243, 244]. Simulation studies also concluded that the indicated thermal efficiency of cooled EGR is slightly higher than that of a hot EGR strategy. By increasing the EGR percentage (whether cooled or hot), the indicated thermal efficiency increases firstly and then decreases due to the unstable combustion at high EGR rates. The indicated thermal efficiency is mainly influenced by the properties of the cylinder charge, combustion duration and phasing as well as the wall heat losses. The combination of these factors results in an increased indicated thermal efficiency with moderate EGR levels; however, higher EGR levels result in decreased indicated thermal efficiencies due to inefficient and unstable combustion [127].

\subsection{Summary of possible control strategies}

The preceding sections clearly demonstrate the flexibility of hydrogen as an engine fuel. Consequently, the choices of operating strategies that enable a certain power demand to be met while controlling $\mathrm{NO}_{\mathrm{X}}$ emissions are numerous. This is illustrated in summarized form in the following.

At the lowest loads (including idling), the possible strategies, in ascending order of brake thermal efficiency, are:

- Fixed stoichiometric operation, with throttling (and/or EGR) and aftertreatment.

- Fixed lean equivalence ratio (lean of the $\mathrm{NO}_{\mathrm{X}}$ threshold) with throttling, without any need for aftertreatment.

- Fixed ultra lean equivalence ratio, with throttling to ensure combustion stability, without any need for aftertreatment.

At low loads, again in ascending order of brake thermal efficiency: 
- Fixed stoichiometric operation, with throttling (and/or EGR) and aftertreatment.

- Fixed lean equivalence ratio (lean of the $\mathrm{NO}_{\mathrm{X}}$ threshold) with throttling, without any need for aftertreatment.

- Variable equivalence ratio (lean of the $\mathrm{NO}_{\mathrm{X}}$ threshold) with wide open throttle, without any need for aftertreatment.

At medium loads:

- Fixed stoichiometric operation with throttling (and/or EGR) and aftertreatment.

- Fixed lean equivalence ratio (lean of the $\mathrm{NO}_{\mathrm{X}}$ threshold) with supercharging, without any need for aftertreatment.

- Variable equivalence ratio (between stoichiometric and the $\mathrm{NO}_{\mathrm{X}}$ threshold with wide open throttle and lean $\mathrm{NO}_{\mathrm{X}}$ aftertreatment.

The latter two generally result in higher efficiencies than the first strategy. Which strategy enables the highest efficiency depends on the supercharging setup and resulting losses of the second strategy compared to the fuel economy penalty incurred by the lean $\mathrm{NO}_{\mathrm{X}}$ aftertreatment for the third strategy.

At the highest loads:

- Fixed stoichiometric DI operation with aftertreatment.

- Fixed stoichiometric PFI operation with supercharging and aftertreatment.

- Fixed stoichiometric PFI operation with cryogenic fuel injection and aftertreatment.

- Fixed lean equivalence ratio (lean of the $\mathrm{NO}_{\mathrm{x}}$ threshold) with (high) supercharging, without any need for aftertreatment.

Here the strategy giving the highest efficiency again depends on the systems chosen for injection, supercharging, etc.

This list is not comprehensive; one could also discern, e.g., homogeneous from stratified operations. 


\section{Hydrogen safety}

The unique properties of hydrogen require an adapted approach when laying out a safety concept for both hydrogen engine test cells as well as hydrogen powered vehicles. The gaseous state of the fuel at ambient conditions in combination with the low density, wide flammability and invisibility of the gas as well as its flames require amended measures to guarantee a safety level equivalent to conventional fuels. When properly taking the unique properties into account by facility designers, engineers and operators, hydrogen can be as safe as, or safer than, gasoline or diesel fuel [188].

Differences in local codes and standards for hydrogen application and use make it impossible to provide an all-inclusive summary of all hydrogen safety aspects. Therefore, this chapter is rather meant as a summary of best-practice recommendations based on the authors' expertise and the limited number of publications in this area.

\subsection{Test cell design}

For a hydrogen flame to occur, both an ignitable hydrogen-air mixture and an ignition source need to be present. When operating an internal combustion engine in an enclosed space, it is practically impossible to avoid all ignition sources; therefore, sources of ignition must be expected in the test cell. However, the number of sources and particularly sources where hydrogen likely accumulates (close to the test cell ceiling) should be minimized. It is also common practice to de-energize all electric equipment when increased hydrogen concentrations are detected [245]. Because ignition sources cannot be excluded from the test cell, ignitable hydrogen-air mixtures have to be avoided through proper test cell ventilation.

\subsubsection{Test cell ventilation}

The ventilation capabilities of hydrogen test cells are generally designed much larger than those for conventional fuels. For the layout of a hydrogen test cell, two cases with different requirements for ventilation are considered: an enclosed test cell and an open test cell located inside a hi-bay. Due to the natural convection and large amount of air available in hi-bay settings, the hydrogen-specific ventilation requirements are not as critical as for enclosed test cells. As a rule of thumb for enclosed test cells, a minimum ventilation resulting in 1-2 full air exchanges per minute has been established. In order to effectively remove heat created from the test engine, as well as any hydrogen leakage, cross ventilation is widely used 
for enclosed hydrogen test cells. Fresh air is brought in close to the floor of the test cell and removed from the test cell close to the ceiling after flowing past the experimental setup. This setup results in a controlled flow of fresh air through the test cell and also allows positioning of hydrogen sensors in strategic locations throughout the test cell.

In addition to general test cell ventilation, fume hoods connected to an air blower resulting in a constant stream of flow directly on top of the experimental equipment have been used for hydrogen setups. Due to the number of hydrogen connections in close proximity to the experimental setup and the use of prototype injection equipment, one would expect that a hydrogen leak is most likely to occur in that area. Using a fume hood with constant flow and a hydrogen sensor inside the hood assures fast detection of hydrogen leaks and allows taking countermeasures immediately when a leak occurs [246].

Fume hoods are not only used in enclosed engine test cells but also in hi-bay, open test cell settings. Due to the large volume available for dilution of hydrogen leaks in hi-bay settings, detection of a potential leak could take considerable amount of time. Using hoods on top of the experimental equipment in combination with a hydrogen sensor placed inside the hood is an efficient way of detecting hydrogen leaks, especially in hi-bay settings with no defined air flow pattern [247].

The routing of the crankcase ventilation in hydrogen engine applications also requires special attention since measurements have shown hydrogen crankcase concentrations in excess of $5 \mathrm{vol} \%$ [176]. Possible solutions for test cell setups as well as vehicle applications include venting the crankcase to the atmosphere, routing the crankcase ventilation into the test cell ventilation system as well as variants of combining forced crankcase ventilation with an oil separator with or without a catalyst to convert the hydrogen to water, after which the gases are routed back into the intake manifold $[147,176]$.

\subsubsection{Hydrogen sensors}

For detection of hydrogen, several technologies are commercially available including electrochemical, catalytic, thermal conductivity, semiconductor-based and microelectromechanic sensors. An overview of sensor detection principles and a comparison of sensor performance, including range, cross sensitivity, accuracy, stability, cost, etc., can be found in [248]. Recommended locations for hydrogen sensors include locations where hydrogen leaks or spills are possible, at hydrogen connections that are routinely separated, where hydrogen could accumulate as well as in building air intake and exhaust ducts [249]. When designing a hydrogen detection system one should consider factors including detector re- 
sponse time, detection range, durability/lifetime of the detector, required detector maintenance and calibration, potential cross sensitivity and area coverage.

A generally accepted and commonly used concentration for alarm activation is around 1 vol\% of hydrogen in air (equivalent to $25 \%$ of the lower flammability limit) $[221,245]$. Other hydrogen detection systems use a progressive approach with several warning and alarm limits that warn the operators at low detection limits (e.g., $10 \%$ of the lower flammability limit) and perform automated shutdown of the hydrogen supply system and test equipment if a higher alarm limit is reached. In addition to permanently mounted hydrogen sensors, most experimental facilities also use portable hydrogen detectors for both personal protection and leak checking of hydrogen equipment.

\subsubsection{Hydrogen flame detectors}

A hydrogen-air flame is colorless, and any visibility is caused solely by impurities. At reduced pressures, a pale blue or purple flame may be present. Severe burns have been inflicted on persons exposed to hydrogen flames resulting from the ignition of hydrogen gas escaping from leaks. Therefore, hydrogen detection systems of various levels of sophistication have been developed and implemented to protect operating personnel. Hydrogen flame detectors can be classified in the following groups [250]:

- Thermal fire detectors classified as rate-of-temperature-rise detectors and overheat detectors have been manufactured for many years and are reliable. Thermal detectors need to be located at or very near the site of a fire.

- Optical sensors for detecting hydrogen flames fall into two spectral regions: ultraviolet (UV) and infrared (IR). UV systems are extremely sensitive; however, they are susceptible to false alarms and can be blinded in foggy conditions. Infrared systems typically are designed for hydrocarbon fires and are not very sensitive to hydrogen fires.

- Imaging systems mainly are available in the thermal IR region and do not provide continuous monitoring with alarm capability. The user is required to determine if the image being viewed is a flame. UV imaging systems require special optics and are very expensive. Low-cost systems, using lowlight silicon charge coupled device (CCD) video technology with filters centered on the 940- and 1100-nm emission peaks, have been used at some facilities. 
- A broom has been used for locating small hydrogen fires, as a dry corn straw or sage grass broom easily ignites as it passes through a flame. A dry fire extinguisher or dust thrown into the air also causes the flame to emit visible radiation. This technique should be used with care in windy, outdoor environments in which the light hydrogen flame can easily be blown around.

The selection of a certain detection system should be based on the ability to detect a flame at sufficient distance as well as the size of flames that can still be detected. Other selection factors include response time, insensitivity to false alarms as well as the possibility of automatic periodic checkups.

\subsubsection{Hydrogen supply system}

For most research and test applications, hydrogen is stored in cryogenic liquid form or in compressed form. Typical pressure levels for compressed storage range from 138 bar (2000 PSI) to 414 bar (6000 PSI). Liquid hydrogen is stored at temperatures of $-253^{\circ} \mathrm{C}$ generally in insulated, passive storage systems, meaning that no active cooling is provided. Despite the excessive insulation, the remaining heat input causes liquid hydrogen to evaporate, which increases the pressure. Liquid storage systems require continuous consumption to avoid pressure buildup and ultimately blowoff of hydrogen.

The large volume requirements for hydrogen storage systems for both compressed as well as cryogenic setups usually result in hydrogen being stored outdoors or in dedicated fuel canopies. The hydrogen is then delivered to the test facility via hydrogen supply lines, thereby reducing the amount of energy stored inside the test facility. Also, any leaks resulting from connections of hydrogen cylinders to supply manifolds that have to be opened and re-tightened when changing out high-pressure cylinders are thus located outside where natural ventilation generally decreases the probability of a buildup of ignitable hydrogen-air mixtures.

Depending on the storage system as well as the application, the hydrogen fuel is delivered to the test facility at widely varying pressures. For compressed storage systems, several high-pressure cylinders are usually hooked up to a manifold to allow extended uninterrupted test runs. For purging and safe leak checking of the system, high-pressure helium is generally used, which is also connected to the delivery system. For most setups, hydrogen or helium passes through manual shut-off valves and check valves and is supplied to a pressure regulator. Once regulated to the appropriate delivery pressure, the hydrogen is fed to the experimental equipment after passing through several manual as well as solenoid-operated safety valves. Using a cascade of solenoid-operated valves allows minimizing the 
amount of hydrogen that leaks into the test cell in case of a line rupture. In close proximity to the engine, a fast-acting, normally closed three-way valve is used. This valve can be remotely activated by the operator to supply hydrogen to the engine whenever needed. If the engine does not rotate or a hydrogen leak is detected, the three-way valve automatically closes. The normally open path of the three-way valve is connected to a purge line which allows the engine hydrogen supply line to be depressurized whenever the engine is not operating. The setup with a close-to-the-consumer three-way valve has proven to greatly reduce the risk of unintended hydrogen release into the engine through leaking injectors while minimizing the amount of hydrogen that has to be released to the atmosphere. For long-term shutdowns of the hydrogen supply system or if maintenance is required, hydrogen supply lines are usually purged to the atmosphere and purged with compressed helium.

Accurate metering of the amount of consumed fuel is crucial for the quality of any engine test experiment and provides a necessary baseline for calculation of development-relevant characteristic numbers like engine efficiency or brake specific fuel consumption. Automated or manual monitoring of the fuel consumption can also be used for leak detection, and therefore significantly adds to the safety of hydrogen setups and testing activities. Over the last couple of years, a continuing transition from conventional methods including positive displacement pumps and gravimetric systems towards direct and continuous mass measurement using coriolis meters has been observed [251]. For hydrogen applications, the U.S. Environmental Protection Agency (EPA) has only accepted three methods of hydrogen fuel consumption testing. These three methods are gravimetric measurement; measurement of stabilized pressure, volume and temperature (PVT); and coriolis mass flow measurement [252]. Recently another method similar to the carbon balance that is used for fuel consumption calculations for conventional vehicles based on exhaust emissions measurement has been proposed for hydrogen engines, and a detailed comparison of the methods has been provided [253]. Due to the extensive measurement equipment needed for this method, it has so far only found application where a direct fuel consumption measurement is not feasible [196].

Due to the good accuracy over a wide flow range and the direct measurement of fuel mass, a coriolis meter seems to be the preferred method for hydrogen engine testing [246]. For applications that require a range that cannot be covered by a single coriolis meter, systems that switch from a low-range to a high-range coriolis flow meter have been developed and implemented [188]. 


\subsection{In-vehicle applications}

Even more so than for test cell design, it is practically impossible to avoid all ignition sources on hydrogen-powered vehicles. In order to provide a level of safety for hydrogen vehicles comparable to conventionally fueled cars, strategies combining detection of hydrogen leaks and diluting concentrations of hydrogen below the lower ignition limit have been developed. During regular vehicle operation, hydrogen sensors positioned in critical areas throughout the vehicle monitor the hydrogen concentration. In case a hydrogen leak is detected, the measures taken depend on the level of hydrogen concentration. Mitigation measures include, but are not limited to, advisory measures such as various levels of driver warnings, active ventilation using additional fans as well as executive measures such as disabling the starter relay or hydrogen supply [254]. Hydrogen sensors are used in critical areas of hydrogen vehicles (engine compartment, hydrogen storage area, passenger compartment) to allow the highest level of safety and an early detection of potential hydrogen leaks. Due to the complex design of a vehicle interior and the ventilation systems, 3-D CFD simulation in combination with elaborate hydrogen release and detection tests have been performed to determine the most efficient location for hydrogen sensors [255].

Both compressed hydrogen storage systems as well as cryogenic hydrogen storage systems could potentially allow pressure buildup in case of malfunction or accident. To properly address those risks, extensive tests of hydrogen storage systems including crash tests as well as exposure to fire have been performed. If properly designed, a hydrogen storage system will release hydrogen through overpressure vents strategically positioned in the vehicle.

Measures to increase the safety of hydrogen vehicles also include training of operators as well as potential rescue personnel. Therefore, rescue guidelines have been developed to inform first responders to the different hazards associated with hydrogen-powered vehicles [256].

\section{Hydrogen internal combustion engine vehicles}

Hydrogen internal combustion engines for automotive application are intended to power vehicles and provide an equivalent level of drivability, range and safety as conventional fuel vehicles. However, mainly due to the challenges of onboard hydrogen storage, current hydrogen-powered internal combustion engine vehicles have a limited range and in some cases reduced trunk space available compared to their conventional fuel counterparts. Nonetheless, due to the immediate availability of hydrogen combustion engines, the extensive knowledge in engine produc- 
tion, durability and maintenance as well as the capability of combustion engines to run on both hydrogen as well as conventional fuels (in most cases, gasoline), they are considered a bridging technology towards a widespread hydrogen infrastructure [1]. In this role, hydrogen internal combustion engine vehicles can be considered early adopters to help establishing and expanding a hydrogen infrastructure and building public awareness.

Numerous hydrogen engine-powered vehicles ranging from two-wheelers to passenger cars, pickup trucks to buses and off-road equipment have been designed, built and tested over the last decades. The following section is limited to selected hydrogen internal combustion engine vehicles; design studies and showcars are excluded from this overview.

\subsection{History}

The concept of operating an internal combustion engine on hydrogen is almost as old as the internal combustion engine itself. In 1807, François Isaac de Rivaz of Switzerland invented an internal combustion engine that used a mixture of hydrogen and oxygen for fuel. Rivaz designed a car for this engine - the first internal combustion-powered automobile [257]. Patented by Jean Joseph Etienne Lenoir in 1860, a gas-driven two-stroke engine with horizontal arrangement is considered the first successful internal combustion engine. The engine was powered by hydrogen generated via the electrolysis of water [258]. As early as 1933, Norsk Hydro operated an internal combustion engine vehicle on hydrogen produced from onboard reforming of ammonia [259]. The first hydrogen DI engine dates back to 1933 when Erren Engineering Company proposed injecting slightly pressurized hydrogen into air or oxygen inside the combustion chamber rather than feeding the air-fuel mixture via a carburetor into the engine, a method that commonly resulted in violent backfiring. The patented system required special fuel injection and control mechanisms but left the other engine components intact. With hydrogen used as a booster, the system eliminated backfiring and achieved much better combustion of hydrocarbons with higher output and lower specific fuel consumption [260]. In 1974, Musashi Institute of Technology introduced the first Japanese hydrogen-fueled vehicle, called Musashi 1, using a 4-stroke hydrogen engine and high-pressure storage [261]. The Musashi 2, introduced in 1975, was equipped with hydrogen manifold injection on a 4-stroke engine in combination with liquid hydrogen storage [261]. In 1977, Musashi 3 was presented using a spark-ignited 2-stroke engine with hydrogen DI [262]. BMW in collaboration with DLR introduced their first hydrogen vehicle in 1979. 


\subsection{Hydrogen vehicle characterization}

Hydrogen internal combustion engine vehicles can be characterized as either conversion vehicles or dedicated vehicles, with conversion vehicles adapted for hydrogen operation by either a vehicle manufacturer or an aftermarket supplier, whereas dedicated hydrogen cars are specifically designed and built for hydrogen operation by an original equipment manufacturer (OEM). Hydrogen cars have also been built for mono-fuel operation with hydrogen as the only fuel as well as bi-fuel solutions with hydrogen as well as gasoline as fuel options. Based on the hydrogen onboard storage system, hydrogen cars can be grouped as compressed hydrogen and cryogenic liquid hydrogen vehicles. Hydrogen as an engine fuel has been applied to reciprocating internal combustion engines as well as rotary engines. The following chapters give a brief overview of selected hydrogen vehicles. Automobiles that use hydrogen as a combustion enhancer in combination with another fuel are not considered in this overview.

\subsection{Conversion vehicles}

An example for a conversion truck with compressed hydrogen storage is the ETEC $\mathrm{H}_{2}$ ICE Truck Conversion based on a Chevrolet/GMC Truck Silverado/Sierra 1500HD Crew Cab 2WD LS converted to hydrogen operation by Electric Transportation Engineering Corporation. The 6-seated light-duty pickup truck is powered by a $6.0 \mathrm{~L} \mathrm{V-8} \mathrm{engine} \mathrm{with} \mathrm{hydrogen} \mathrm{port} \mathrm{fuel} \mathrm{injection.} \mathrm{A} \mathrm{belt-driven} \mathrm{super-}$ charger in combination with an intercooler is used to increase the power output of the engine. Hydrogen is stored in three 150 L, Type 3 (aluminum lined, carbonfiber reinforced) tanks at a storage pressure of up to 350 bar, which results in approximately $10.5 \mathrm{~kg}$ of usable fuel. The vehicle has an estimated curb weight of $3000 \mathrm{~kg}$ [217]. A performance, emissions and fuel economy study of this vehicle at different air fuel ratios $(2<\lambda<2.85 / 0.35<\phi<0.50)$ showed fuel consumption numbers between 4.1 and $4.5 \mathrm{~kg}$ of hydrogen per $100 \mathrm{~km}$ which is energy equivalent to 15.5 and $17 \mathrm{~L}$ of gasoline per $100 \mathrm{~km}(13.8$ to $15.2 \mathrm{mpg})$ at $\mathrm{NO}_{\mathrm{X}}$ emissions levels in the Ultra Low Emissions Vehicle (ULEV) and Super U1tra Low Emissions Vehicle (SULEV) ranges [263]. So far about 20 ETEC $\mathrm{H}_{2}$ ICE Truck Conversion vehicles have been built.

Quantum Tecstar has converted over 30 vehicles to hydrogen operation using the Toyota Prius hybrid as a platform. Two compressed hydrogen tanks replace the conventional gasoline tank, leaving the interior of the vehicle unchanged. The converted Prius engine is turbocharged in order to increase the power output in hydrogen operation. With a drivability similar to the gasoline counterpart, the 
Quantum Hydrogen Prius has an estimated range of 100 - $130 \mathrm{~km}$ per fill while meeting SULEV emissions standards [264].

\subsection{Bi-fuel vehicles}

Since 1979, BMW has introduced six generations of hydrogen-powered internal combustion engine vehicles. The latest generation is the BMW Hydrogen 7 bi-fuel, a luxury sedan powered by a $6.0 \mathrm{~L} \mathrm{V12}$ engine. According to the manufacturer's claims, the BMW Hydrogen 7 vehicle has successfully completed the process of series development, meaning that the vehicle and all components have gone through the same design, manufacturing and quality control processes as any other BMW vehicle. The new hydrogen model is built at BMW's Dingolfing Plant (Germany) parallel to the other models in the BMW 7, 6 and 5 Series, with the drive unit in the BMW Hydrogen 7 coming like all BMW twelve-cylinder engines from the BMW engine production plant in Munich (Germany). The engine is equipped with two separate fuel systems allowing the vehicle to operate on gasoline as well as hydrogen. Gasoline is injected directly into the combustion chambers; hydrogen is injected into the intake manifolds of the naturally aspirated engine [154]. The vehicle is equipped with a cryogenic hydrogen tank located in the trunk of the vehicle in addition to the conventional gasoline tank. The cryogenic tank holds about $8 \mathrm{~kg}$ of liquid hydrogen which allows an estimated range of $200 \mathrm{~km}$ in hydrogen operation and another $480 \mathrm{~km}$ on gasoline [265]. Approximately 100 BMW Hydrogen 7 bi-fuel vehicles were built.

Since 1991, Mazda has developed several generations of hydrogen-powered rotary engine vehicles with the Mazda RX-8 Hydrogen RE being the most recent one unveiled in 2003. The hydrogen version of the Renesis engine is equipped with an electric-motor-assist turbocharger that is used to maximize the effectiveness of forced induction throughout the engine speed range [266]. The most recent generation is equipped with two compressed hydrogen tanks with an operating pressure of up to 350 bar, giving the vehicle a range of approximately $100 \mathrm{~km}$ in hydrogen operation plus and additional $550 \mathrm{~km}$ on gasoline. A combination of lean and stoichiometric hydrogen combustion operation results in a $23 \%$ improvement in fuel economy compared to gasoline operation. The performance of the vehicle meeting Japanese SULEV standards is reduced from $154 \mathrm{~kW}$ in gasoline to $80 \mathrm{~kW}$ in hydrogen operation [201].

\subsection{Dedicated hydrogen vehicles}

The BMW Hydrogen 7 Mono-Fuel demonstration vehicle was built based on the BMW Hydrogen 7 bi-fuel car to showcase the emissions reduction poten- 
tial of a dedicated hydrogen vehicle. On the hardware side, the most significant changes are the removal of the gasoline fuel system including fuel injectors, fuel lines, charcoal filters for tank ventilation and fuel rail. The two high-pressure fuel pumps were also removed, which reduces the parasitic losses on the engine. For stability reasons, the gasoline fuel tank remains in the vehicle because it is a structural element. The vehicles are equipped with improved catalysts. Independent test results showed that these vehicles achieved emissions levels that were only a fraction of the SULEV standard for $\mathrm{NO}_{\mathrm{X}}$ and $\mathrm{CO}$ emissions. For non-methane hydrocarbon (NMHC) emissions, the cycle-averaged emissions were actually 0 $\mathrm{g} / \mathrm{mile}$, which required the car to actively reduce emissions compared to the ambient concentration. The fuel economy numbers on the FTP-75 test cycle were 3.7 $\mathrm{kg}$ of hydrogen per $100 \mathrm{~km}$, which, on an energy basis, is equivalent to a gasoline fuel consumption of $13.8 \mathrm{~L}$ per $100 \mathrm{~km}(17 \mathrm{mpg})$. Fuel economy numbers for the highway cycle were determined to be $2.1 \mathrm{~kg}$ of hydrogen per $100 \mathrm{~km}$, equivalent to $7.8 \mathrm{~L}$ of gasoline per $100 \mathrm{~km}(30 \mathrm{mpg})$ [196].

Ford Motor Company has been evaluating hydrogen since 1997 as an alternative fuel option for vehicles with internal combustion engines. In 2001, Ford presented the hydrogen engine-powered P2000 vehicle, the first production viable, North American OEM hydrogen internal combustion engine vehicle. The aluminum-intensive five-passenger family sedan was equipped with a highly optimized hydrogen port injection, 14.5:1 compression ratio, 2.0 L engine, gaseous $\mathrm{H}_{2}$ fuel supply with an operating pressure of up to 250 bar and a triple-redundant hydrogen safety system consisting of gas sensing as well as active and passive elements. The hydrogen P2000 vehicle met SULEV standards for HC and CO and emitted 0.37 - $0.74 \mathrm{~g} / \mathrm{mile}$ of $\mathrm{NO}_{\mathrm{X}}$ while showing a metro cycle fuel economy improvement of up to $17.9 \%$ relative to gasoline [215]. To demonstrate a commercially viable hydrogen ICE-powered vehicle application, Ford fully engineered a demonstration fleet of $30 \mathrm{E}-450$ shuttle buses with a $6.8 \mathrm{~L}$ Triton engine that runs on hydrogen. The 8 to 12 passenger shuttle bus with a $4.5 \mathrm{~m}$ wheelbase and an estimated gross vehicle weight of $6373 \mathrm{~kg}$ is equipped with a compressed hydrogen onboard storage system that holds up to $29.6 \mathrm{~kg}$ of hydrogen at a pressure of 350 bar with a resulting vehicle range of 240 to $320 \mathrm{~km}$. The target specified for the hydrogen powered shuttle bus is to meet 2010 Phase II heavy duty emission standards [221, 254, 255, 267].

\subsection{Overview of hydrogen vehicles}

Table 4 summarizes the most relevant information for the hydrogen-powered vehicles that were described in detail in the previous chapters. The summary 
includes technological aspects such as the type of engine used or the hydrogen storage system as well as vehicle range for hydrogen and, if bi-fuel, gasoline, and the number of vehicles produced or converted.

\section{Hydrogen in combination with other fuels}

\subsection{Overview - motivation}

The properties of hydrogen, in particular its wide flammability limits, make it an ideal fuel to combine with other fuels and thereby improve their combustion properties. Based on the mixture formation strategy, one can differentiate between blended operation and dual-fuel operation. Blended operation refers to combinations of hydrogen with one or several other gaseous fuels. Typically the fuel is already stored and delivered to the engine in blended form using a single carburetion or fuel injection system. In this respect, hydrogen is frequently used to improve the lean-burn behavior of natural gas. On the other hand, dualfuel $^{6}$ operation describes any combination of hydrogen and liquid fuels in which several mixture preparation devices are used. These systems either use separate storage and fuel systems for the different fuels or in some cases hydrogen may be produced onboard.

\subsection{Blends with hydrogen as a constituent}

The main motivation for adding hydrogen to natural gas is to extend the lean limit of natural gas. On the other hand, the low gravimetric storage density of compressed hydrogen tanks can be significantly improved by blending hydrogen with methane.

\subsubsection{Natural gas dominated blends}

Hydrogen has a burning velocity that is several times higher than that of methane (see Section 2.2). An overall better combustion with the addition of hydrogen to natural gas has been verified, even in a wide range of operating conditions (lambda, compression ratio, etc.), generally showing benefits including a higher efficiency, lower $\mathrm{CO}_{2}$ production and emissions [268, 269, 270]. Addition of hydrogen to natural gas allows extending the lean limit of natural gas without going into the lean misfire region, thereby achieving extremely low emission levels that meet the equivalent zero emission vehicle (EZEV) requirements [268]. A

\footnotetext{
${ }^{6}$ Note that this definition is different from the commonly used one to denote the combustion of a homogeneous gas-air mixture by diesel pilot injection.
} 
study on a turbocharged lean-burn SI engine operated on natural gas as well as mixtures of hydrogen and natural gas (20/80 and $30 / 70 \mathrm{H}_{2}$ /natural gas by vol\%) demonstrated that it was possible to achieve lower $\mathrm{NO}_{\mathrm{X}}$ and total hydrocarbons (THC) emissions without sacrificing engine torque or fuel economy [271].

Hythane ${ }^{R}$ is a registered fuel referring to mixtures of $20 \mathrm{vol} \% \mathrm{H}_{2}$ and methane, with the trademark being the property of Eden Innovations Ltd. The Denver Hythane Project in 1991 showed a more than $75 \%$ reduction in $\mathrm{CO}$ and $\mathrm{NO}_{\mathrm{X}}$ emissions when using hythane instead of natural gas [272].

\subsubsection{Hydrogen dominated blends}

Adding methane to hydrogen significantly improves the storage density of compressed storage systems, and therefore increases the vehicle range of gaseous fueled vehicles. Blending hydrogen with 5 vol $\%$ of methane increases the stored energy content by $11 \%$, while a 20 vol\% blend of methane with hydrogen increases the stored energy content by $46 \%$ compared to neat hydrogen [273]. Tests performed on a single-cylinder research engine operated on hydrogen as well as 5 and 20 vol\% blends of methane showed a slight reduction in $\mathrm{NO}_{\mathrm{X}}$ emissions with increased methane content while engine efficiencies decreased with increased methane content especially at low engine loads [274]. Vehicle-level tests on a Mercedes Benz E 200 NGT, a bi-fuel gasoline - natural gas vehicle that was adapted to operate on gasoline, natural gas, hydrogen and any $\mathrm{H}_{2} /$ natural gas mixture showed up to $3 \%$ improvement in brake thermal efficiency when operated with hydrogen compared to gasoline [168].

\subsubsection{Multiple gas blends}

Multi gas blends can result from pyrolysis, the carbonization of biomass, thermally utilizable waste substances or excess gases containing $\mathrm{H}_{2}$ that arise from chemical processes. Gases containing $\mathrm{H}_{2}$ help shift the lean-burn limit towards greater amounts of excess air than with natural gas. This effect causes mean combustion chamber temperatures to sink while $\mathrm{NO}_{\mathrm{X}}$ emissions are reduced to a very low level. Depending on the amount of hydrogen and other gas components, it is possible to attain $\mathrm{NO}_{\mathrm{X}}$ values of under $5 \mathrm{ppm}$. These $\mathrm{H}_{2}$-rich gas mixtures also have a neutral influence on the degree of efficiency even with extremely high amounts of excess air. The background of this property lies in the considerably higher laminar burning velocity of hydrogen. In the case of coke gas $\left(60 \% \mathrm{H}_{2}\right)$, the laminar burning velocity at $\lambda=2 / \phi=0.5$ is the same as that for natural gas at $\lambda=1.1 / \phi=0.9$. Especially in the lower and medium load range this effect can be utilized directly resulting in an efficiency increase of up to $2 \%$ with 
operation using pure hydrogen compared with natural gas [275]. The power output is limited with turbocharged lean-burn gas engines operating with $\mathrm{H}_{2}$-rich gas mixtures, especially due to the turbocharging unit.

\subsection{Dual-fuel applications}

Dual-fuel application of hydrogen with diesel and biodiesel as well as gasoline and alcohol fuels aims at improving combustion properties, hence reducing emissions and increasing fuel conversion efficiencies.

\subsubsection{Diesel and biodiesel}

Engine testing as well as chassis dynamometer testing of a GM $1.3 \mathrm{~L} 53 \mathrm{~kW}$ diesel engine operated on $20 \%$ bio-derived / $80 \%$ petroleum-derived diesel fuel (B20) with up to $10 \%$ hydrogen addition of the total fuel energy showed a slight decrease in $\mathrm{NO}_{\mathrm{X}}$ emissions and slightly increased exhaust temperatures at constant engine efficiencies with no negative impact on engine performance or drivability [276].

Use of biodiesel and vegetables oils has been reported to result in reduced thermal efficiencies and increased smoke numbers. Injection of hydrogen in the intake showed a consistent reduction in smoke, $\mathrm{CO}$ and $\mathrm{HC}$ emissions for operation on diesel fuel as well as Jatropha oil. Up to a hydrogen mass share of $5 \%$ a simultaneous increase in brake thermal efficiency of up to $2 \%$ is observed at full load. The faster heat release rate with addition of 10 mass $\%$ of hydrogen results in a $10 \%$ increase in NO emissions at full load for diesel as well as Jatropha [277].

Experiments were also conducted on onboard production of hydrogen-rich gas to assist partially premixed charge compression ignition engine operation on ultra low sulfur diesel (ULSD) as well as rapeseed methyl ester (RME). It was concluded that hydrogen-rich gas produced by exhaust gas fuel reforming can promote partially premixed compression ignition and result in improved performance and reduced emissions [278].

\subsubsection{Gasoline and alcohol fuels}

Test results on a GMC 2500 Sierra 4WD pickup truck showed a fuel consumption reduction relative to pure gasoline operation of approximately $3 \%$ in city driving and $4 \%$ in highway driving. The operating strategy for this dual-fuel pickup truck consisted of a variable substitution rate of gasoline with hydrogen ranging from $100 \%$ at idle and very light load to $0 \%$ substitution at full load to avoid any power loss. The average substitution rate of 40 to $50 \%$ resulted in a vehicle range in dual-fuel application of 110 to $180 \mathrm{~km}$ using a single 350 bar 150 
L compressed hydrogen tank. For a similar vehicle using an identical operating strategy emissions reduction for $\mathrm{CO}, \mathrm{NO}_{\mathrm{X}}$ and $\mathrm{THC}$ emissions of approximately 20 to $28 \%$ were observed [279].

Tests carried out on a single-cylinder research engine at compression ratios of $7: 1,9: 1$ and $11: 1$ and blend ratios of $0,20,40,60$ and 80 vol\% of hydrogen in ethanol showed increasing brake thermal efficiencies of up to $4 \%$ with increased compression ratio as well as a hydrogen fraction up to a level of $60 \mathrm{vol} \%$. The hydrogen addition also resulted in higher peak pressures and faster rates of heat release [280]. However, due to the addition of low-density hydrogen in the intake manifold, the brake power of the engine is reduced by up to $10 \%$ compared to operation on neat ethanol.

\section{Filling in the blanks}

As is apparant from the preceding sections, significant progress in hydrogenfueled engines has been made lately in terms of achievable power density, efficiencies and emissions. However, it is also clear that some issues still need to be addressed. Here, an attempt at listing some of these is presented.

Concerning the "fundamentals", the following questions still remain open:

- Quenching distance: in order to substantiate or disprove the crevice combustion hypothesis as a possible cause for backfire occurrence (see Section 5), more quantitative data are needed on the dependence of the quenching distance on mixture composition, pressure and temperature. This also is an important parameter for engine heat transfer, as described in Section 3.4.

- Surface ignition: it would be good to obtain insights into the specific mechanisms of surface ignition, as this can cause backfire and pre-ignition, which both limit the operational range of hydrogen engines.

- Autoignition temperature: as described in Sections 2 and 4 there is no octane-type measure for hydrogen's knock resistance, and widely varying and sometimes contradictory claims can be found in the literature. A detailed study reporting autoignition behavior of different hydrogen mixtures under engine conditions would probably remove much of the current confusion.

- Laminar combustion data: as Section 2.2 reviews, there are little to no data available on the laminar burning velocity, the stretch rate dependence and 
laminar flame stability at engine conditions, of hydrogen mixtures. As this is an important parameter for engine modeling work (Section 3), this is an important area for further study. Both experimental data on burning velocities and reaction mechanism validation at engine conditions are needed.

- Engine cycle computation sub-models: next to laminar burning velocity data, there is a strong need for a turbulent combustion model that incorporates differential diffusion as a defining characteristic of laminar and turbulent hydrogen combustion (Section 2.3). Other sub-models needed for a complete engine cycle calculation are jet formation and ignition models as well as an in-cylinder heat transfer model (Sections 2.4 and 3.4).

Relating the engine hardware, the single most important component needing further development is clearly the hydrogen DI injector, as maximum flow rate and durability are currently the main culprits.

In terms of optimizations, or engine software, lots of conditions are still to be explored for DI operation, given the large flexibility of this mixture formation concept: works reporting the impact of injector location, nozzle design, injection pressure, multiple injections, injection strategy, etc., have just recently started. Accurate but computationally efficient engine models would be of great benefit to this optimization process if they could be developed.

Finally, a number of laboratory experiments have been reported here that look very promising but remain to be proven in the field. Thus, demonstration of these concepts would be very interesting. Current vehicles are limited to some operating strategies, so further testing is required to assess the practicality, durability and actual performance of the more complex but potentially significantly improved operating strategies demonstrated on engine test benches.

\section{Conclusion}

Hydrogen seems to be a viable solution for future transportation, and the hydrogen internal combustion engine could act as a bridging technology towards a widespread hydrogen infrastructure, since hydrogen combustion engine vehicles can initially be designed for bi-fuel applications. Although hydrogen is the most abundant element in the universe, it is not readily available in its molecular form and has to be produced using other energy sources. Hydrogen is therefore considered an energy carrier rather than an energy source. In order for hydrogen vehicles to become commercially feasible, challenging tasks in hydrogen production, distribution and storage have to be addressed. 
The unique properties of hydrogen compared to both conventional liquid fuels like gasoline as well as gaseous fuels like methane make it a challenging yet promising fuel for internal combustion engine applications. In particular, the low density of $0.08 \mathrm{~kg} / \mathrm{m}^{3}$ at $300 \mathrm{~K}$ and $1 \mathrm{~atm}$, the wide flammability limits ranging from 4 to $75 \mathrm{vol} \%$ of hydrogen in air and the low minimum ignition energy of $0.02 \mathrm{~mJ}$ require special attention when employing hydrogen as an engine fuel. Due to the low density the mixture calorific value as a measure for theoretical power output is $14 \%$ lower than gasoline for mixture-aspirating operation; however, air-aspirating operation results in a theoretical increase in power output of $19 \%$ compared to the gasoline baseline. Also, the laminar burning velocity at stoichiometric conditions at $360 \mathrm{~K}$ of approximately $290 \mathrm{~cm} / \mathrm{s}$ is a factor of 6 higher than that of gasoline or methane.

As the wide flammability limits allow hydrogen engines to be operated with substantial dilution (excess air or EGR), the laminar burning velocity and laminar flame stability can vary widely, and consequently are important parameters. The influence of the flame stretch rate on the burning velocity and flame stability is likely significant. Currently, there is a lack of data at engine conditions. Both experimental data and chemical reaction mechanism validation at these conditions are needed.

Most modern hydrogen combustion engines employ fuel injection, either in the intake manifold or directly into the combustion chamber. In order to allow accurate metering of the amount of fuel injected into the engine, critical pressure conditions are generally used for the injection process requiring the hydrogen supply pressure to be approximately twice the back-pressure. The ratio of the largest scales versus the smallest scales to be considered during an injection event, of approximately 4000, precludes direct numerical simulation of the injection event, and various approaches to accurately simulate the hydrogen injection process have been developed. More advanced combustion concepts require consideration of ignited hydrogen jets, which have been studied experimentally as well as by using 3-D CFD simulations but which could benefit from further study.

The turbulent combustion of hydrogen mixtures has been investigated experimentally and numerically, highlighting some pecularities of hydrogen combustion, with much larger burning velocity enhancements through turbulence for lean (unstable) mixtures than for stoichiometric or rich (stable) mixtures. Very few models have been proposed to take this into account and remain to be validated. Thus, many uncertainties remain in the modeling of the combustion in hydrogen engines, with additional complexity due to currently inaccurate sub-models such as in-cylinder heat transfer. 
The same properties that make hydrogen such a desirable fuel for internal combustion engines are also responsible for abnormal combustion events associated with hydrogen. In particular, the wide flammability limits, low required ignition energy and high flame speeds can result in undesired combustion phenomena generally summarized as combustion anomalies, including surface ignition and backfiring as well as autoignition. Backfiring is limited to external mixture formation operation and can be successfully avoided with DI operation. Proper engine design can largely reduce the occurrence of surface ignition. Autoignition is a topic of controversy, and a wide range of octane ratings for hydrogen as fuel has been reported. Evaluating the guidelines for determinating the most common octane ratings, motor octane number and research octane number, leads to the conclusion that these methods must not be applied to hydrogen as a gaseous fuel. Comparative analysis of knock intensities of gasoline and hydrogen revealed that knocking pressure traces exhibit similar peak amplitudes as well as similar durations and decays of pressure oscillations.

A dedicated design for a hydrogen internal combustion engine should include the ignition system and spark plugs, a hydrogen fuel-injection system, a properly sized engine cooling system as well as proper design and selection of lubrication and materials. A wide variety of mixture formation strategies have been developed for hydrogen engine applications, with hydrogen port fuel injection and hydrogen direct injection as the two most common concepts. Inherent disadvantages of port fuel injection include a lower power density compared to gasoline engines as well as operational limitations due to the occurrence of combustion anomalies. However, due to the simplicity of the concept, the availability of dedicated fuel-injection systems and the straightforward conversion process of conventional engines, hydrogen port fuel injection is widely used mainly for demonstration vehicle applications. The wide ignition limits allow hydrogen port fuel injected engines to operate unthrottled, and therefore efficiently, over the entire operating regime. The dependence of the only relevant emissions component in hydrogen operation, oxides of nitrogen, is well documented. At fuel-to-air equivalence ratios, $\phi$, of less than $0.5(\lambda>2)$, the engine operates without creation of $\mathrm{NO}_{\mathrm{X}}$ emissions; increasing the fuel-to-air equivalence ratio beyond this critical threshold results in a sharp increase of $\mathrm{NO}_{\mathrm{X}}$ emissions with a peak around $\phi \sim 0.75$ and a slight decrease when approaching stoichiometric mixtures. Measures to increase the power density of port fuel injected hydrogen operation mainly focus on charging strategies. Hydrogen direct injection opens up another array of variables for influencing the mixture formation and combustion process. Optimizing operational parameters like fuel injector location and nozzle design, injection pressure 
as well as injection strategy can be used to influence the mixture distribution and thereby engine efficiency and $\mathrm{NO}_{\mathrm{X}}$ emissions characteristics. A $15 \%$ increase of power density in hydrogen DI operation compared to gasoline operation has also been demonstrated, and extrapolations from single-cylinder engine efficiency data suggest that a brake thermal efficiency of $45 \%$ is achievable. However, due to the limited availability of high-pressure hydrogen injection equipment, hydrogen direct injection strategies are still in a research stage. Hydrogen direct injection using a multiple injection strategy has also been demonstrated as an effective measure for significant $\mathrm{NO}_{\mathrm{X}}$ emission reductions of up to $95 \%$. Other emissions reduction provisions include engine internal measures like EGR and water injection as well as aftertreatment concepts including 3-way catalysts as well as lean $\mathrm{NO}_{\mathrm{X}}$ traps.

The unique properties of hydrogen also require special attention when designing a safety concept for both test cell applications as well as in-vehicle applications. In practical applications, the presence of ignition sources cannot be excluded; hence, proper ventilation to avoid buildup of ignitable mixtures becomes a necessity. Since hydrogen gas as well as hydrogen flames are invisible to the human eye, hydrogen flame cameras as well as hydrogen detectors have been developed for increased safety. Especially for engine test cell applications, a properly designed hydrogen fuel supply system can significantly add to the overall safety.

Hydrogen internal combustion engine vehicles have a long history, with the earliest attempts dating back to 1807. Major contributions to the development and demonstration of hydrogen internal combustion engines have been made by Musashi Institute of Technology, BMW as well as Ford Motor Company. Modern $\mathrm{H}_{2}$ ICE vehicles have shown emissions levels that are only a fraction of the most stringent standards while exceeding the fuel economy numbers of their conventionalfuel counterparts. Apart from use as a neat fuel, hydrogen is also considered as a combustion enhancer, as a blending agent with gaseous fuels and bi-fuel applications with both gasoline- and diesel-type fuels.

Finally, although the $\mathrm{H}_{2} \mathrm{ICE}$ has made significant progress recently, there remain many topics requiring further investigation, ranging from fundamentals to demonstrations.

\section{Acknowledgments}

This work would not have been possible without the help of a number of colleagues, friends, mentors and financing bodies. 
S. Verhelst would like to thank Prof. Roger Sierens, who initiated the $\mathrm{H}_{2} \mathrm{ICE}$ work at Ghent University in 1992 and under whose supervision S. Verhelst did his $\mathrm{Ph} . \mathrm{D}$. on this fascinating topic. Rene Janssens is also to be mentioned, as the technician whose golden hands were of tremendous help to the experimental work. Part of the research at Ghent was sponsored by the Belgian Science Policy TAP programme in the framework of the CHASM project (contract CP/02/222).

Significant progress in S. Verhelst's understanding of hydrogen combustion was made during his stay with the Combustion Group at Leeds University. Many thanks are due to Dr. Rob Woolley, Dr. Malcolm Lawes, Prof. Derek Bradley, Prof. Chris Sheppard and the European Commission who funded the stay with a Marie Curie Fellowship (ENK6-CT-2000-57).

Parts of the submitted manuscript have been created by UChicago Argonne, LLC, Operator of Argonne National Laboratory ("Argonne"). Argonne, a U.S. Department of Energy Office of Science laboratory, is operated under Contract No. DEAC02-06CH11357. The U.S. Government retains for itself, and others acting on its behalf, a paid-up nonexclusive, irrevocable worldwide license in said article to reproduce, prepare derivative works, distribute copies to the public, and perform publicly and display publicly, by or on behalf of the Government.

Research referenced in this manuscript was partially funded by DOE's FreedomCAR and Vehicle Technologies Program, Office of Energy Efficiency and Renewable Energy. T. Wallner wishes to thank Gurpreet Singh and Lee Slezak, program managers at DOE, for their support.

A hydrogen engine used to run certain experiments presented in this manuscript was provided by Ford Motor Company. Special thanks to the team from Ford Motor Company for their support. T. Wallner would also like to express his gratitude to all of the individuals from BMW Research and Development and Graz University of Technology involved in preparing, performing as well as analyzing hydrogen engine research referenced in this manuscript as well as collaborators from BMW North America LLC and BMW Germany involved in the testing of the BMW Hydrogen 7 vehicle at Argonne National Laboratory.

\section{References}

[1] U.S. Department of Energy, FreedomCAR and Vehicle Technologies Multi-Year Program Plan 2006-2011.

[2] European Commission, The Fuel Cells and Hydrogen Joint Technology Initiative (FCH JTI). 
[3] Japanese Ministry of Economy, Trade and Industry, Japan Hydrogen \& Fuel Cell Demonstration Project.

[4] National Hydrogen Energy Board, Ministry of New and Renewable Energy, Government of India, National hydrogen energy road map.

[5] A. Yilancia, I. Dincer, H. K. Ozturk, A review on solar-hydrogen/fuel cell hybrid energy systems for stationary applications, Progress in Energy and Combustion Science 35 231-244 (2009).

[6] W. Weindorf, M. Altmann, Yield of biofuels versus hydrogen from photovoltaics and wind power, Ludwig-Bölkow-Systemtechnik GmbH (2007).

[7] M. Shelef, C. A. Kukkonen, Prospects of hydrogen-fueled vehicles, Progress in Energy and Combustion Science 20 139-148 (1994).

[8] A. Delorme, A. Rousseau, P. Sharer, S. Pagerit, T. Wallner, Evolution of hydrogen fueled vehicles compared to conventional vehicles from 2010 to 2045, SAE Paper No. 2009-01-1008 (2009).

[9] European Commission's Directorate General Joint Research Center, CONCAWE and EUCAR, Well-to-wheel analysis of future automotive fuels and powertrains in the European context.

[10] L. M. Das, Hydrogen engines: a view of the past and a look into the future, Int. J. Hydrogen Energy 15 425-443 (1990).

[11] L. M. Das, Hydrogen-oxygen reaction mechanism and its implication to hydrogen engine combustion, Int. J. Hydrogen Energy 21 703-715 (1996).

[12] H. Eichlseder, T. Wallner, R. Freymann, J. Ringler, The potential of hydrogen internal combustion engines in a future mobility scenario, SAE Paper No. 2003-01-2267 (2003).

[13] C. M. White, R. Steeper, A. E. Lutz, The hydrogen-fueled internal combustion engine: a technical review, Int. J. Hydrogen Energy 31 1292-1305 (2006).

[14] I. Glassman, Combustion, Academic Press, Inc., Orlando, FL, 1987.

[15] J. B. Heywood, Internal Combustion Engine Fundamentals, McGraw-Hill, 1988. 
[16] C. Morley, GASEQ, a chemical equilibrium program for windows.

[17] R. H. Perry, D. W. Green (Eds.), Perry's chemical engineers' handbook, McGraw-Hill, 1997.

[18] M. Molnarne, T. Schendler, V. Schroeder, Sicherheitstechnische Kenngroessen, Band 2: Explosionsbereiche von Gasgemischen, Wirtschaftsverlag NW - Verlag fuer neue Wissenschaft, 2003.

[19] V. Schroeder, K. Holtappels, Explosion characteristics of hydrogen-air and hydrogen-oxygen mixtures at elevated pressures, International Conference on Hydrogen Safety, Pisa, Italy, Paper No. 120001 (2005).

[20] I. L. Drell, F. E. Belles, Survey of hydrogen combustion properties, Tech. Rep. 1383, National Advisory Committee for Aeronautics (1958).

[21] M. Hertzberg, Selective diffusional demixing: occurrence and size of cellular flames, Progress in Energy and Combustion Science 15 203-239 (1989).

[22] R. Ono, M. Nifuku, S. Fujiwara, S. Horiguchi, T. Oda, Minimum ignition energy of hydrogen-air mixture: effects of humidity and spark duration, Journal of Electrostatics 65 87-93 (2007).

[23] S.-W. Hong, Y.-S. Shin, J.-H. Song, S.-H. Chang, Performance test of the quenching meshes for hydrogen control, Journal of Nuclear Science and Technology 40 (10) 814-819 (2003).

[24] A. E. P. Jr., Flame quenching, Vol. 1, Progress in Combustion and Fuel Technology. Edited by J. Durcarme, M. Gerstain and A. H. Lefebvre. Pergamon Press, New York, 1960, p. 145182.

[25] U.S. Department of Energy, Freedomcar and fuel partnership 'hydrogen storage technologies roadmap'.

[26] T. Wallner, Development of combustion concepts for a hydrogen powered internal combustion engine, Ph.D. thesis, Graz University of Technology (2004).

[27] International Programme on Chemical Safety, INCHEM - chemical safety information from intergovernmental organizations.

[28] BOC Gases, Material safety data sheets. 
[29] The Engineering Toolbox, Fuels and chemicals - auto ignition temperatures, accessed on Feb. 3rd 2009.

URL http://www.engineeringtoolbox.com

[30] U.S. Department of Energy, Hydrogen analysis resource center, accessed on Feb. 3rd 2009.

URL http://hydrogen.pnl.gov/cocoon/morf/hydrogen

[31] B. Martel, Chemical Risk Analysis: A Practical Handbook, Taylor \& Francis, 2000.

[32] G. Konig, C. G. W. Sheppard, End gas autoignition and knock in a spark ignition engine, SAE Paper No. 902135 (1990).

[33] S. Verhelst, R. Sierens, S. Verstraeten, A critical review of experimental research on hydrogen fueled SI engines, SAE Paper No. 2006-01-0430 (2006).

[34] W. Peschka, Liquid hydrogen - fuel of the future, Springer-Verlag, New York, NY, 1992.

[35] G. Herdin, F. Gruber, J. Klausner, R. Robitschko, D. Chvatal, Hydrogen and hydrogen mixtures as fuel in stationary gas engines, SAE Paper No. 200701-0012 (2007).

[36] J. Manton, G. von Elbe, B. Lewis, Nonisotropic propagation of combustion waves in explosive gas mixtures and the development of cellular flames, Journal of Chemical Physics 20 153-157 (1952).

[37] P.Clavin, Dynamic behaviour of premixed flame fronts in laminar and turbulent flows, Progress in Energy and Combustion Science 11 1-59 (1985).

[38] F. A. Williams, Combustion Theory, 2nd Edition, Addison-Wesley, 1985.

[39] C. Law, Dynamics of stretched flames, 22nd Symp. (Int.) on Combustion 1381-1402 (1988).

[40] S. Kwon, L. K. Tseng, G. M. Faeth, Laminar burning velocities and transition to unstable flames in $\mathrm{H}_{2} / \mathrm{O}_{2} / \mathrm{N}_{2}$ and $\mathrm{C}_{3} \mathrm{H}_{8} / \mathrm{O}_{2} / \mathrm{N}_{2}$ mixtures, Combustion and Flame 90 230-246 (1992). 
[41] D. Bradley, R. A. Hicks, M. Lawes, C. G. W. Sheppard, R. Woolley, The measurement of laminar burning velocities and Markstein numbers for isooctane-air and iso-octane-n-heptane-air mixtures at elevated temperatures and pressures in an explosion bomb, Combustion and Flame 115 126-144 (1998).

[42] L.-K. Tseng, M. A. Ismail, G. M. Faeth, Laminar burning velocities and Markstein numbers of hydrocarbon/air flames, Combustion and Flame 95 410-426 (1993).

[43] X. J. Gu, M. Z. Haq, M. Lawes, R. Woolley, Laminar burning velocity and markstein lengths of methane-air mixtures, Combustion and Flame $12141-$ 58 (2000).

[44] C. Law, C. Sung, Structure, aerodynamics and geometry of premixed flamelets, Progress in Energy and Combustion Science 26 459-505 (2000).

[45] S. Verhelst, R. Sierens, A laminar burning velocity correlation for hydrogen/air mixtures valid at spark-ignition engine conditions, ASME Spring Engine Technology Conference paper nr. ICES2003-555 (Salzburg, Austria, 2003).

[46] S. Verhelst, A study of the combustion in hydrogen-fuelled internal combustion engines, Ph.D. thesis, Ghent University (2005).

URL http: //hdl. handle. net/1854/3378

[47] S. C. Taylor, Burning velocity and the influence of flame stretch, Ph.D. thesis, Leeds University (1991).

[48] C. M. Vagelopoulos, F. N. Egolfopoulos, C. K. Law, Further considerations on the determination of laminar flame speeds with the counterflow twinflame technique, 25th Symp. (Int.) on Combustion 1341-1347 (1994).

[49] O. C. Kwon, G. M. Faeth, Flame/stretch interactions of premixed hydrogen-fueled flames: Measurements and predictions, Combustion and Flame 124 590-610 (2001).

[50] S. Verhelst, R. Woolley, M. Lawes, R. Sierens, Laminar and unstable burning velocities and markstein lengths of hydrogen-air mixtures at engine-like conditions, Proceedings of the Combustion Institute 30 209-216 (2005). 
[51] D. D. S. Liu, R. MacFarlane, Laminar burning velocities of hydrogen-air and hydrogen-air-steam flames, Combustion and Flame 49 59-71 (1983).

[52] B. Milton, J. Keck, Laminar burning velocities in stoichiometric hydrogen and hydrogen-hydrocarbon gas mixtures, Combustion and Flame 58 13-22 (1984).

[53] T. Iijima, T. Takeno, Effects of temperature and pressure on burning velocity, Combustion and Flame 65 35-43 (1986).

[54] G. W. Koroll, R. K. Kumar, E. M. Bowles, Burning velocities of hydrogenair mixtures, Combustion and Flame 94 330-340 (1993).

[55] J. K. Bechtold, M. Matalon, Hydrodynamic and diffusion effects on the stability of spherically expanding flames, Combustion and Flame 67 77-90 (1987).

[56] D. Bradley, C. G. W. Sheppard, R. Woolley, D. A. Greenhalgh, R. D. Lockett, The development and structure of flame instabilities and cellularity at low Markstein numbers in explosions, Combustion and Flame 122 195-209 (2000).

[57] C. K. Wu, C. K. Law, On the determination of laminar flame speeds from stretched flames, 20th Symp. (Int.) on Combustion 1941-1949 (1984).

[58] V. Knop, A. Benkenida, S. Jay, O. Colin, Modelling of combustion and nitrogen oxide formation in hydrogen-fuelled internal combustion engines within a 3D CFD code, Int. J. Hydrogen Energy 33 5083-5097 (2008).

[59] K. T. Aung, M. I. Hassan, G. M. Faeth, Effects of pressure and nitrogen dilution on flame/stretch interactions of laminar premixed $\mathrm{H}_{2} / \mathrm{O}_{2} / \mathrm{N}_{2}$ flames, Combustion and Flame 112 1-15 (1998).

[60] D. Bradley, M. Lawes, K. Liu, S. Verhelst, R. Woolley, Laminar burning velocities of lean hydrogen-air mixtures at pressures up to $1.0 \mathrm{MPa}$, Combustion and Flame 149 162-172 (2007).

[61] S. Verhelst, R. Sierens, A quasi-dimensional model for the power cycle of a hydrogen fuelled ICE, Int. J. Hydrogen Energy 32 3545-3554 (2007). 
[62] P. Saxena, F. A. Williams, Testing a small detailed chemical-kinetic mechanism for the combustion of hydrogen and carbon monoxide, Combustion and Flame 145 316-323 (2006).

[63] A. A. Konnov, Remaining uncertainties in the kinetic mechanism of hydrogen combustion, Combustion and Flame 152 507-528 (2008).

[64] S. Verhelst, R. Sierens, A two-zone thermodynamic model for hydrogenfueled S.I. engines, 7th COMODIA - International Conference on Modeling and Diagnostics for Advanced Engine Systems paper nr. FL1-3 (Sapporo, Japan, 2008).

[65] M. Ó Conaire, H. Curran, J. Simmie, W. Pitz, C. Westbrook, A comprehensive modeling study of hydrogen oxidation, International Journal of Chemical Kinetics 36 603-622 (2004).

[66] F. A. Williams, J. F. Grcar, A hypothetical burning-velocity formula for very lean hydrogen-air flames, Proceedings of the Combustion Institute 32 1351-1357 (2009).

[67] A. A. Konnov, Refinement of the kinetic mechanism of hydrogen combustion, J. Adv. Chem. Phys. 23 5-18 (2004).

[68] F. A. Williams, Detailed and reduced chemistry for hydrogen autoignition, Journal of Loss Prevention in the Process Industries 21 131-135 (2008).

[69] J. F. Driscoll, Turbulent premixed combustion: flamelet structure and its effect on turbulent burning velocities, Progress in Energy and Combustion Science 34 91-134 (2008).

[70] A. Lipatnikov, J. Chomiak, Molecular tranport effects on turbulent flame propagation and structure, Progress in Energy and Combustion Science 31 1-73 (2005).

[71] R. G. Abdel-Gayed, D. Bradley, M. N. Hamid, M. Lawes, Lewis number effects on turbulent burning velocity, 20th Symp. (Int.) on Combustion 505-512 (1984).

[72] R. G. Abdel-Gayed, D. Bradley, M. Lawes, Turbulent burning velocities: a general correlation in terms of straining rates, Proc. R. Soc. Lond. A-414 389-413 (1987). 
[73] D. Bradley, M. Z. Haq, R. A. Hicks, T. Kitagawa, M. Lawes, C. G. W. Sheppard, R. Woolley, Turbulent burning velocity, burned gas distribution and associated flame surface definition, Combustion and Flame 133 415430 (2003).

[74] M.-S. Wu, S. Kwon, J. F. Driscoll, G. M. Faeth, Turbulent premixed hydrogen/air flames at high Reynolds numbers, Combustion Science and Technology 73 327-350 (1990).

[75] M.-S. Wu, S. Kwon, J. F. Driscoll, G. M. Faeth, Preferential diffusion effects on the surface structure of turbulent premixed hydrogen/air flames, Combustion Science and Technology 78 69-96 (1991).

[76] K. T. Aung, M. I. Hassan, S. Kwon, L.-K. Tseng, O.-C. Kwon, G. M. Faeth, Flame/stretch interaction in laminar and turbulent premixed flames, Combustion Science and Technology 174 61-99 (2002).

[77] P. J. Goix, I. G. Shepherd, Lewis number effects on turbulent premixed flame structure, Combustion Science and Technology 91 191-206 (1993).

[78] B. Renou, A. Boukhalfa, D. Puechberty, M. Trinité, Effects of stretch on the local structure of freely propagating premixed low-turbulent flames with various Lewis numbers, 27th Symp. (Int.) on Combustion 841-847 (1998).

[79] H. Kido, M. Nakahara, K. Nakashima, J. Hashimoto, Influence of local flame displacement velocity on turbulent burning velocity, 29th Symp. (Int.) on Combustion 1855-1861 (2002).

[80] H. Kido, M. Nakahara, K. Nakashima, J.-H. Kim, Turbulent burning velocity of lean hydrogen mixtures, SAE Paper No. 2003-01-1773 (2003).

[81] A. N. Lipatnikov, J. Chomiak, A. S. Betev, V. P. Karpov, Effect of Lewis number on mass burning rate in lean hydrogen turbulent flames, European Combustion Meeting Paper No. 169 (2003).

[82] J. H. Chen, H. G. Im, Correlation of flame speed with stretch in turbulent premixed methane/air flames, 27th Symp. (Int.) on Combustion 819-826 (1998).

[83] J. H. Chen, H. G. Im, Stretch effects on the burning velocity of turbulent premixed hydrogen/air flames, 28th Symp. (Int.) on Combustion 211-218 (2000). 
[84] H. G. Im, J. H. Chen, Preferential diffusion effects on the burning rate of interacting turbulent premixed hydrogen-air flames, Combustion and Flame $131246-258$ (2002).

[85] L. Gillespie, M. Lawes, C. G. W. Sheppard, R. Woolley, Aspects of laminar and turbulent burning velocity relevant to SI engines, SAE Paper No. 200001-0192 (2000).

[86] H. Kobayashi, Y. Kawabata, K. Maruta, Experimental study on general correlation of turbulent burning velocity at high pressure, 27th Symp. (Int.) on Combustion 941-948 (1998).

[87] D. Bradley, P. H. Gaskell, X. J. Gu, Burning velocities, Markstein lengths, and flame quenching for spherical methane-air flames: a computational study, Combustion and Flame 104 176-198 (1996).

[88] H. Kobayashi, H. Kawazoe, Flame instability effects on the smallest wrinkling scale and burning velocity of high pressure turbulent premixed flames, 28th Symp. (Int.) on Combustion 375-382 (2000).

[89] M. Z. Haq, C. G. W. Sheppard, R. Woolley, D. A. Greenhalgh, R. D. Lockett, Wrinkling and curvature of laminar and turbulent premixed flames, Combustion and Flame 131 1-15 (2002).

[90] D. Bradley, Problems of predicting turbulent burning rates, Combustion Theory and Modelling 6 361-382 (2002).

[91] J. B. Heywood, F. R. Vilchis, Comparison of flame development in a sparkignition engine fueled with propane and hydrogen, Combustion Science and Technology 38 313-324 (1984).

[92] D. Bradley, A. K. C. Lau, M. Lawes, Flame stretch rate as a determinant of turbulent burning velocity, Phil. Trans. R. Soc. Lond. A-338 359-387 (1992).

[93] K. N. C. Bray, Studies of the turbulent burning velocity, Proc. R. Soc. Lond. A-431 315-335 (1990).

[94] Ö. L. Gülder, Turbulent premixed flame propagation models for different combustion regimes, 23rd Symp. (Int.) on Combustion 743-750 (1990). 
[95] V. Zimont, Gas premixed combustion at high turbulence. Turbulent flame closure combustion model, Experimental Thermal and Fluid Science 21 179-186 (2000).

[96] H. G. Weller, G. Tabor, A. D. Gosman, C. Fureby, Application of a flamewrinkling LES combustion model to a turbulent mixing layer, 27th Symp. (Int.) on Combustion 899-907 (1998).

[97] A. Lipatnikov, J. Chomiak, Lewis number effects in premixed turbulent combustion and highly perturbed laminar flames, Combustion Science and Technology 137 277-298 (1998).

[98] D. Bradley, P. H. Gaskell, X. J. Gu, A. Sedaghat, Flame instabilities in large scale atmospheric gaseous explosions, 4th International Seminar on Fire and Explosion Hazards (Londonderry, Northern Ireland, 2003).

[99] N. Peters, Turbulent combustion, Cambridge University Press, 2000.

[100] A. N. Lipatnikov, J. Chomiak, Turbulent flame speed and thickness: phenomenology, evaluation, and application in multi-dimensional simulations, Progress in Energy and Combustion Science 28 1-74 (2002).

[101] R. Owston, V. Magi, J. Abraham, Fuel-air mixing characteristics of DI hydrogen jets, SAE Paper No. 2008-01-1041 (2008).

[102] N. L. Johnson, A. A. Amsden, J. D. Naber, D. L. Siebers, Threedimensional computer modeling of hydrogen injection and combustion, '95 SMC Simulation Multiconference (Phoenix/AZ, 1995).

[103] B. K. Yüceil, V. M. Ötügen, Scaling parameters for underexpanded supersonic jets, Physics of Fluids 14 4206-4215 (2002).

[104] A. Schüers, F. Gerbig, A. Wimmer, K. Kovac, Thermodynamic analysis of the working process of hydrogen internal combustion engines with direct injection, 9th Symposium 'The Working Process of the Internal Combustion Engine' Institute for Internal Combustion Engines and Thermodynamics, Graz University of Technology (2003).

[105] K. Takeyuki, K. Takayoshi, S. Hidemi, Y. Yoshitaka, M. Yasuo, A study on behavior of a transient hydrogen jet in a high swirl flow, THIESEL 2002 Conference on Thermo- and Fluid Dynamic Processes in Diesel Engines (Valencia, Spain, 2002). 
[106] W. Kirchweger, R. Haslacher, M. Hallmannsegger, U. Gerke, Application of the LIF-method for the diagnostics of the combustion process of gas-ICengines, 13th International Symposium on Application of Laser Techniques to Fluid Mechanics (Lisbon, Portugal, 2006).

[107] W. Kirchweger, H. Eichlseder, F. Gerbig, U. Gerke, Optical measurement methods for the optimization of the hydrogen DI combustion, 7th International Symposium on Internal Combustion Engines Diagnostics (BadenBaden, Germany, 2006).

[108] W. G. Houf, G. H. Evans, R. W. Schefer, Analysis of jet flames and unignited jets from unintended hydrogen release, International Conference on Hydrogen Safety (San Sebastian, Spain, 2007).

[109] S. L. Brennan, D. V. Makarov, V. Molkov, LES of high pressure hydrogen jet fire, Journal of Loss Prevention in the Process Industries 22 353-359 (2009).

[110] A. Mohammadi, M. Shioji, Y. Matsui, R. Kajiwara, Spark-ignition and combustion characteristics of high-pressure hydrogen and natural-gas intermittent jets, Trans. ASME: J. Eng. Gas Turbines Power 130 062801-1-7 (2008).

[111] H. Kawanabe, Y. Matsui, A. Kato, M. Shioji, Study on the flame propagation process in an ignited hydrogen jet, SAE Paper No. 2008-01-1035 (2008).

[112] E. Conte, K. Boulouchos, A quasi-dimensional model for estimating the influence of hydrogen- rich gas addition on turbulent flame speed and flame front propagation in IC-SI engines, SAE Paper No. 2005-01-0232 (2005).

[113] T. Noda, D. E. Foster, A numerical study to control combustion duration of hydrogen-fueled HCCI by using multi-zone chemical kinetics simulation, SAE Paper No. 2001-01-0250 (2001).

[114] C. Liu, G. A. Karim, A simulation of the combustion of hydrogen in HCCI engines using a 3D model with detailed chemical kinetics, Int. J. Hydrogen Energy 33 3863-3875 (2008).

[115] J. J. Fagelson, W. J. McLean, P. C. T. de Boer, Performance and $\mathrm{NO}_{\mathrm{X}}$ emissions of spark-ignited combustion engines using alternative fuels - quasi 
one-dimensional modeling. I. hydrogen fueled engines, Combustion Science and Technology 18 47-57 (1978).

[116] S. Verhelst, C. G. W. Sheppard, Multi-zone thermodynamic modelling of spark-ignition engine combustion an overview, Energy Conversion and Management 50 1326-1335 (2009).

[117] G. P. Prabhu-Kumar, B. Nagalingam, K. V. Gopalakrishnan, Theoretical studies of a spark-ignited supercharged hydrogen engine, Int. J. Hydrogen Energy 10 389-397 (1985).

[118] M. A. R. S. Al-Baghdadi, H. A. K. S. Al-Janabi, A prediction study of a spark ignition supercharged hydrogen engine, Energy Conversion and Management 44 3143-3150 (2003).

[119] M. A. R. S. Al-Baghdadi, Effect of compression ratio, equivalence ratio and engine speed on the performance and emission characteristics of a spark ignition engine using hydrogen as a fuel, Renewable Energy 29 2245-2260 (2004).

[120] J. Keck, Turbulent flame structure and speed in spark-ignition engines, 19th Symp. (Int.) on Combustion 1451-1466 (1982).

[121] M. Takats, J. Macek, M. Polasek, Z. Kovar, S. Beroun, C. Schloz, Hydrogen fueled reciprocating engine as an automotive prime mover?, Fisita World Automotive Congress Paper No. F98T/P693 (Paris, France, 1998).

[122] M. Polasek, J. Macek, M. Takats, O. Vitek, Application of advanced simulation methods and their combination with experiments to modeling of hydrogen fueled engine emission potentials, SAE Paper No. 2002-01-0373 (2002).

[123] J. A. Miller, C. T. Bowman, Mechanism and modeling of nitrogen chemistry in combustion, Progress in Energy and Combustion Science 15 287338 (1989).

[124] J. Ma, Y. Su, Y. Zhou, Z. Zhang, Simulation and prediction on the performance of a vehicle's hydrogen engine, Int. J. Hydrogen Energy 28 77-83 (2003). 
[125] G. D'Errico, A. Onorati, S. Ellgas, A. Obieglo, Thermo-fluid dynamic simulation of a S.I. single-cylinder $\mathrm{H}_{2}$ engine and comparison with experimental data, ASME Spring Engine Technology Conference paper nr. ICES2003-1311 (Aachen, Germany, 2006).

[126] G. D'Errico, A. Onorati, S. Ellgas, 1d thermo-fluid dynamic modelling of an SI single-cylinder $\mathrm{H}_{2}$ engine with cryogenic port injection, Int. J. Hydrogen Energy 33 5829-5841 (2008).

[127] H. Safari, S. Jazayeri, R. Ebrahimi, Potentials of $\mathrm{NO}_{\mathrm{x}}$ emission reduction methods in SI hydrogen engines: simulation study, Int. J. Hydrogen Energy 34 1015-1025 (2009).

[128] G. Woschni, A universally applicable equation for the instantaneous heat transfer coefficient in the internal combustion engine, SAE Paper No. 670931 (1967).

[129] N. Johnson, Hydrogen as a zero-emission, high-efficiency fuel: uniqueness, experiments and simulation, 3rd Int. Conf. ICE97, Internal combustion engines: experiments and modeling (Naples, Italy, 1997).

[130] P. V. Blarigan, Development of a hydrogen fueled internal combustion engine designed for single speed/power operation, SAE Paper No. 961690 (1996).

[131] G. Fontana, E. Galloni, E. Jannelli, M. Minutillo, Numerical modeling of a spark-ignition engine using premixed lean gasoline-hydrogen-air mixtures, 14th World Hydrogen Energy Conference (Montreal, Canada, 2002).

[132] M. Shioji, H. Kawanabe, Y. Taguchi, T. Tsunooka, CFD simulation for the combustion process in hydrogen engines, 15th World Hydrogen Energy Conference (Yokohama, Japan, 2004).

[133] D. D. Adgulkar, N. V. Deshpande, S. B. Thombre, I. K. Chopde, 3D CFD simulations of hydrogen fuelled spark ignition engine, ASME Spring Engine Technology Conference paper nr. ICES2008-1649 (Chicago, Illinois, USA, 2008).

[134] A. Wimmer, T. Wallner, J. Ringler, F. Gerbig, $\mathrm{H}_{2}$-direct injection a highly promising combustion concept, SAE Paper No. 2005-01-0108 (2005). 
[135] D. Messner, A. Wimmer, U. Gerke, F. Gerbig, Application and validation of the 3D CFD method for a hydrogen fueled IC engine with internal mixture formation, SAE Paper No. 2006-01-0448 (2006).

[136] U. Gerke, K. Boulouchos, A. Wimmer, Numerical analysis of the mixture formation and combustion process in a direct injected hydrogen internal combustion engine, Proceedings 1st international symposium on hydrogen internal combustion engines pp94-106 (Graz, Austria, 2006).

[137] A. Benkenida, O. Colin, S. Jay, V. Knop, Adaptation of the ECFM combustion model to hydrogen internal combustion engines, Proceedings 1st international symposium on hydrogen internal combustion engines pp195206 (Graz, Austria, 2006).

[138] G. Borman, K. Nishiwaki, Internal-combustion engine heat transfer, Progress in Energy and Combustion Science 13 1-46 (1987).

[139] W. J. D. Annand, Heat transfer in the cylinders of reciprocating internal combustion engines, Proc Instn Mech Engrs 177 (36) 973-996 (1963).

[140] S. W. Wei, Y. Y. Kim, H. J. Kim, J. T. Lee, A study on transient heat transfer coefficient of in-cylinder gas in the hydrogen fueled engine, 6th KoreaJapan Joint Symposium on Hydrogen Energy (2001).

[141] T. Shudo, S. Nabetani, Analysis of degree of constant volume and cooling loss in a hydrogen fuelled SI engine, SAE Paper No. 2001-01-3561 (2001).

[142] T. Shudo, H. Suzuki, New heat transfer equation applicable to hydrogenfuelled engines, ASME Fall Technical Conference Paper No. ICEF2002515 (New Orleans, Louisiana, 2002).

[143] A. Nefischer, M. Hallmannsegger, A. Wimmer, G. Pirker, Application of a flow field based heat transfer model to hydrogen internal combustion engines, SAE Paper No. 2009-01-1423 (2009).

[144] C. Schubert, A. Wimmer, F. Chmela, Advanced heat transfer model for CI engines, SAE Paper No. 2005-01-0695 (2005).

[145] J. Demuynck, M. Zuliani, N. Raes, S. Verhelst, M. D. Paepe, R. Sierens, Local heat flux measurements in a hydrogen and methane spark ignition engine with a thermopile sensor, Int. J. Hydrogen Energy To be submitted (2009). 
[146] J. Ringler, F. Gerbig, H. Eichlseder, T. Wallner, Insights into the development of a hydrogen combustion process with internal mixture formation, Proceedings 6th International Symposium on Internal Combustion Diagnostics (Baden Baden, Germany, 2004).

[147] W. F. Stockhausen, R. J. Natkin, L. Reams, Crankcase ventilation system for a hydrogen fueled engine, US patent no. 6,606,982 B1 (August 2003).

[148] S. J. Lee, H. S. Yi, E. S. Kim, Combustion characteristics of intake port injection type hydrogen fueled engine, Int. J. Hydrogen Energy 20 317322 (1995).

[149] W. Kirchweger, Investigations on the use of an alternative fuel in an internal combustion engine, Master's thesis, Graz University of Technology (2002).

[150] R. Sierens, E. Rosseel, Backfire mechanism in a carburetted hydrogen fuelled engine, 12th World Hydrogen Energy Conference 1537-1546 (Buenos Aires, Argentina, 1998).

[151] M. Swain, M. Swain, Elimination of abnormal combustion in a hydrogenfueled engine, Tech. Rep. NREL/TP-425-8196, Department of Energy (1995).

[152] X.-H. Liu, F.-S. Liu, L. Zhou, B.-G. Sun, H. J. Schock, Backfire prediction in a manifold injection hydrogen internal combustion engine, Int. J. Hydrogen Energy 33 3847-3855 (2008).

[153] S. A. Ciatti, T. Wallner, H. Ng, W. F. Stockhausen, B. Boyer, Study of combustion anomalies of $\mathrm{H}_{2}$-ICE with external mixture formation, ASME Spring Technical Conference Paper No. ICES 2006-1398 (2006).

[154] G. Kiesgen, M. Klüting, C. Bock, H. Fischer, The new 12-cylinder hydrogen engine in the 7 series. the $\mathrm{H}_{2}$ ICE age has begun., SAE Paper No. 200601-0431 (2006).

[155] Standard test method for research octane number of a spark-ignition engine fuel, ASTM ASTM Designation: D 2699-04a ASTM International (2004).

[156] Standard test method for motor octane number of a spark-ignition engine fuel, ASTM ASTM Designation: D 2700-04a ASTM International (2004). 
[157] M. Specht, Infomaterial: Regenerative kraftstoffe, Zentrum für Sonnenenergie- und Wasserstoff-Forschung Baden-Württemberg (ZSW) Fachgebiet Regenerative Energieträger und Verfahren.

[158] N. Saravanan, G. Nagarajan, C. Dhanasekaran, K. Kalaiselvan, Experimental investigation of hydrogen port fuel injection in DI diesel engine, Int. J. Hydrogen Energy 32 4071-4080 (2007).

[159] College of the Desert, Hydrogen Fuel Cell Engines and Related Technologies Course Manual (2001).

[160] A. Swarts, A. Yates, Insights into the role of autoignition during octane rating, SAE Paper No. 2007-01-0008 (2007).

[161] M. Leiker, W. Cartelliere, H. Christoph, U. Pfeifer, M. Rankl, Evaluation of antiknocking property of gaseous fuels by means of methane number and its practical application to gas engines, ASME 94(7) 55 (1972).

[162] H. Li, G. A. Karim, Hydrogen fueled spark-ignition engines predictive and experimental performance, Trans. ASME: J. Eng. Gas Turbines Power 128 230-236 (2006).

[163] X. Tang, W. F. Stockhausen, D. M. Kabat, R. J. Natkin, J. W. Heffel, Ford P2000 hydrogen engine dynamometer development, SAE Paper No. 200201-0242 (2002).

[164] S. Szwaja, K. Bhandary, J. Naber, Comparisons of hydrogen and gasoline combustion knock in a spark ignition engine, Int. J. Hydrogen Energy 32 5076-5087 (2007).

[165] M. A. R. S. Al-Baghdadi, Development of a pre-ignition submodel for hydrogen engines, Proc. IMechE Part D: J. Automobile Engineering 219 1203-1212 (2005).

[166] A. M. Douaud, P. Eyzat, Four-octane-number method for predicting the anti-knock behavior of fuels and engines, SAE Paper No. 780080 (1978).

[167] H. Li, G. Karim, Knock in spark ignition hydrogen engines, Int. J. Hydrogen Energy 29 859-865 (2004). 
[168] H. Eichlseder, M. Klell, M. Sartory, K. Schaffer, D. Leitner, Potential of synergies in a vehicle for variable mixtures of $\mathrm{CNG}$ and hydrogen, SAE Paper No. 2009-01-1420 (2009).

[169] L. M. Das, Near-term introduction of hydrogen engines for automotive and agricultural application, Int. J. Hydrogen Energy 27 479-487 (2002).

[170] T. Kondo, S. Iio, M. Hiruma, A study on the mechanism of backfire in external mixture formation hydrogen engines -about backfire occurred by the cause of the spark plug-, SAE Paper No. 971704 (1997).

[171] W. F. Stockhausen, R. J. Natkin, D. M. Kabat, L. Reams, X. Tang, S. Hashemi, S. J. Szwabowski, V. P. Zanardelli, Ford P2000 hydrogen engine design and vehicle development program, SAE Paper No. 2002-010240 (2002).

[172] L. G. Olavson, N. R. Baker, F. E. Lynch, L. C. Meija, Hydrogen fuel for underground mining machinery, SAE Paper No. 840233 (1984).

[173] Project Coordinator Motor Vehicles and Road Transport, TÜV Rheinland e.V. for the Federal Ministry for Research and Technology, Alternative energy sources for road transport - hydrogen drive test, Tech. rep., TÜV Rheinland (1990).

[174] C. A. MacCarley, A study of factors influencing thermally induced backfiring in hydrogen fuelled engines, and methods for backfire control, 16th IECEC conference (Atlanta, USA, 1981).

[175] F. Gerbig, W. Strobl, H. Eichlseder, A. Wimmer, Potentials of the hydrogen combustion engine with innovative hydrogen-specific combustion proces, Fisita World Automotive Congress Paper No. F2004V113 (Barcelona, Spain, 2004).

[176] S. Verhelst, R. Sierens, Hydrogen engine - specific properties, Int. J. Hydrogen Energy 26 987-990 (2001).

[177] G. G. Lucas, L. E. Morris, The backfire problem of the hydrogen engine, Symposium organized by the university's internal combustion engine group (King's College, London, UK, 1980). 
[178] A. Welch, D. Mumford, S. Munshi, J. Holbery, B. Boyer, M. Younkins, H. Jung, Challenges in developing hydrogen direct injection technology for internal combustion engines, SAE Paper No. 2008-01-2379 (2008).

[179] M. R. Swain, M. N. Swain, R. R. Adt, Consideration in the design of an inexpensive hydrogen-fueled engine, SAE Paper No. 881630 (1988).

[180] M. R. Swain, G. J. Schade, M. N. Swain, Design and testing of a dedicated hydrogen-fueled engine, SAE Paper No. 961077 (1996).

[181] M. Berckmüller, H. Rottengruber, A. Eder, N. Brehm, G. Elsässer, G. Müller-Alander, C. Schwarz, Potentials of a charged SI-hydrogen engine, SAE Paper No. 2003-01-3210 (2003).

[182] K. Koyanagi, M. Hiruma, S. Furuhama, Study on mechanism of backfire in hydrogen engines, SAE Paper No. 942035 (1994).

[183] J. T. Lee, Y. Y. Kim, C. W. Lee, J. A. Caton, An investigation of a cause of backfire and its control due to crevice volumes in a hydrogen fueled engine, ASME Spring Technical Conference Paper No. 2000-ICE-284 (San Antonio, USA, 2000).

[184] E. Berger, C. Bock, H. Fischer, M. Gruber, G. Kiesgen, H. Rottengruber, The new BMW 12-cylinder hydrogen engine as clean efficient and powerful vehicle powertrain, Fisita World Automotive Congress Paper No. F2006P114 (Yokohama, Japan, 2006).

[185] W. Prümm, Hydrogen engines for city buses, Proceedings 1st international symposium on hydrogen internal combustion engines pp111 (Graz, Austria, 2006).

[186] M. A. DeLuchi, Hydrogen vehicles: an evaluation of fuel storage, performance, safety, environmental impacts, and cost, Int. J. Hydrogen Energy 14 81-130 (1989).

[187] K. C. Strebig, R. W. Waytulonis, The bureau of mines' hydrogen powered mine vehicle, SAE Paper No. 871678 (1987).

[188] R. J. Natkin, X. Tang, K. M. Whipple, D. M. Kabat, W. F. Stockhausen, Ford hydrogen engine laboratory testing facility, SAE Paper No. 2002-010241 (2002). 
[189] G. P. Tiwari, A. Bose, J. K. Chakravartty, S. L. Wadekar, M. K. Totlani, R. N. Arya, R. K. Fotedar, A study of internal hydrogen embrittlement of steels, Materials Science and Engineering A286 269-281 (2000).

[190] E. Herms, J. M. Olive, M. Puiggali, Hydrogen embrittlement of 3161 type stainless steel, Materials Science and Engineering A272 279-283 (1999).

[191] V. Madina, I. Azkarate, Compatibility of materials with hydrogen. particular case: Hydrogen embrittlement of titanium alloys, Int. J. Hydrogen Energy doi:10.1016/j.ijhydene.2009.01.058 (2009).

[192] H. Barthélémy, Compatibility of metallic materials with hydrogen, International Conference on Hydrogen Safety. Review of the present knowledge paper nr. 1.4.66 (San Sebastian, Spain, 2007).

[193] D. Hardie, E. A. Charles, A. H. Lopez, Hydrogen embrittlement of high strength pipeline steels, Corrosion Science 48 4378-4385 (2006).

[194] C. S. Marchi, B. P. Somerday, Technical reference on hydrogen compatibility of materials, Tech. Rep. SAND2008-1163, Sandia National Laboratories (2008).

[195] B. Göschel, Der wasserstoff-verbrennungsmotor als antrieb für den BMW der zukunft, Proceedings 24 Internationales Wiener Motorensymposium (Vienna, Austria, 2003).

[196] T. Wallner, H. Lohse-Busch, S. Gurski, M. Duoba, W. Thiel, D. Martin, T. Korn, Fuel economy and emissions evaluation of a BMW hydrogen 7 mono-fuel demonstration vehicle, Int. J. Hydrogen Energy 33 7607-7618 (2008).

[197] H. Rottengruber, U. Wiebicke, G. Woschni, K. Zeilinger, Wasserstoffdieselmotor mit direkteinspritzung, hoher leistungsdichte und geringer abgasemission - part 3: Versuche und berechnungen am motor, Motortechnische Zeitschrift 61 122-128 (2000).

[198] S. Osafune, H. Akagawa, H. Ishida, H. Egashira, Y. Kuma, W. Iwasaki, Development of hydrogen injection clean engine, CIMAC Congress Paper No. 207 (Kyoto, Japan, 2004). 
[199] R. Heindl, H. Eichlseder, C. Spuller, F. Gerbig, K. Heller, New and innovative combustion systems for the $\mathrm{H}_{2}$-ICE: Compression ignition and combined processes, SAE Paper No. 2009-01-1421 (2009).

[200] P. Aleiferis, M. Rosati, Hydrogen SI and HCCI combustion in a directinjection optical engine, SAE Paper No. 2009-01-1921 (2009).

[201] N. Wakayama, K. Morimoto, A. Kashiwagi, T. Saito, Development of hydrogen rotary engine vehicle, 16th World Hydrogen Energy Conference (Lyon, France, 2006).

[202] H. Rottengruber, M. Berckmüller, G. Elsässer, N. Brehm, C. Schwarz, Operation strategies for hydrogen engines with high power density and high efficiency, 15th Annual U.S. Hydrogen Conference (Los Angeles, California, 2004).

[203] H. S. Yi, K. Min, E. S. Kim, The optimised mixture formation for hydrogen fuelled engines, Int. J. Hydrogen Energy 25 685-690 (2000).

[204] M. Hallmannsegger, H.-C. Fickel, The mixture formation process of an internal combustion engine for zero $\mathrm{CO} 2$-emission vehicles fueled with cryogenic hydrogen, IFP International Conference (Rueil-Malmaison, France, 2004).

[205] M. Hallmannsegger, Potentials of the four-stroke Otto engine with PFI of cryogenic hydrogen, Ph.D. thesis, Graz University of Technology (2005).

[206] K. Heller, S. Ellgas, Optimisation of a hydrogen internal combustion engine with cryogenic mixture formation, 1st (Int.) Symp. on Hydrogen Internal Combustion Engines 49-58 (2006).

[207] S. Ellgas, Simulation of a hydrogen internal combustion engine with cryogenic mixture formation, Ph.D. thesis, University of Armed Forces Munich (2008).

[208] A. Boretti, H. Watson, Numerical study of a turbocharged, jet ignited, cryogenic, port injected, hydrogen engine, SAE Paper No. 2009-01-1425 (2009).

[209] H. Eichlseder, M. Klell, Wasserstoff in der Fahrzeugtechnik, Vieweg+Teubner, 2008. 
[210] S. M. Aceves, A. Weisberg, F. Espinosa-Loza, G. Berry, T. Ross, Advanced concepts for containment of hydrogen and hydrogen storage materials, Tech. Rep. DOE Hydrogen Program Annual Progress Report, U.S. Department of Energy (2007).

[211] R. K. Ahluwalia, J. K. Peng, Dynamics of cryogenic hydrogen storage in insulated pressure vessels for automotive applications, Int. J. Hydrogen Energy $334622-4633$ (2008).

[212] F. Salimi, A. H. Shamekhi, A. M. Pourkhesalian, Role of mixture richness, spark and valve timing in hydrogen-fuelled engine performance and emission, Int. J. Hydrogen Energy 34 3922-3929 (2009).

[213] D. Davidson, M. Fairlie, A. Stuart, Development of a hydrogen-fuelled farm tractor, Int. J. Hydrogen Energy 11 39-42 (1986).

[214] H. Knorr, W. Held, W. Prümm, H. Rüdiger, The MAN hydrogen propulsion system for city buses, 11th World Hydrogen Energy Conference 16111620 (Stuttgart, Germany, 1996).

[215] S. Szwabowski, S. Hashemi, W. Stockhausen, R. Natkin, L. Reams, D. Kabat, C. Potts, Ford hydrogen engine powered P2000 vehicle, SAE Paper No. 2002-01-0243 (2002).

[216] S. Verhelst, P. Maesschalck, N. Rombaut, R. Sierens, Increasing the power output of hydrogen internal combustion engines by means of supercharging and exhaust gas recirculation, Int. J. Hydrogen Energy 34 4406-4412 (2009).

[217] ETEC hydrogen internal combustion engine full-size pickup truck conversion. hydrogen ICE truck brochure.

[218] J. E. Francfort, D. Karner, Hydrogen ICE vehicle testing activities, SAE Paper No. 2006-01-0433 (2006).

[219] S. Verhelst, R. Sierens, Aspects concerning the optimisation of a hydrogen fueled engine, Int. J. Hydrogen Energy 26 981-985 (2001).

[220] T. Wallner, H. Lohse-Busch, N. Shidore, Operating strategy for a hydrogen engine for improved drive-cycle efficiency and emissions behavior, Int. J. Hydrogen Energy 34 4617-4625 (2008). 
[221] R. Natkin, A. Denlinger, M. Younkins, A. Weimer, S. Hashemi, A. Vaught, Ford 6.81 hydrogen IC engine for the E-450 shuttle van, SAE Paper No. 2007-01-4096 (2007).

[222] S. Verhelst, P. Maesschalck, N. Rombaut, R. Sierens, Efficiency comparison between hydrogen and gasoline, on a bi-fuel hydrogen/gasoline engine, Int. J. Hydrogen Energy 3425042510 (2009).

[223] T. Wallner, R. Scarcelli, A. Nande, J. Naber, Assessment of multiple injection strategies in a direct injection hydrogen research engine, SAE Paper No. 2009-01-1920 (2009).

[224] P. Steinrück, G. Ranegger, Timed injection of hydrogen for fuel cells and internal combustion engines, Proceedings 1st international symposium on hydrogen internal combustion engines pp164177 (Graz, Austria, 2006).

[225] K.Kovac, A. Wimmer, M. Hallmannsegger, A. Obieglo, Mixture formation and combustion in a hydrogen engine - a challenge for the numerical simulation, International Congress on Engine Combustion Processes - Current Problems and Modern Techniques (Munich, Germany, 2005).

[226] S. A. Kaiser, C. M. White, PIV and PLIF to evaluate mixture formation in a direct-injection hydrogen-fueled engine, SAE Paper No. 2008-01-1034 (2008).

[227] T. Wallner, S. Ciatti, B. Bihari, W. Stockhausen, B. Boyer, Endoscopic investigations in a hydrogen internal combustion engine, Proceedings 1st international symposium on hydrogen internal combustion engines pp107117 (Graz, Austria, 2006).

[228] T. Wallner, S. Ciatti, B. Bihari, Investigation of injection parameters in a hydrogen DI engine using an endoscopic access to the combustion chamber, SAE Paper No. 2007-01-1464 (2007).

[229] V. M. Salazar, S. A. Kaiser, A. M. Nande, T. Wallner, The influence of injector position and geometry on mixture preparation in a DI hydrogen engine, 9th International Congress 'Engine Combustion Process - Current Problems and Modern Technologies' (Munich, Germany, 2009). 
[230] T. Wallner, A. Nande, J. Naber, Study of basic injection configurations using a direct-injection hydrogen research engine, SAE Paper No. 2009-011418 (2009).

[231] C. Vogel, Wasserstoff-dieselmotor mit direkteinspritzung, hoher leistungsdichte und geringer abgasemission - part 1: Konzept, Motortechnische Zeitschrift 60 704-708 (1999).

[232] P. Prechtl, F. Dorer, Wasserstoff-dieselmotor mit direkteinspritzung, hoher leistungsdichte und geringer abgasemission - part 2: Untersuchung der gemischbildung, des zünd- und des verbrennungsverhaltens, Motortechnische Zeitschrift 60 830-837 (1999).

[233] Y. Sakashita, H. Suzuki, Y. Takagi, Controlling onset of heat release by assisted spark ignition in hydrogen HCCI engine supported by DME supplement, SAE Paper No. 2009-01-1419 (2009).

[234] Y. Narioka, Y. Takagi, T. Yokoyama, S. Iio, HCCI combustion characteristics of hydrogen and hydrogen-rich natural gas reformate supported by DME supplement, SAE Paper No. 2006-01-0628 (2006).

[235] T. Fujita, S. Ozawa, K. Yamane, Y. Takagi, Y. Goto, M. Odaka, Performance of nox absorption 3-way catalysis applied to a hydrogen fueled engine, 15th World Hydrogen Energy Conference (Yokohama, Japan, 2004).

[236] A. Kawamura, T. Yanai, Y. Sato, K. Naganuma, K. Yamane, Y. Takagi, Summary and progress of the hydrogen ICE truck development project, SAE Paper No. 2009-01-1922 (2009).

[237] X. Tang, J. R. Theis, R. J. Natkin, S. Hashemi, W. F. Stockhausen, Hydrogen fueled spark ignition engine, US Patent No US 7,059,114B2 (August 2004).

[238] X. Tang, J. R. Theis, R. J. Natkin, S. Hashemi, W. F. Stockhausen, Hydrogen fueled spark ignition engine, US Patent No US 6,779,337B2 (June 2006).

[239] C. Bleechmore, S. Brewster, Dilution strategies for load and $\mathrm{NO}_{\mathrm{X}}$ management in a hydrogen fuelled direct injection engine, SAE Paper No. 200701-4097 (2007). 
[240] V. Subramaniam, J. M. Mallikarjuna, A. Ramesh, Effect of water injection and spark timing on the nitric oxide emission and combustion parameters of a hydrogen fueled spark ignition engine, Int. J. Hydrogen Energy 32 1159-1173 (2007).

[241] A. Nande, T. Wallner, J. Naber, Influence of water injection on performance and emissions of a direct-injection hydrogen research engine, SAE Paper No. 2008-01-2377 (2008).

[242] A. Nande, S. Swaja, J. Naber, Impact of egr on combustion processes in a hydrogen fuelled si engine, SAE Paper No. 2008-01-1039 (2008).

[243] J. W. Heffel, $\mathrm{NO}_{\mathrm{X}}$ emission and performance data in a hydrogen fueled internal combustion engine at $1500 \mathrm{rpm}$ using exhaust gas recirculation, Int. J. Hydrogen Energy 28 901-908 (2003).

[244] J. W. Heffel, $\mathrm{NO}_{\mathrm{X}}$ emission reduction in a hydrogen fueled internal combustion engine at $3000 \mathrm{rpm}$ using exhaust gas recirculation, Int. J. Hydrogen Energy 28 1285-1292 (2003).

[245] K. Pehr, Safety concept of an engine test rig with liquid hydrogen supply, Int. J. Hydrogen Energy 18 773-781 (1993).

[246] W. Rossegger, U. Posch, Design criteria and instrumentation of hydrogen test benches, Proceedings 1st international symposium on hydrogen internal combustion engines pp132-148 (Graz, Austria, 2006).

[247] T. Wallner, H. Lohse-Busch, Light duty hydrogen engine application research at ANL, Seminar Bridging the Technology ... Hydrogen Internal Combustion Engines (Argonne National Laboratory, 2006).

[248] A. Kessler, et al., Chapter V: Hydrogen safety barriers and measures, HySafe: Biennal report on Hydrogen Safety (2006).

[249] Basic considerations for the safety of hydrogen systems, ISO ISO/TR 15916 (2004).

[250] Safety standard for hydrogen and hydrogen systems. guidelines for hydrogen system design, materials selection, operations, storage, and transportation, National Aeronautics and Space Administration NSS 1740.16 (1997). 
[251] H. Ebner, K. Koeck, Coriolis fuel meter - a modern and reliable approach to continuous and accurate fuel consumption measurement, SAE Paper No. 2000-01-1330 (2000).

[252] C. Paulina, Hydrogen fuel cell vehicle fuel economy testing at the U.S. EPA national vehicle and fuel emissions laboratory, SAE Paper No. 200401-2900 (2004).

[253] W. Thiel, B. Krough, Hydrogen fuel consumption correlation between established EPA measurement methods and exhaust emissions measurements, SAE Paper No. 2008-01-1038 (2008).

[254] A. Richardson, R. Gopalakrishnan, T. Chhaya, S. Deasy, J. Kohn, Design considerations for hydrogen management system on Ford hydrogen fueled E-450 shuttle bus, SAE Paper No. 2009-01-1422 (2009).

[255] R. Gopalakrishnan, M. J. Throop, A. Richardson, J. M. Lapetz, Engineering the Ford $\mathrm{H}_{2}$ IC engine powered E-450 shuttle bus, SAE Paper No. 200701-4095 (2007).

[256] BMW, BMW Hydrogen 7 - rescue guidelines (2006).

[257] K. Dutton, A brief history of the car, New Ideas 1 (2006).

[258] J. W. Fairbanks, Engine maturity, efficiency, and potential improvements, Diesel Engine Emission Reduction Conference (Coronado, California, 2004).

[259] K. Schöffel, Hydrogen - the energy carrier for the future, Workshop - Environmental issues in theory and practice (Porsgrunn, Norway, 2005).

[260] R. A. Erren, Der Erren-Wasserstoffmotor, Automobiltechnische Zeitschrift 19 (1933).

[261] S. Furuhama, Problems of forecasting the future of advanced engines and engine characteristics of the hydrogen injection with $\mathrm{LH}_{2}$ tank and pump, Trans. ASME: J. Eng. Gas Turbines Power 119 227-242 (1982).

[262] S. Furuhama, Y. Kobayashi, A liquid hydrogen car with a two-stroke direct injection engine and $\mathrm{LH}_{2}$-pump, Int. J. Hydrogen Energy 7 809-820 (1982). 
[263] H. A. Lohse-Busch, T. Wallner, J. Fleming, Transient efficiency, performance, and emissions analysis of a hydrogen internal combustion engine pick-up truck, SAE Paper No. 2006-01-3430 (2006).

[264] A. R. Abele, Quantum hydrogen prius, ARB ZEV Technology Symposium (Sacramento, California, 2006).

[265] A. Klugescheid, BMW introduces world's first hydrogen-drive luxury performance car - the BMW HYDROGEN 7, Press release BMW of North America, LLC (2006).

[266] Mazda, Mazda Renesis hydrogen rotary engine (2003).

[267] J. Lapetz, R. Natkin, V. Zanardelli, The design, development, validation and delivery of the Ford $\mathrm{H}_{2}$ ICE E-450 shuttle bus, 1st (Int.) Symp. on Hydrogen Internal Combustion Engines 20-33 (2006).

[268] R. Sierens, E. Rosseel, Variable composition hydrogen/natural gas mixtures for increased engine efficiency and decreased emissions, Journal of Engineering for Gas Turbines and Power 122 135-140 (2000).

[269] C. G. Bauer, T. W. Forest, Effect of hydrogen addition on the performance of methane-fueled vehicles. part I: effect on S.I. engine performance, Int. J. Hydrogen Energy 26 55-70 (2001).

[270] C. G. Bauer, T. W. Forest, Effect of hydrogen addition on the performance of methane-fueled vehicles. part II: driving cycle simulations, Int. J. Hydrogen Energy 26 71-90 (2001).

[271] S. Munshi, Medium/heavy duty hydrogen enriched natural gas spark ignition IC engine operation, Proceedings 1st international symposium on hydrogen internal combustion engines pp71-82 (Graz, Austria, 2006).

[272] F. Ortenzi, M. Chiesa, R. Scarcelli, G. Pede, Experimental tests of blends of hydrogen and natural gas in light-duty vehicles, Int. J. Hydrogen Energy 33 3225-3229 (2008).

[273] T. Wallner, H. Lohse-Busch, H. Ng, R. W. Peters, Results of research engine and vehicle drive cycle testing during blended hydrogen/methane operation, Proceedings National Hydrogen Association Annual Conference (San Antonio, Texas, 2007). 
[274] T. Wallner, H. Ng, R. W. Peters, The effects of blending hydrogen with methane on engine operation, efficiency, and emissions, SAE Paper No. 2007-01-0474 (2007).

[275] F. Gruber, G. Herdin, J. Klausner, R. Robitschko, Use of hydrogen and hydrogen mixtures in a gas engine, Proceedings 1st international symposium on hydrogen internal combustion engines pp34-48 (Graz, Austria, 2006).

[276] M. G. Shirk, T. P. McGuire, G. L. Neal, D. C. Haworth, Investigation of a hydrogen-assisted combustion system for a light-duty diesel vehicle, Int. J. Hydrogen Energy 33 7237-7244 (2008).

[277] M. S. Kumar, A. Ramesh, B. Nagalingam, Use of hydrogen to enhance the performance of a vegetable oil fuelled compression ignition engine, Int. J. Hydrogen Energy 28 1143-1154 (2003).

[278] A. Tsolakis, A. Megaritis, Partially premixed charge compression ignition engine with on-board $\mathrm{H} 2$ production by exhaust gas fuel reforming of diesel and biodiesel, Int. J. Hydrogen Energy 30 731-745 (2005).

[279] M. Sulatisky, S. Hill, B. Lung, Dual-fuel hydrogen pickup trucks, 16th World Hydrogen Energy Conference (Lyon, France, 2006).

[280] S. Yousufuddin, S. N. Mehdi, M. Masood, Performance and combustion characteristics of a hydrogen-ethanol-fuelled engine, Energy \& Fuels 22 3355 - 3362 (2008).

[281] T. Wallner, A. Nande, J. Naber, Evaluation of injector location and nozzle design in a direct-injection hydrogen research engine, SAE Paper No. 200801-1785 (2009). 


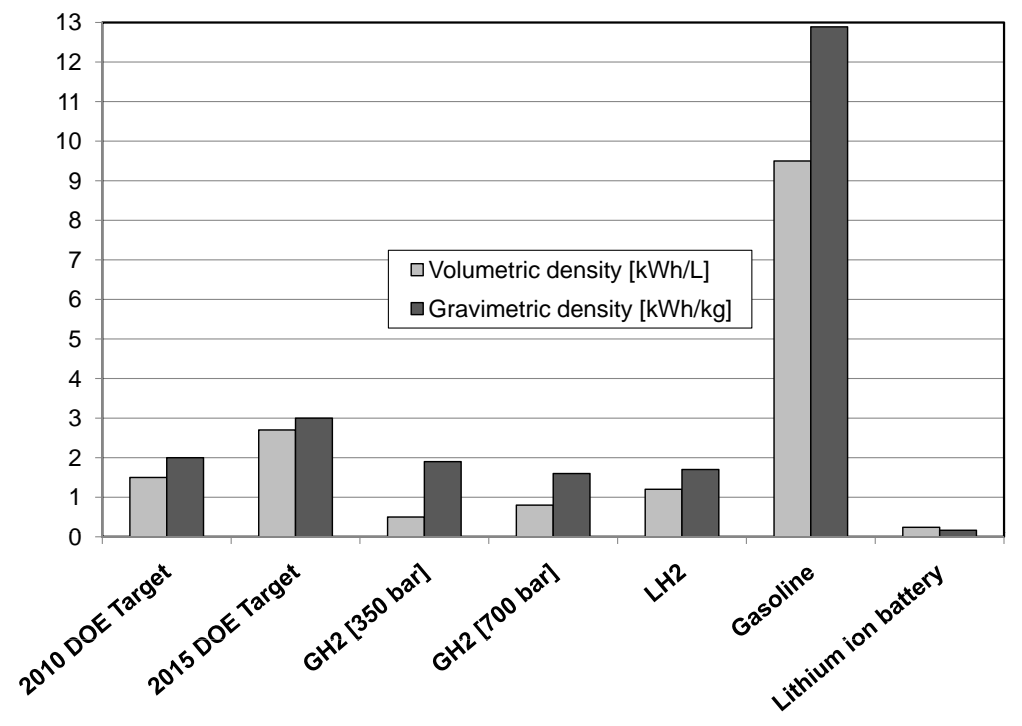

Figure 1: Volumetric and gravimetric energy storage densities of compressed gaseous hydrogen (GH2) and liquified hydrogen (LH2): DOE targets and current levels compared to gasoline and lithium ion batteries. 


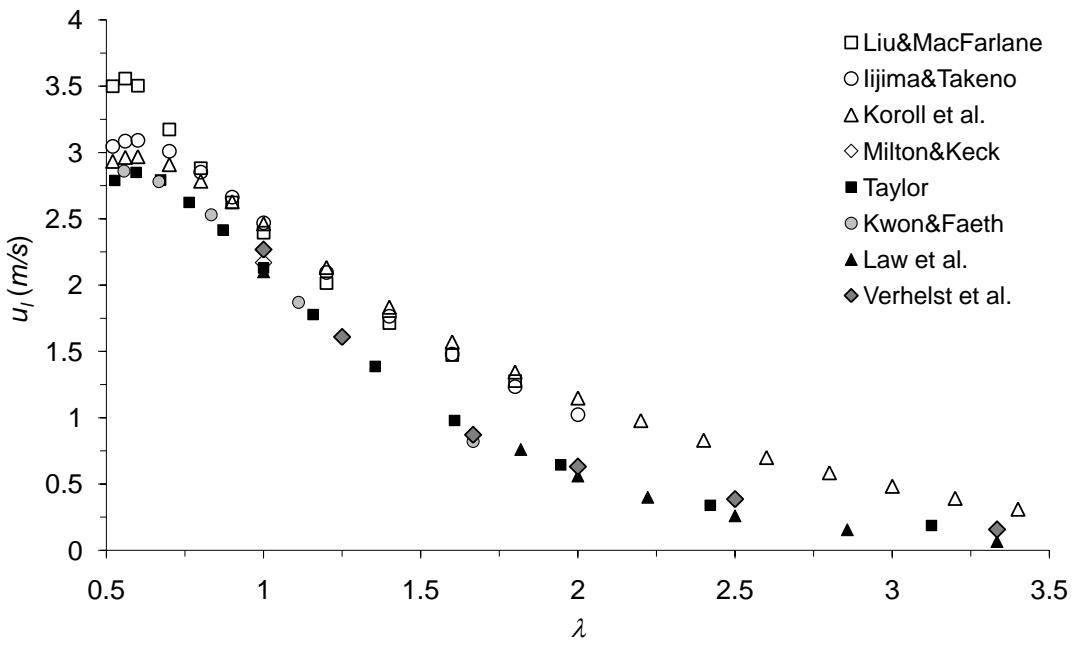

Figure 2: Laminar burning velocities plotted against air-to-fuel equivalence ratio, for NTP hydrogen-air flames. Experimentally derived correlations from Liu and MacFarlane [51], Milton and Keck [52], Iijima and Takeno [53] and Koroll et al. [54]. Other experimental data from Taylor [47], Vagelopoulos et al. [48], Kwon and Faeth [49] and Verhelst et al. [50]. 


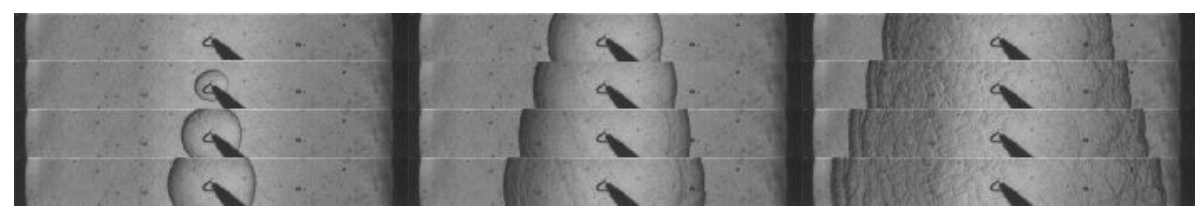

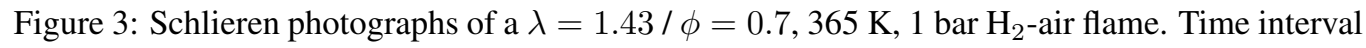
between frames: $0.641 \mathrm{~ms}$. 


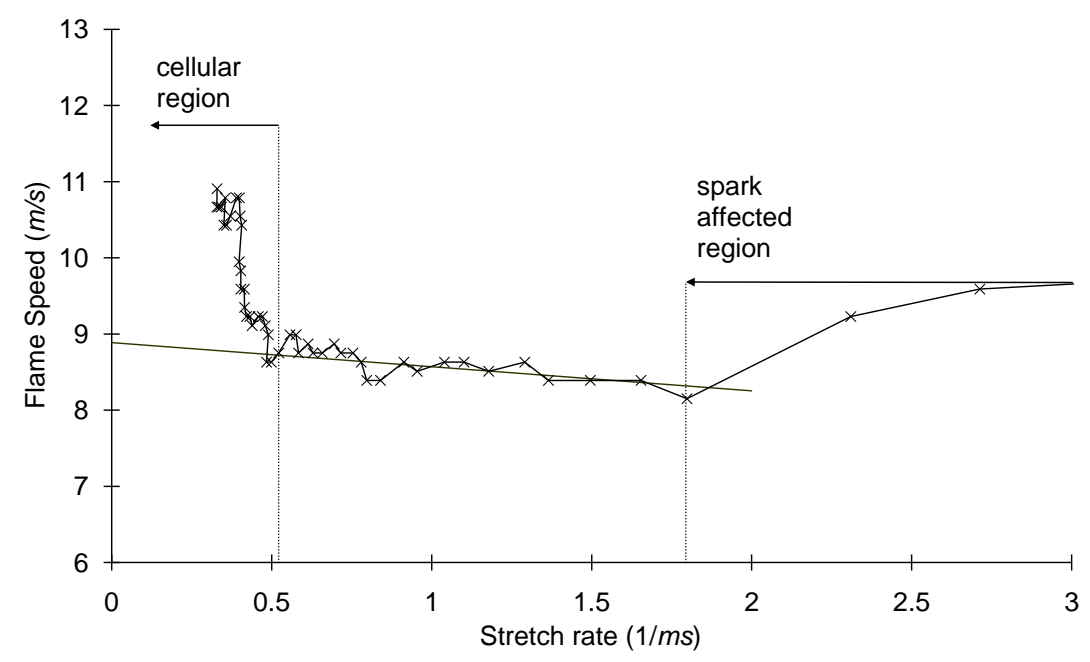

Figure 4: Development of a $\lambda=1.43 / \phi=0.7,365 \mathrm{~K}, 1$ bar $\mathrm{H}_{2}$-air flame [46]. 


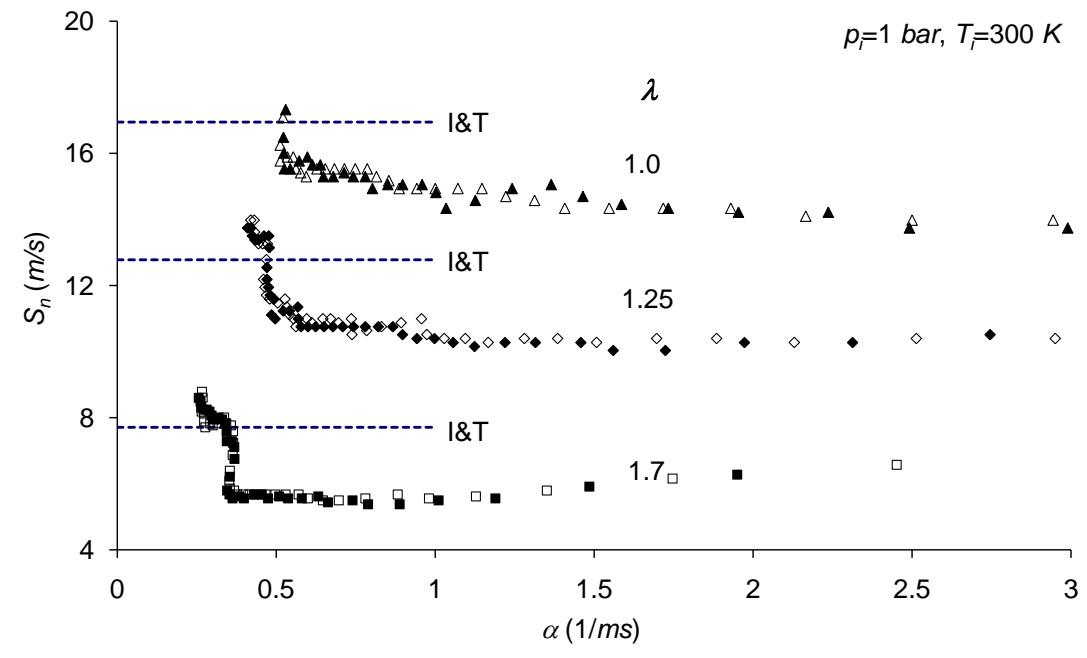

Figure 5: Flame speed predictions obtained from the correlation by Iijima and Takeno (I\&T) [53] plotted on $S_{n}$ vs. $\alpha$ graph [46]. Two different experiments (open and solid symbols) plotted for each condition. 


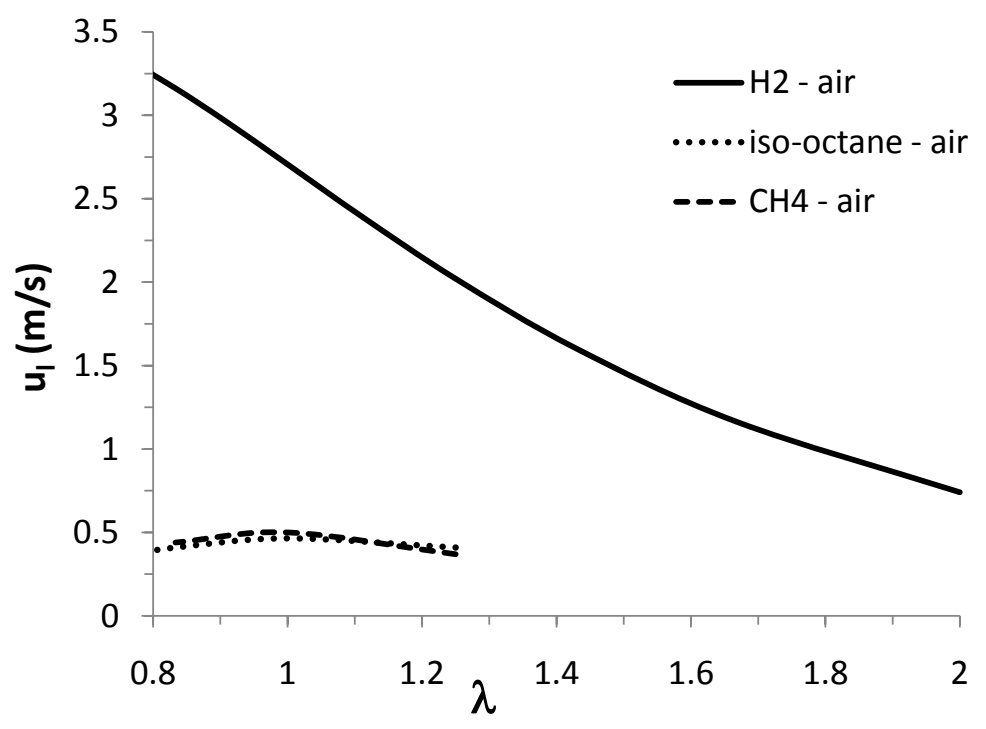

Figure 6: Laminar burning velocities for hydrogen-, iso-octane- and methane-air mixtures, at 1 bar and $\sim 360 \mathrm{~K}$, as a function of the air-to-fuel equivalence ratio. 


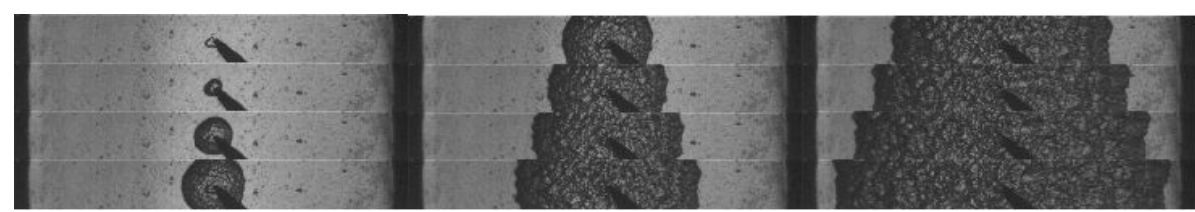

Figure 7: Schlieren photographs of a $\lambda=1.25 / \phi=0.8,300 \mathrm{~K}, 5$ bar $\mathrm{H}_{2}$-air flame, time interval: $0.385 \mathrm{~ms}$. 


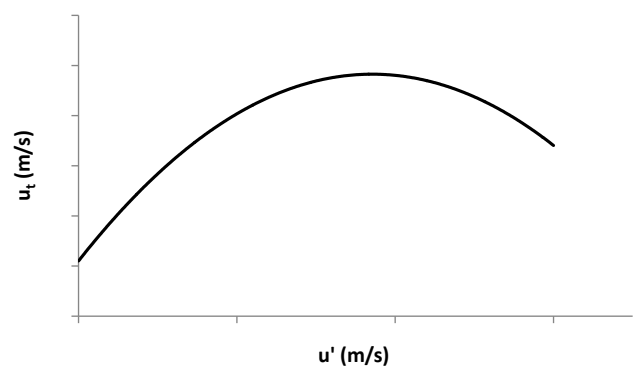

Figure 8: Illustration of the "bending" of $u_{t}$ versus $u^{\prime}: u_{t}$ initially increases with increasing $u^{\prime}$, reaches a maximum and then decreases again until flame quenching occurs. 


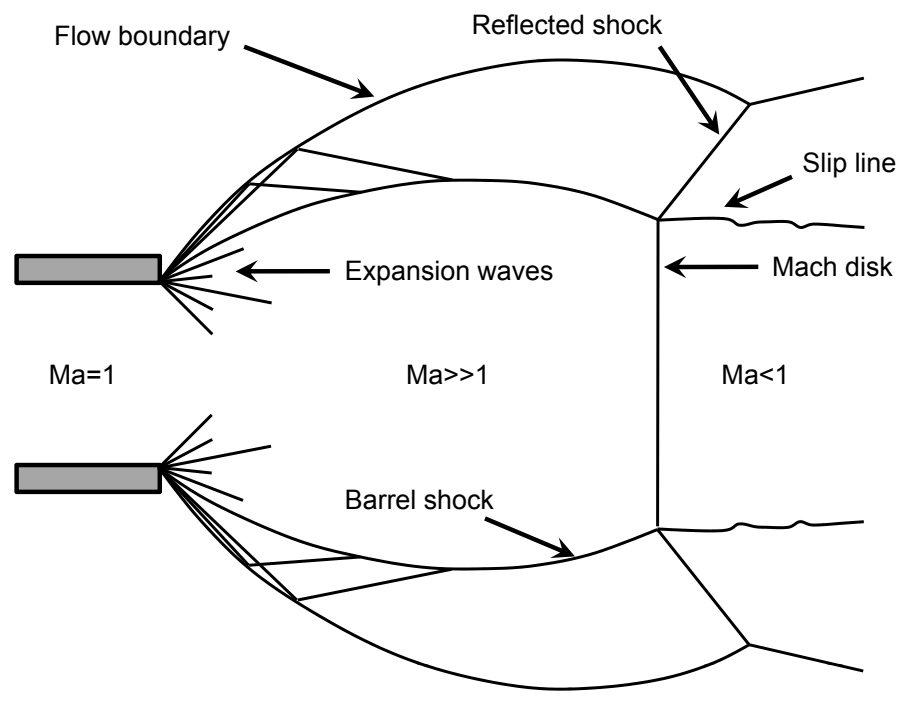

Figure 9: Principal regions around nozzle exit for an underexpanded jet [101]. 


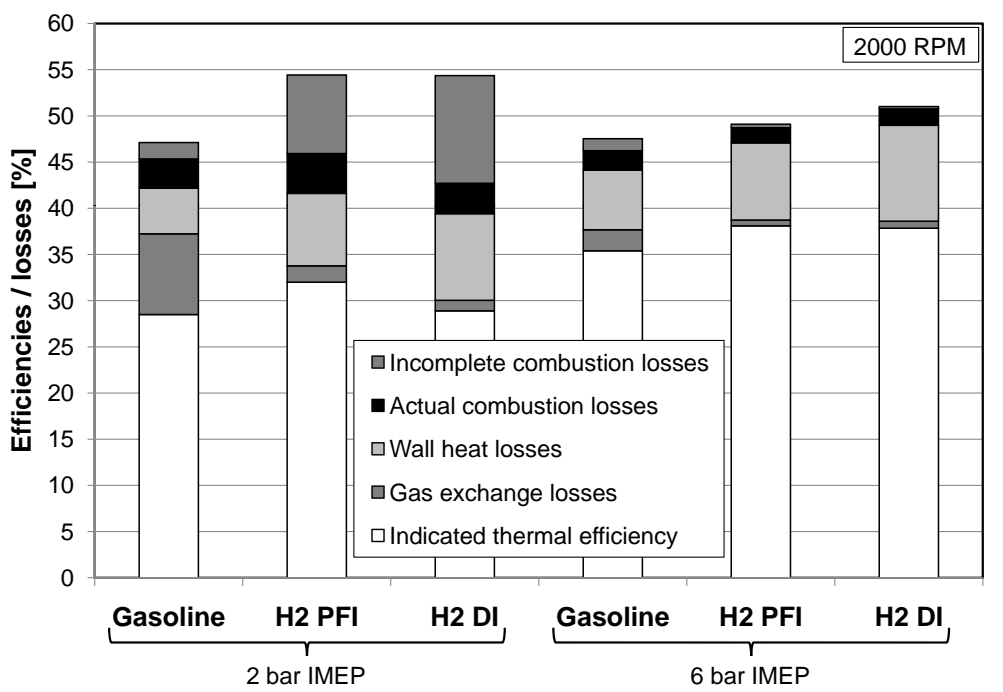

Figure 10: Analysis of losses compared to the theoretical engine cycle: gasoline versus hydrogen (PFI and DI), at two loads 


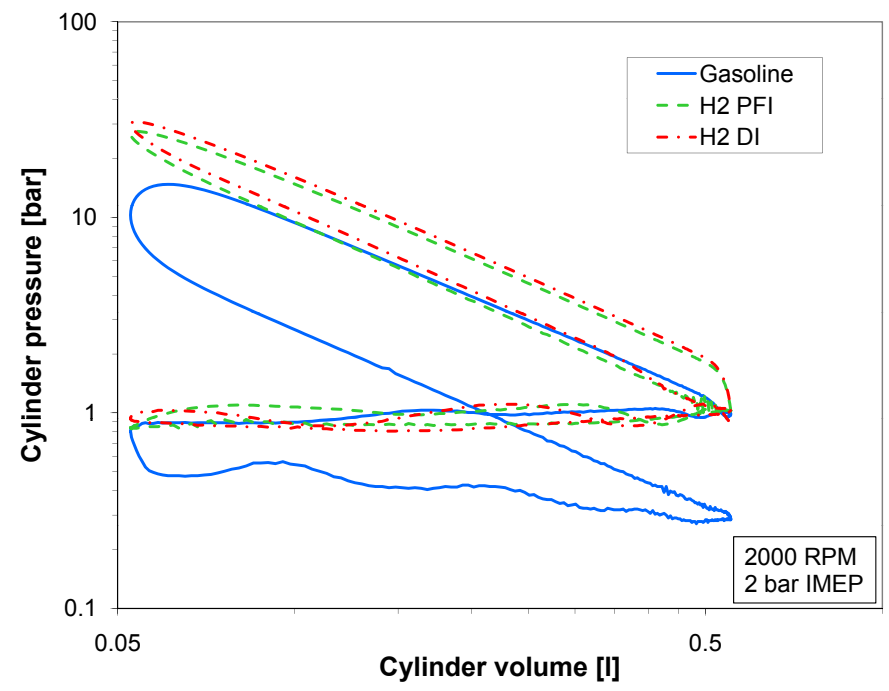

Figure 11: Pressure versus volume diagrams at 2 bar IMEP for gasoline (stoichiometric throttled), hydrogen PFI and hydrogen DI (lean WOT). 


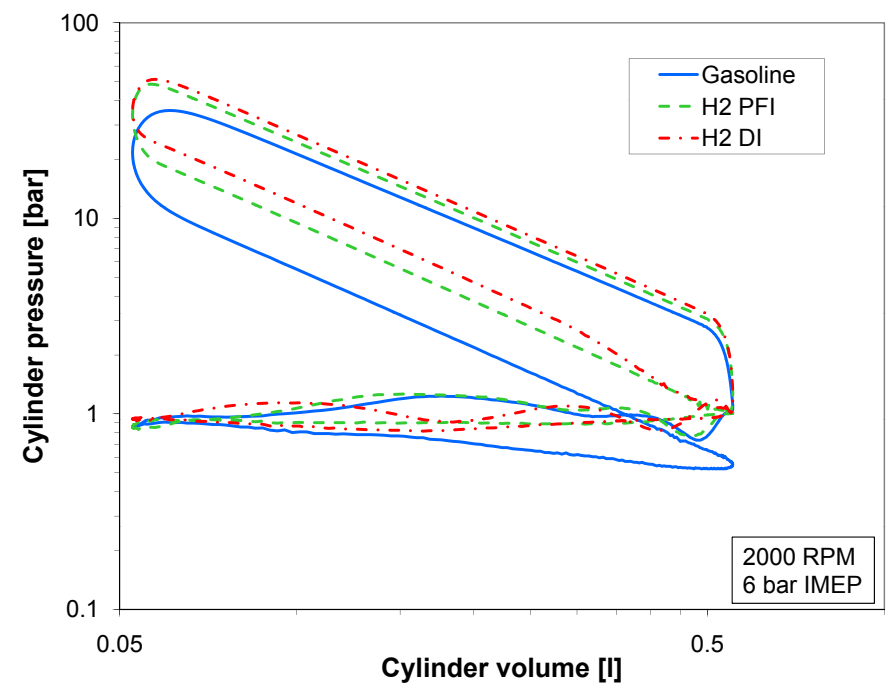

Figure 12: Pressure versus volume diagrams at 6 bar IMEP for gasoline, hydrogen PFI and hydrogen DI. 


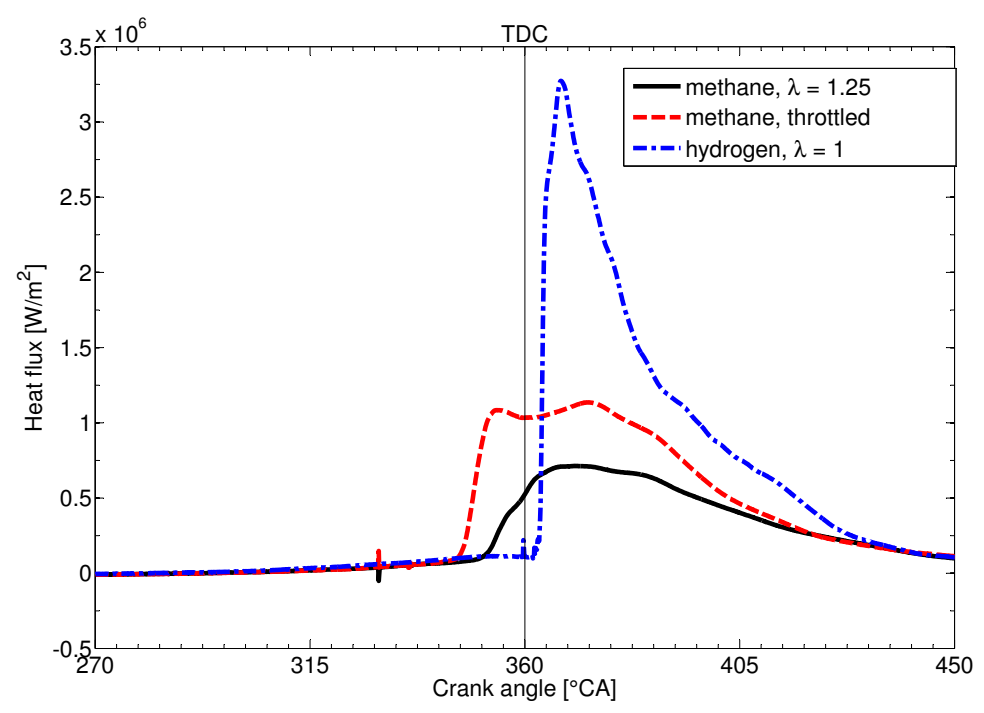

Figure 13: Measured local heat flux (ensemble average over 35 cycles) for equal indicated power: hydrogen stoichiometric WOT, methane lean WOT and methane stoichiometric throttled. 600 RPM, compression ratio 8:1. 


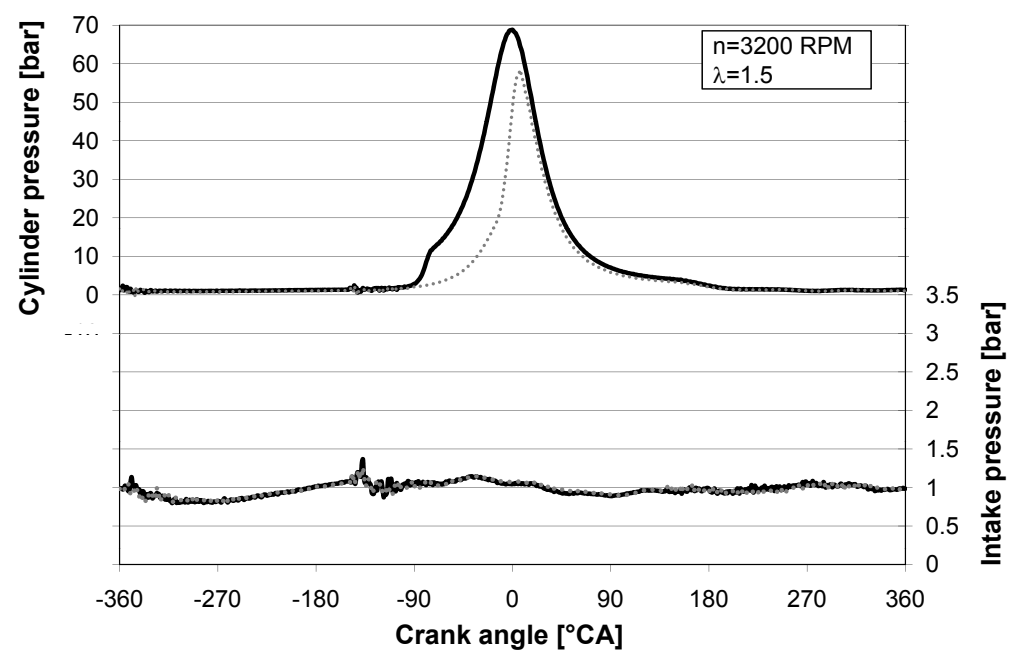

Figure 14: Typical cylinder and intake manifold pressure traces with pre-ignition (solid lines), compared to regular pressure traces (dotted lines). 


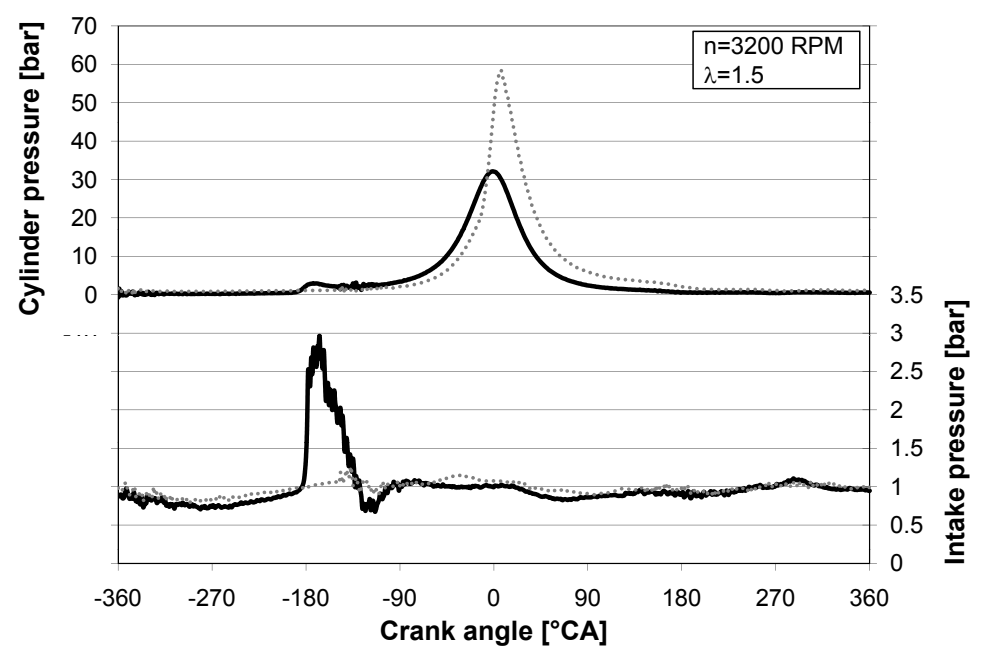

Figure 15: Typical cylinder and intake pressure traces for backfiring cycle (solid lines), compared to regular pressure traces (dotted lines). 


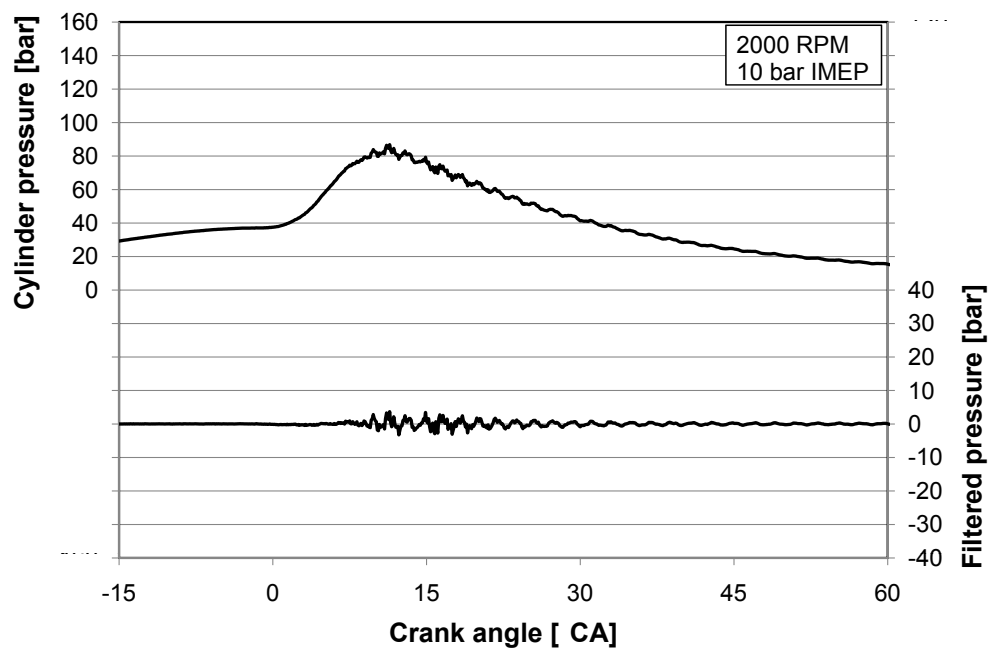

Figure 16: Typical cylinder pressure trace for light knocking cycle. 


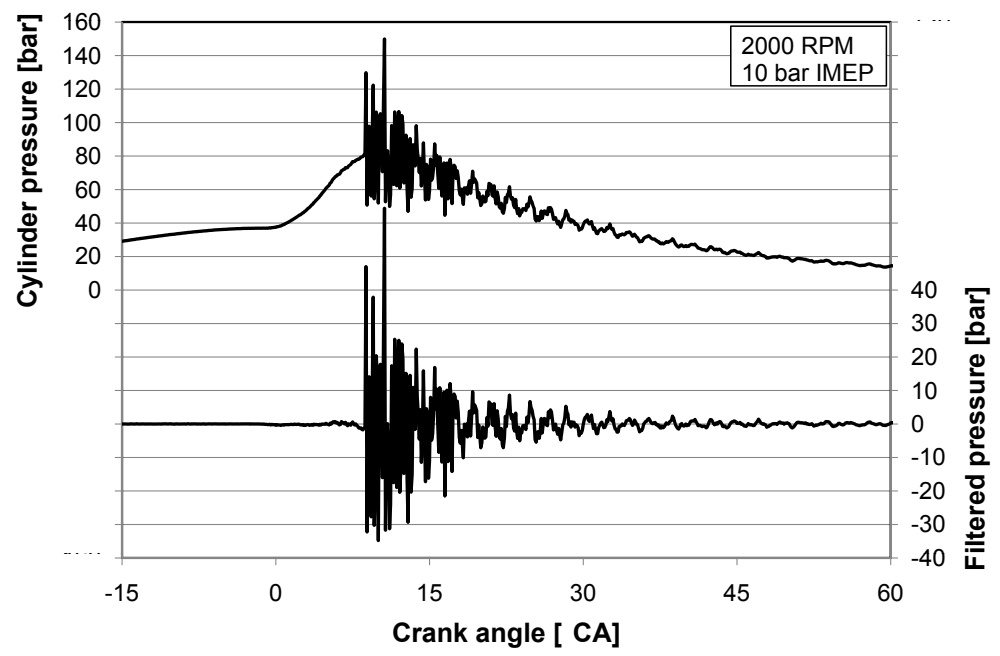

Figure 17: Typical cylinder pressure trace for heavy knocking cycle. 


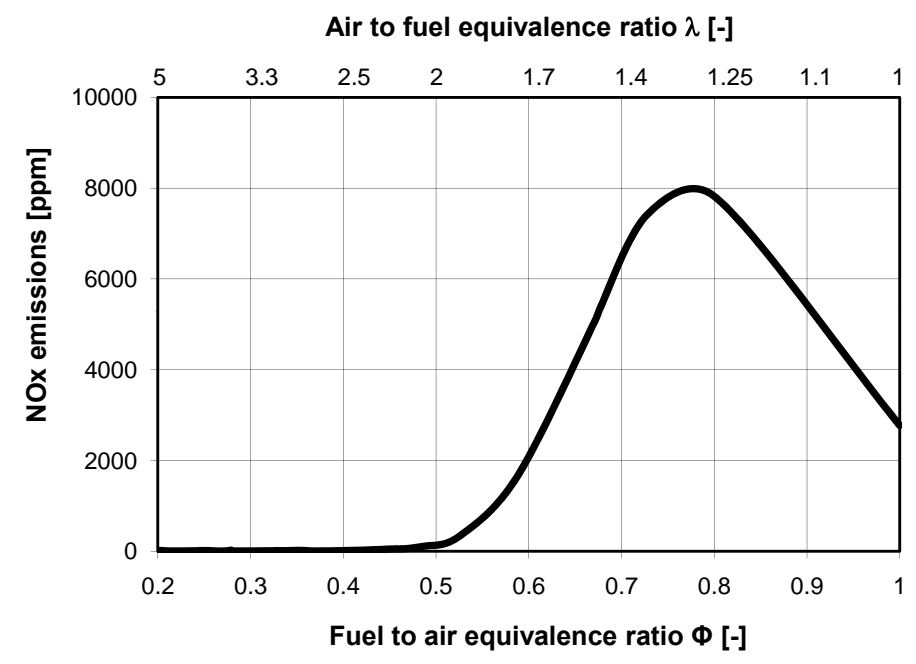

Figure 18: Correlation of air-fuel ratio and $\mathrm{NO}_{\mathrm{X}}$ emissions for homogeneous operation [281]. 


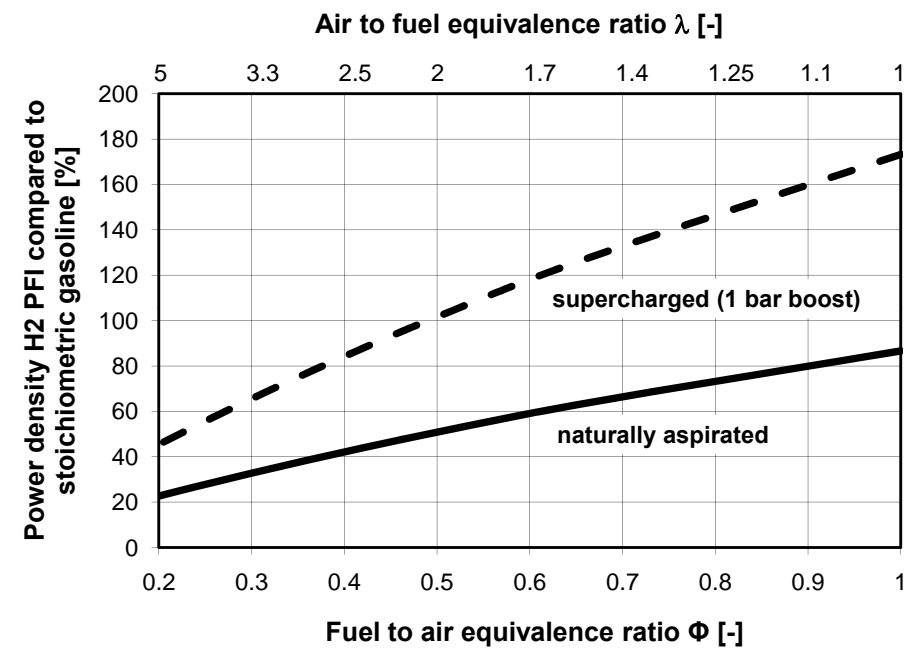

Figure 19: Theoretical power density of a PFI $\mathrm{H}_{2}$ engine compared to stoichiometric gasoline operation as a function of equivalence ratio and charging strategy. 


\begin{tabular}{|c|c|c|c|c|}
\hline \multirow{3}{*}{$\begin{array}{l}\text { Early DI } \\
\text { (homogenous) }\end{array}$} & VC & \multicolumn{3}{|c|}{ TDC } \\
\hline & Injection & \multirow{2}{*}{$\beta$} & & Low Load \\
\hline & Injection & & & High Load \\
\hline \multirow{2}{*}{$\begin{array}{l}\text { Late DI } \\
\text { (stratified) }\end{array}$} & & Injection & & Low Load \\
\hline & \multicolumn{2}{|r|}{ Injection } & \multirow[b]{2}{*}{ Injection } & High Load \\
\hline \multirow{2}{*}{$\begin{array}{l}\text { Multiple DI } \\
\text { (after spark) }\end{array}$} & Injection & & & Low Load \\
\hline & Injection & & Injection & High Load \\
\hline \multirow{2}{*}{$\begin{array}{l}\text { Multiple DI } \\
\text { (before spark) }\end{array}$} & Injection & & cation & Low Load \\
\hline & Injection & & diection & High Load \\
\hline
\end{tabular}

Figure 20: Schematic of injection strategies for DI [223]. 


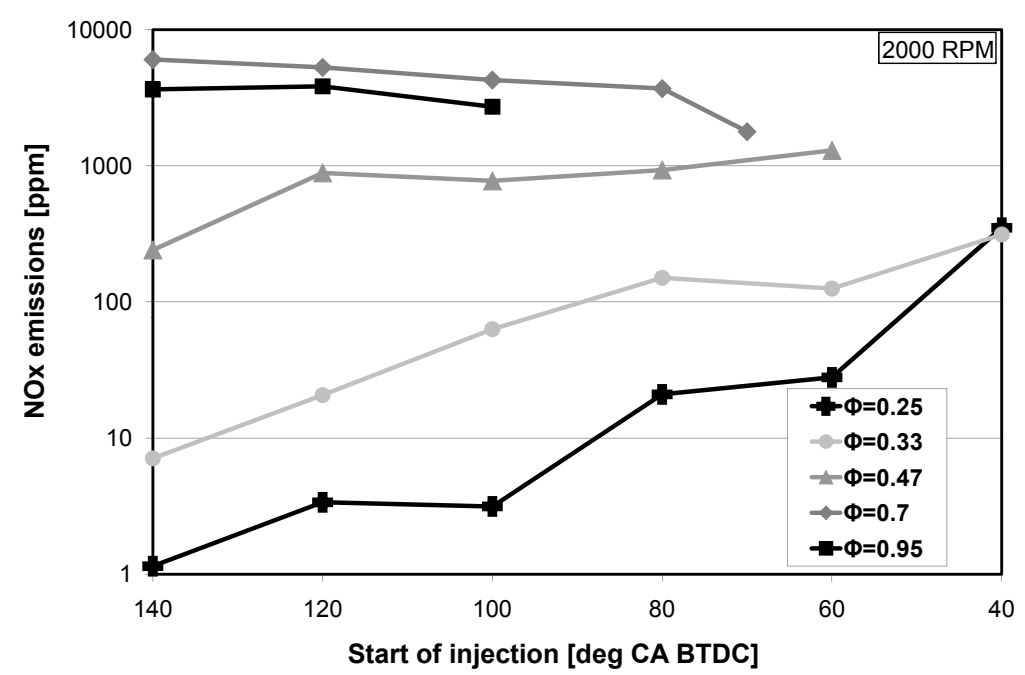

Figure 21: Typical $\mathrm{NO}_{\mathrm{X}}$ emissions pattern for $\mathrm{H}_{2}$ DI operation [227, 228]. 


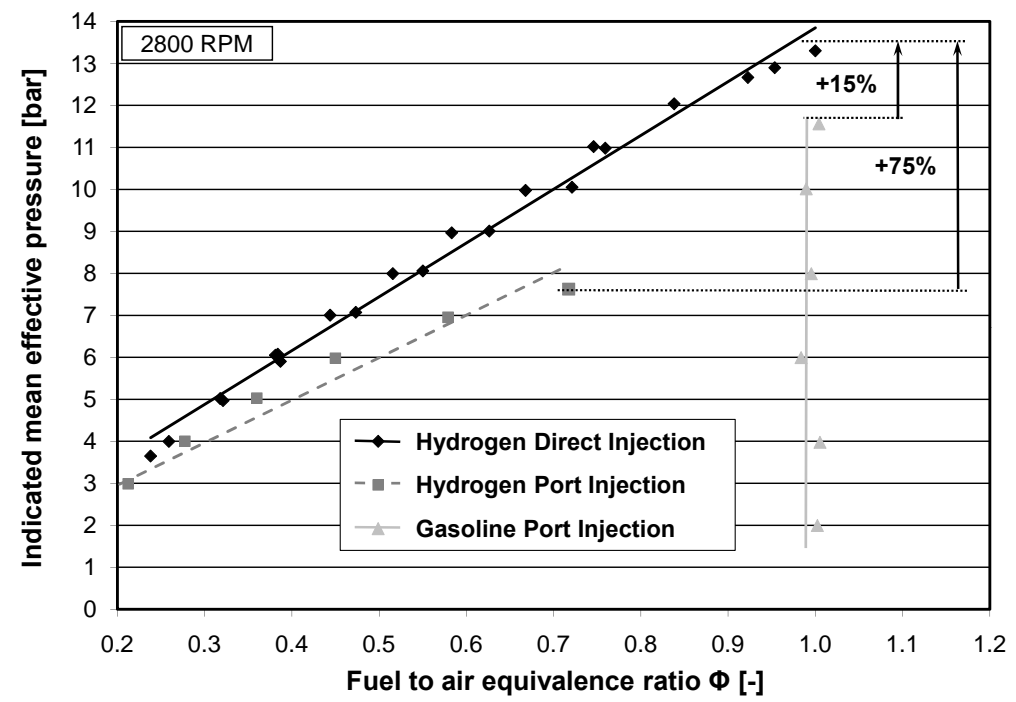

Figure 22: Indicated mean effective pressure comparison for gasoline and hydrogen port injection as well as hydrogen DI operation [12]. 


\begin{tabular}{|c|c|c|c|}
\hline Property & Hydrogen & Methane & Iso-octane \\
\hline "Molecular weight $(\mathrm{g} / \mathrm{mol})$ & 2.016 & 16.043 & 114.236 \\
\hline Density $\left(\mathrm{kg} / \mathrm{m}^{3}\right)$ & 0.08 & 0.65 & 692 \\
\hline Mass diffusivity in air $\left(\mathrm{cm}^{2} / \mathrm{s}\right)$ & 0.61 & 0.16 & $\sim 0.07$ \\
\hline Minimum ${ }^{\mathrm{a}}$ ignition energy $(\mathrm{m} J)$ & 0.02 & 0.28 & 0.28 \\
\hline Minimum $^{\mathrm{a}}$ quenching distance $(\mathrm{mm})$ & 0.64 & 2.03 & 3.5 \\
\hline Flammability limits in air (vol\%) & $4-75$ & $5-15$ & $1.1-6$ \\
\hline Flammability limits $(\lambda)$ & $10-0.14$ & $2-0.6$ & $1.51-0.26$ \\
\hline Flammability limits $(\phi)$ & $0.1-7.1$ & $0.5-1.67$ & $0.66-3.85$ \\
\hline Lower heating value $(M J / k g)$ & 120 & 50 & 44.3 \\
\hline Higher heating value $(M J / \mathrm{kg})$ & 142 & 55.5 & 47.8 \\
\hline Stoichiometric air to fuel ratio $(\mathrm{kg} / \mathrm{kg})$ & 34.2 & 17.1 & 15.0 \\
\hline Stoichiometric air to fuel ratio $(\mathrm{kmol} / \mathrm{kmol})$ & 2.387 & 9.547 & 59.666 \\
\hline
\end{tabular}

Table 1: Hydrogen properties compared with methane and iso-octane properties. Data given at $300 \mathrm{~K}$ and $1 \mathrm{~atm} .{ }^{\mathrm{a}}$ : corresponding equivalence ratios given in text. 


\begin{tabular}{lllll}
\hline Property & $\mathrm{H}_{2}$-air, & $\mathrm{H}_{2}$-air, & $\mathrm{CH}_{4}$-air, & $\mathrm{C}_{8} \mathrm{H}_{18}$-air, \\
& $\lambda=1$ & $\lambda=4$ & $\lambda=1$ & $\lambda=1$ \\
& $\phi=1$ & $\phi=0.25$ & $\phi=1$ & $\phi=1$ \\
\hline \hline Volume fraction fuel $(\%)$ & 29.5 & 9.5 & 9.5 & 1.65 \\
Mixture density $\left(\mathrm{kg} / \mathrm{m}^{3}\right)$ & 0.850 & 1.068 & 1.123 & 1.229 \\
Kinematic viscosity $\left(\mathrm{mm}^{2} / \mathrm{s}\right)$ & 21.6 & 17.4 & 16 & 15.2 \\
Autoignition temperature $(\mathrm{K})$ & $858^{\mathrm{a}}$ & $>858^{\mathrm{a}}$ & $813^{\mathrm{a}}$ & $690^{\mathrm{a}}$ \\
Adiabatic flame temperature $(\mathrm{K})$ & 2390 & 1061 & 2226 & 2276 \\
Thermal conductivity $\left(10^{-2} \mathrm{~W} / \mathrm{mK}\right)$ & 4.97 & 3.17 & 2.42 & 2.36 \\
Thermal diffusivity $\left(\mathrm{mm}^{2} / \mathrm{s}\right)$ & 42.1 & 26.8 & 20.1 & 18.3 \\
Ratio of specific heats & 1.401 & 1.400 & 1.354 & 1.389 \\
Speed of sound $(\mathrm{m} / \mathrm{s})$ & 408.6 & 364.3 & 353.9 & 334.0 \\
Air-to-fuel ratio $(\mathrm{kg} / \mathrm{kg})$ & 34.2 & 136.6 & 17.1 & 15.1 \\
Mole ratio before/after combustion & 0.86 & 0.95 & 1.01 & 1.07 \\
Laminar burning velocity, $\sim 360 \mathrm{~K}(\mathrm{~cm} / \mathrm{s})$ & 290 & 12 & 48 & 45 \\
Gravimetric energy content $(\mathrm{kJ} / \mathrm{kg})$ & 3758 & 959 & 3028 & 3013 \\
Volumetric energy content $\left(\mathrm{kJ} / \mathrm{m}^{3}\right)$ & 3189 & 1024 & 3041 & 3704 \\
\hline
\end{tabular}

Table 2: Mixture properties of hydrogen-air, methane-air and iso-octane-air. Data given at $300 \mathrm{~K}$ and $1 \mathrm{~atm}$ (with the exception of the laminar burning velocity, given at $360 \mathrm{~K}$ and $1 \mathrm{~atm}$ ). ${ }^{\mathrm{a}}$ : see text. 


\begin{tabular}{llll}
\hline & Hydrogen & Methane & Iso-octane \\
\hline \hline PFI & $86 \%$ & $92 \%$ & $100 \%$ \\
DI & $119 \%$ & $100 \%$ & $100 \%$ \\
\hline
\end{tabular}

Table 3: Theoretical power densities of hydrogen-, methane- and iso-octane-fueled engines. 


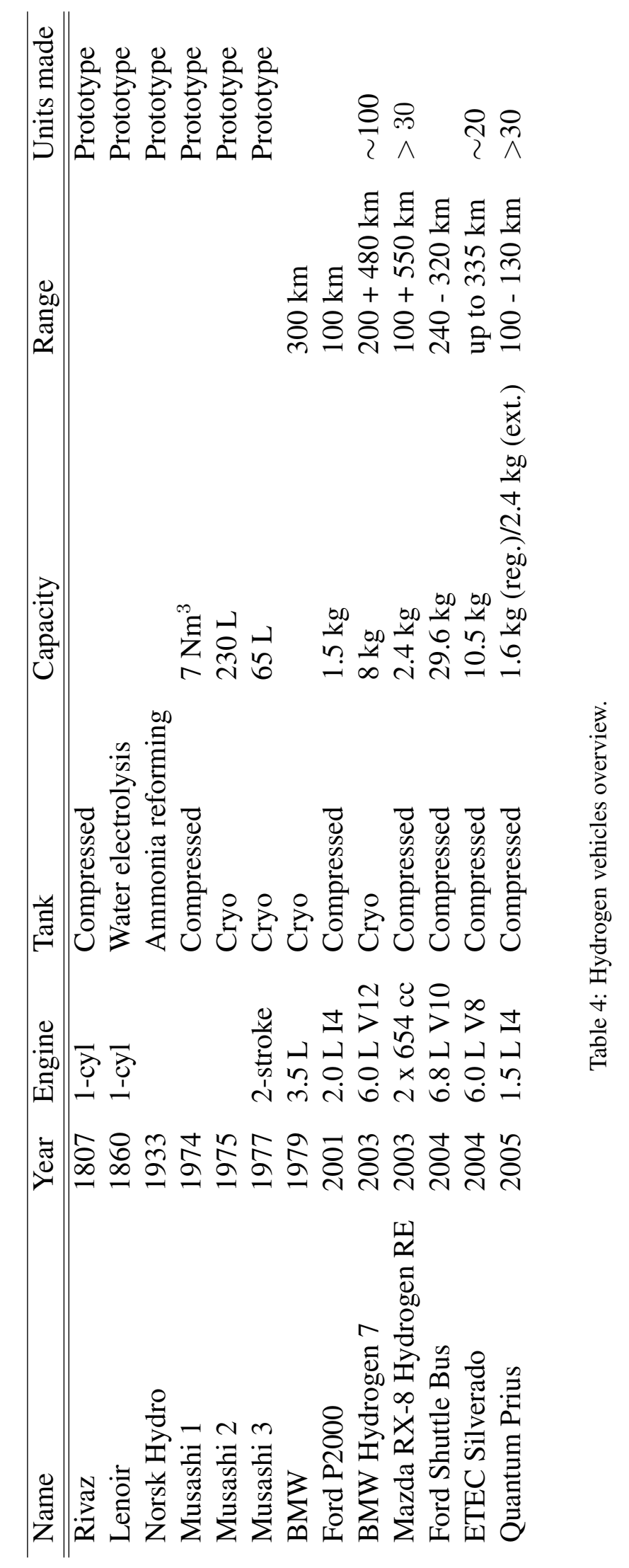

